MAURICIO ROGERIO RAMOS RIBEIRO

APLICAÇÃO DA TEORIA DE CONFIABILIDADE NA ANÁLISE ESTRUTURAL DE EDIFÍCIOS CONSIDERANDO A INTERAÇÃO SOLO-ESTRUTURA

São Paulo 
MAURICIO ROGERIO RAMOS RIBEIRO

\title{
APLICAÇÃO DA TEORIA DE CONFIABILIDADE NA ANÁLISE ESTRUTURAL DE EDIFÍCIOS CONSIDERANDO A INTERAÇÃO SOLO-ESTRUTURA
}

\author{
Versão corrigida \\ (Versão original encontra-se na unidade que aloja \\ o Programa de Pós-Graduação) \\ Dissertação apresentada à Escola \\ Politécnica da Universidade de São Paulo \\ para Obtenção do Título de Mestre em \\ Ciências.
}

São Paulo 


\title{
APLICAÇÃO DA TEORIA DE CONFIABILIDADE NA ANÁLISE ESTRUTURAL DE EDIFÍCIOS CONSIDERANDO A INTERAÇÃO SOLO-ESTRUTURA
}

\author{
Versão corrigida \\ (Versão original encontra-se na unidade que aloja \\ o Programa de Pós-Graduação) \\ Dissertação apresentada à Escola \\ Politécnica da Universidade de São Paulo \\ para Obtenção do Título de Mestre em \\ Ciências. \\ Área de Concentração: Engenharia de \\ Estruturas e Geotécnica. \\ Orientador: Prof. Dr. Valério da Silva \\ Almeida
}

São Paulo 
Autorizo a reprodução e divulgação total ou parcial deste trabalho, por qualquer meio convencional ou eletrônico, para fins de estudo e pesquisa, desde que citada a fonte.

Este exemplar foi revisado e corrigido em relação à versão original, sob responsabilidade única do autor e com a anuência de seu orientador.

São Paulo, de de

Assinatura do autor:

Assinatura do orientador:

\section{Catalogação-na-publicação}

Ribeiro, Mauricio Rogerio Ramos

Aplicação da teoria de confiabilidade na análise estrutural de edifícios considerando a interação solo-estrutura / M. R. R. Ribeiro -- versão corr. -São Paulo, 2019.

$120 \mathrm{p}$.

Dissertação (Mestrado) - Escola Politécnica da Universidade de São Paulo. Departamento de Engenharia de Estruturas e Geotécnica.

1.Estruturas (Confiabilidade) 2.Interação solo-estrutura 3.Edifício 3D 4.Recalque diferencial 5.Flexo-compressão I.Universidade de São Paulo. Escola Politécnica. Departamento de Engenharia de Estruturas e Geotécnica Il.t. 
Dedico este trabalho a todos os educadores do Brasil. 


\section{AGRADECIMENTOS}

Gratifico à minha família, meus pais Marco Antônio e Vera Lúcia, pelo apoio, confiança e crença em todas as fases da minha vida, desde a singular educação até todas as dificuldades que passamos e tiveram que lidar sozinhos. Aos meus irmãos Marco Antônio e Douglas Alexandre por todo o zelo e companheirismo em todos os momentos.

Gratifico à minha esposa, amiga e companheira Renata Guimarães, presente por todo este percurso peculiar de nossas vidas, me alimentando a alma com muito amor, carinho, força e fé para trilhar este caminho.

Gratifico ao meu amigo e orientador professor Dr. Valério Silva Almeida, pela confiança no meu potencial e aceitar me orientar para o desenvolvimento deste trabalho, por todo o conhecimento e auxílio prestados, pelas conversas e amizade.

Gratifico aos meus amigos de curso, Gian Calobrezi, Eduardo Ascenso, Jonas Teixeira, Társis Travassos, Cátia Silva e Paulo Refachinho por toda a amizade e por terem me passado tanto conhecimento durante este gratificante período, por mais que fora um curto tempo, se tornaram pessoas importantes para mim.

Gratifico aos professores Doutores Alfredo Gay, Carlos Mazzilli e Hélio Simonetti por toda a sabedoria e amizade durante o curso. Por terem se tornado exemplos de educadores e terem me inspirado a ter desenvoltura para ser pesquisador e educador.

Gratifico aos meus amigos de infância, que sempre se mantiveram ao meu lado durante maior parte da minha existência, quem me ensinaram a estudar, evoluir e viver. Durante esta fase tiveram enorme importância, com palavras sábias de inspiração e incentivo, em especial Gabriel Sérgio, Eric Haruki, Juliano Abreu e Bruno Vieira.

Gratifico ainda, não menos importante por estarem ao final deste item, a todos os professores e educadores que passaram pela minha trajetória, todos vocês ajudaram a construir meu caráter e todo conhecimento obtido para o desenvolvimento deste trabalho e ademais pesquisas, projetos, e futuras publicações.

Por fim, agradeço a todos os funcionários e professores da Escola Politécnica da USP que tornaram esta realização possível, a CNPq pela bolsa concebida durante certo período e a todos que tiveram parte nesta conquista. 
Human error is important, perhaps dominant, cause of failure in structures. Effective control of reliability requires control of the influence of human error. Human error mechanisms differ from the physical causes of random fluctuations in loads and resistances, and they are not yet well understood.

(H. O. Madsen) 


\section{RESUMO}

RIBEIRO, M. R. R. Aplicação da teoria de confiabilidade na análise estrutural de edifícios considerando a interação solo-estrutura. 2019. 120 p. Dissertação (Mestrado em Engenharia Civil) - PPGEC, Universidade de São Paulo, São Paulo, 2019.

O trabalho propõe avaliação das respostas de esforços e deslocamentos de edifícios 3D considerando a interação solo-fundação-estrutura usando o conceito de Confiabilidade Estrutural. Para isso, empregam-se os Métodos dos Elementos Finitos (MEF) para a análise de estruturas e os métodos de Monte Carlo Simples (MCS) e First Order Second Moment (FOSM) para calcular sua segurança perante a inserção de variabilidade em certos parâmetros significativos no projeto, como as incertezas dos dados de rigidez do solo e a velocidade de vento.

A formulação do edifício é baseada no MEF com elementos de barra e de casca, sendo as vigas, pilares e estacas elementos de barra e as sapatas em elementos de casca. Essa formulação é elastostática, mas permitindo a analise não-linear geométrica para os pilares. O solo é representado pelo modelo discreto de Winkler, o qual substitui sua influência contínua por molas pontuais com rigidezes equivalentes, tanto para a fundação rasa (sapatas isoladas) como para profunda (estacas).

Com os resultados obtidos pelos modelos gerados, são feitas discussões e comparações com os métodos tradicionais de avaliação do fenômeno de recalque diferencial confrontando limites de índices de confiabilidade apresentados no Joint Committee on Structural Safety (JCSS, 2001) e os valores absolutos propostos pela literatura com base na Associação Brasileira de Normas Técnicas, ABNT, NBR6122: Projeto e execução de fundações (2010). Realiza-se também a análise de Estado Limite Último de pilares submetidos a flexo-compressão oblíqua com não linearidade física, de modo a avaliar o dimensionamento com fatores de segurança parciais da NBR 8681: Ações e segurança nas estruturas - Procedimento (2004) e Métodos de Confiabilidade Estrutural.

Palavras chave: Confiabilidade Estrutural, Edifício 3D, Interação SoloEstrutura, Recalque Diferencial, Flexo-compressão. 
RIBEIRO, M. R. R. Application of the structural reliability theory in the structural analysis of buildings considering soil-structure interaction. 2019. $120 \mathrm{p}$. Dissertation (Msc.) - PPGEC, University of São Paulo, São Paulo, 2019.

This work proposes the evaluation for the effects of forces and displacements about 3D buildings considering the soil-foundation-structure interaction using the concept of Structural Reliability. To do so, it is applied the Finite Elements Method (FEM) for the structural analysis and Simple Monte Carlo Method (SMC) and the First Order Second Moment (FOSM) to calculate its safety towards the application of variability at certain significant parameters of the project, as the uncertainness about the data of soil stiffness and wind speed.

The building's formulation is based on the FEM with framed bars and shell elements, being beams, columns and piles as beam elements and the footings as shell elements. That formulation is elastostatic, although permits a non-linear geometric analysis for the columns. The soil is represented by the discrete Winkler's model, in which substitutes its continuum influence by nodal springs with equivalent stiffness, such as for shallow foundations (isolated footings), as for deep foundations (piles).

With the results obtained by the generated models, discussions are done and comparisons about traditional method to evaluate the phenomenon of the differential settlement confronting the limits of the reliability presents in the Joint Committee on Structural Safety (JCSS,2001) and the absolute values proposed by the literature based on the Brazilian Association of Technical Standards, ABNT, NBR6122: Project and execution of foundations (2010). An analysis about the Ultimate Limit State of columns submitted by flexo-compression with physical non-linearity it is also performed, so that to compare the design with partial safety factors of the NBR 8681 : Action and safety on structures - Proceedings (2004) and structural reliability methods.

Key words: Structural Reliability, 3D Building, Soil-Structure Interaction, Differential Settlement, Flexo-compression 


\section{LISTA DE ILUSTRAÇÕES}

Figura 1 - Diagrama esquemático de um problema de confiabilidade estrutural (Fonte: Beck, 2015) 31

Figura 2 - Domínios da equação de estado limite (Beck, 2015, adaptado) 32

Figura 3 - Curvas de distribuição Normal para as variáveis aleatórias R e S (Fonte: Autor) 34

Figura 4 - Curva de distribuição Normal da Variável Aleatória M. (Fonte: Autor) .....35 Figura 5 - Curva de distribuição Normal Padrão da Variável Aleatória M. (Fonte: Autor)

Figura 6 - Transformação de Hasofer Lind do espaço $\mathbb{X}$ para $\mathbb{Y}$ (Fonte: Autor) .37

Figura 7 -Interpretação geométrica do algoritmo iterativo HLFR (Beck, 2015, adaptado)

Figura 8 - Modelo do exemplo proposto. (Fonte: Du, 2005)

Figura 9 - Função cumulativa inversa de probabilidade proposta por Beck (2015) com valores y e u para a i-ésima variável aleatoria. (Fonte: Autor)

Figura 10 - Transformação da Distribuição Normal Padrão para Normal da Variável Aleatória. (Fonte: Autor)

Figura 11 - Transformação da Distribuição Normal Padrão para Lognormal da Variável Aleatória. (Fonte: Autor).... .52

Figura 12 - Modelo do exemplo proposto por Beck, 2008 (Fonte: Autor) 53

Figura 13 - Gráfico de convergência das probabilidades de falha dos estados limites (Fonte: Autor)

Figura 14 - Gráfico de convergência da probabilidade de falha do estado limites. (Fonte: Autor) 56

Figura 15 - Modelo da viga mista do exemplo proposto. (Fonte: Du, 2005) 57

Figura 16 - Gráfico de convergência da probabilidade de falha do estado limite (Fonte: Autor) 60

Figura 17 - Gráfico de convergência da probabilidade de falha do estado limite (Fonte: Autor)

Figura 18 - Fluxograma do procedimento de cálculo desenvolvido para o método FOSM (Fonte: Autor)

Figura 19 - Fluxograma do procedimento de cálculo desenvolvido para o método de Monte Carlo (Fonte: Autor) 
Figura 20 - Acoplamento entre sapata e solo via hipótese de Winkler (Fonte: Almeida, 2003)

Figura 21 - Modelo de estaca com as molas representando o solo (Fonte: Autor) ..69 Figura 22 - a) Representação explícita dos elementos de estaca com mola, bloco e pilar; b) Representação condensada das estacas e molas (Fonte: Autor) ................70 Figura 23 - Modelo renderizado e em frames no STRAP. (Fonte: Autor) ..................71 Figura 24 - Desenho esquemático de um recalque diferencial (NBR6122, 2010) ....73 Figura 25 - Modelo do edifício gerado (Fonte: Autor) …….................................75

Figura 26 - Modelo do edifício TIPO-A gerado (Fonte: Autor) ….............................77 Figura 27 - Planta do edifício TIPO-B à esquerda e seção transversal no plano ZX à direita. (Fonte: Autor) .79

Figura 28 - Posições das estacas nos blocos, estacas azuis claro com a caracterização de molas distintas das azuis escuro. (Fonte: Autor). 89 Figura 29 - Planta do edifício TIPO-B à esquerda e seção transversal no plano ZX à direita. (Fonte: Autor)

Figura 30 - Probabilidades de falha para seção com barras de 10mm. (Fonte: Autor) .96

Figura 31 - Probabilidades de falha para seção com barras de 12,5mm. (Fonte: Autor) 96

Figura 32 - Histogramas dos esforços solicitantes no pilar 1 com respectivas média e desvio padrão, edifício engastado. (Fonte: Autor) 98 Figura 33 - Histogramas dos esforços solicitantes no pilar 2 com respectivas média e desvio padrão, edifício engastado. (Fonte: Autor). 98 Figura 34 - Histogramas dos esforços solicitantes no pilar 4 com respectivas média e desvio padrão, edifício engastado. (Fonte: Autor) 99 Figura 35 - Histogramas dos esforços solicitantes no pilar 5 com respectivas média e desvio padrão, edifício engastado. (Fonte: Autor). 99 Figura 36 - Histogramas dos esforços solicitantes no pilar 7 com respectivas média e desvio padrão, edifício engastado. (Fonte: Autor). 100 Figura 37 - Histogramas dos esforços solicitantes no pilar 8 com respectivas média e desvio padrão, edifício engastado. (Fonte: Autor) 100 Figura 38 - Histogramas dos esforços solicitantes no pilar 1 com respectivas média e desvio padrão, com interação solo-estrutura. (Fonte: Autor) 101 
Figura 39 - Histogramas dos esforços solicitantes no pilar 2 com respectivas média e desvio padrão, com interação solo-estrutura. (Fonte: Autor) 101

Figura 40 - Histogramas dos esforços solicitantes no pilar 4 com respectivas média e desvio padrão, com interação solo-estrutura. (Fonte: Autor) 102 Figura 41 - Histogramas dos esforços solicitantes no pilar 5 com respectivas média e desvio padrão, com interação solo-estrutura. (Fonte: Autor) 102 Figura 42 - Histogramas dos esforços solicitantes no pilar 7 com respectivas média e desvio padrão, com interação solo-estrutura. (Fonte: Autor) 103 Figura 43 - Histogramas dos esforços solicitantes no pilar 8 com respectivas média e desvio padrão, com interação solo-estrutura. (Fonte: Autor) 103 


\section{LISTA DE TABELAS}

Tabela 1 - Estados Limite típicos para estruturas, segundo Melchers (1999) .........24

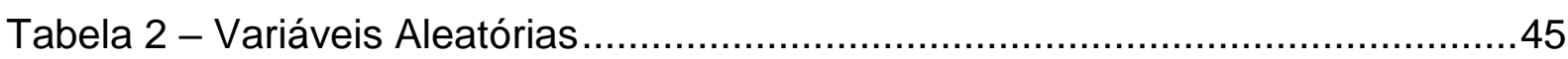

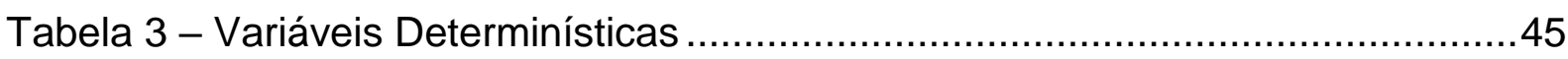

Tabela 4 - Resultados obtidos para o ponto de projeto, segundo Du (2005) ...........46

Tabela 5 - Resultados obtidos para o ponto de projeto, de acordo com o presente

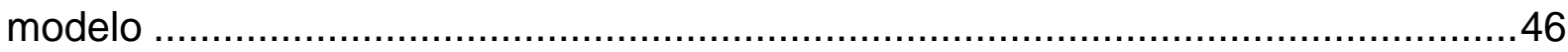

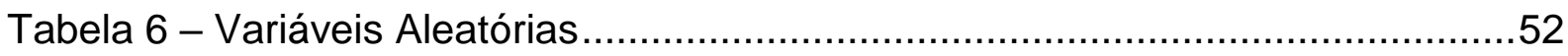

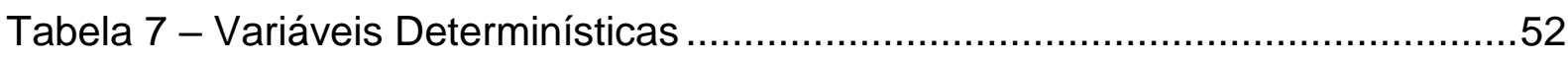

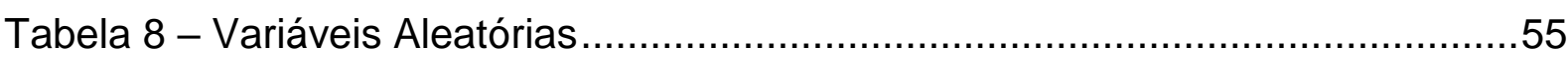

Tabela 9 - Resultados obtidos para o ponto de projeto, de acordo com a rotina

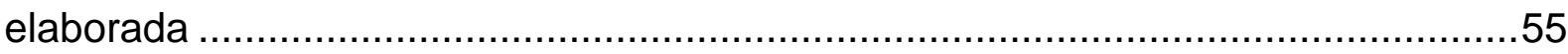

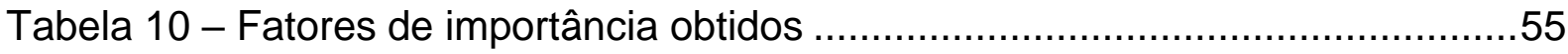

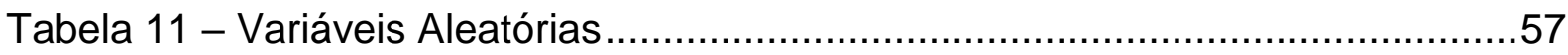

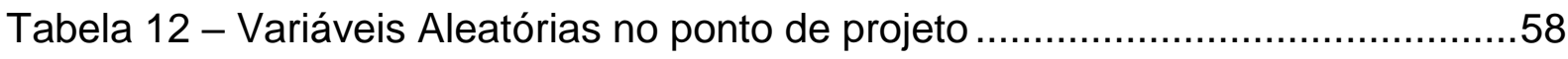

Tabela 13 - Fatores de Importância das Variáveis Aleatórias .................................59

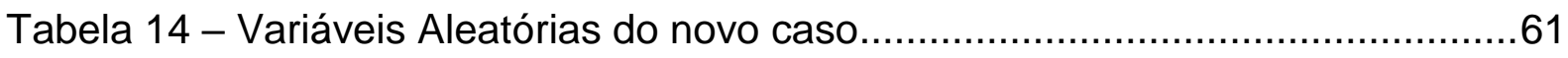

Tabela 15 - Variáveis Aleatórias no ponto de projeto ..............................................61

Tabela 16 - Fatores de Importância das Variáveis Aleatórias ...................................62

Tabela 17 - Valores dos recalques obtidos no presente modelo e pelo STRAP ......72

Tabela 18 - Valores de $\boldsymbol{\alpha}$ de acordo com a NBR6122(2010) …...............................73

Tabela 19 - Valores de recalque diferencial máximo ( $\boldsymbol{\delta} \boldsymbol{m a ́} \boldsymbol{x}$ ) de acordo com a literatura .73

Tabela 20 - Variáveis aleatórias aplicadas na simulação ………………………....79

Tabela 21 - Resultados de recalques obtidos pelo programa MEF ........................82

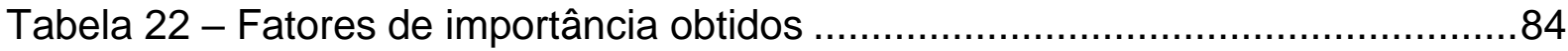

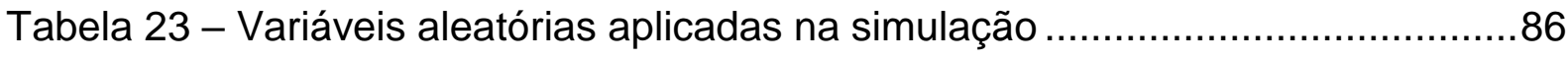

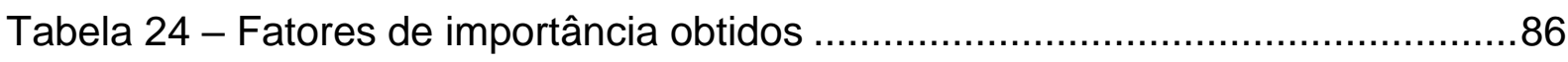

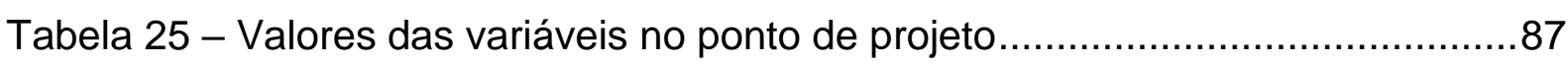

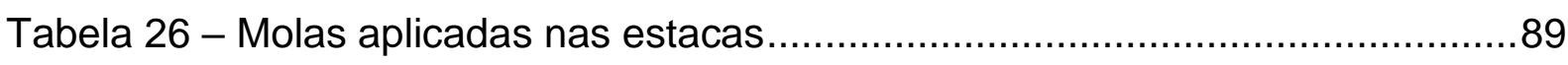

Tabela 27 - Variáveis aleatórias aplicadas na simulação .........................................90

Tabela 28 - Fatores de importância obtidos ....................................................... 
Tabela 29 - Valore das variáveis no ponto de projeto .91

Tabela 30 - Variáveis aleatórias aplicadas na simulação .......................................94

Tabela 31 - Variáveis aleatórias aplicadas na simulação com edifício engastado 104 Tabela 32 - Variáveis aleatórias aplicadas na simulação com edifício com solo-

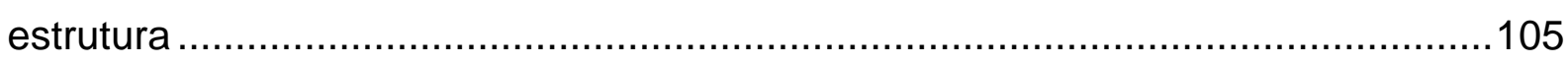

Tabela 33 - Valores limites de acordo com o JCSS (2001) para ELS. …..............108

Tabela 34 - Valores limites de acordo com o JCSS (2001) para ELU...................110 


\section{LISTA DE ABREVIATURAS E SIGLAS}

$\begin{array}{ll}\text { DF } & \text { Diferenças Finitas } \\ \text { EF } & \text { Elementos Finitos } \\ \text { ELS } & \text { Estado Limite de Serviço } \\ \text { ELU } & \text { Estado Limite Último } \\ \text { FORM } & \text { First Order Reliability Method } \\ \text { FOSM } & \text { First Order Second Moment } \\ \text { JCSS } & \text { Joint Committee on Safety of Structures } \\ \text { MATLAB } & \text { Matrix Laboratory (Software) } \\ \text { MCS } & \text { Monte Carlo Simples } \\ \text { MEF } & \text { Método dos Elementos Finitos } \\ \text { NBR } & \text { Norma Brasileira } \\ \text { PPGEC } & \text { Programa de Pós-Graduação em Engenharia Civil } \\ \text { SORM } & \text { Second Order Reliability Method } \\ \text { StRAnD } & \text { Structural Risk Analysis and Design (Software) } \\ \text { STRAP } & \text { Structural Analysis Program (Software) }\end{array}$




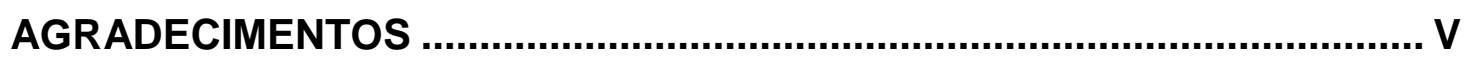

RESUMO .......................................................................................... VII

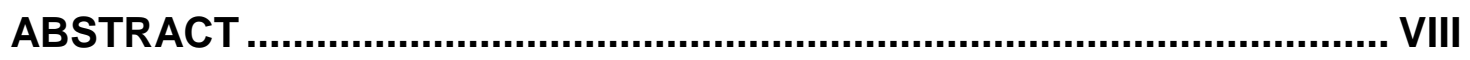

LISTA DE ILUSTRAÇÕES.................................................................. IX

LISTA DE TABELAS................................................................................ XII

LISTA DE ABREVIATURAS E SIGLAS ............................................. XIV

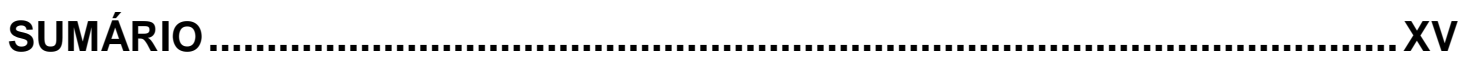

1 INTRODUÇÃO

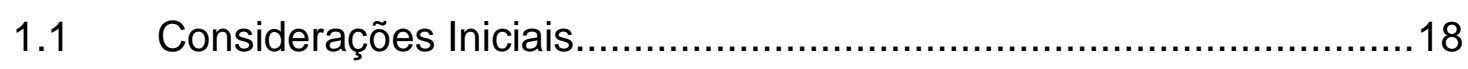

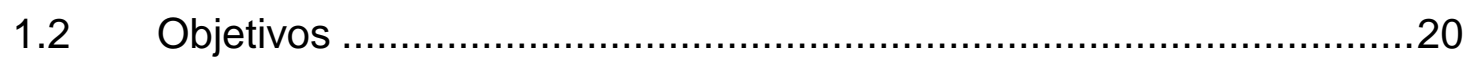

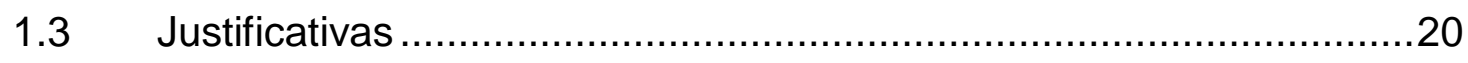

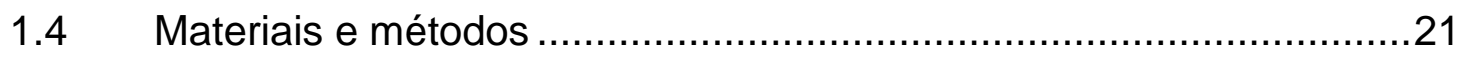

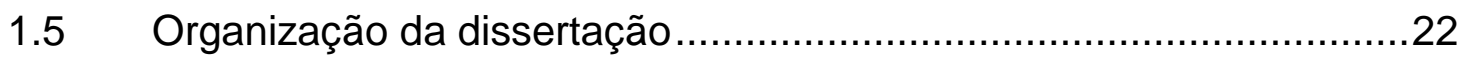

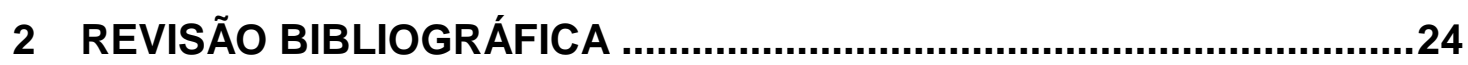

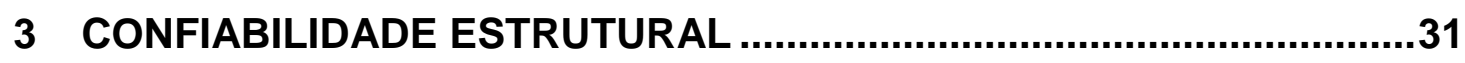

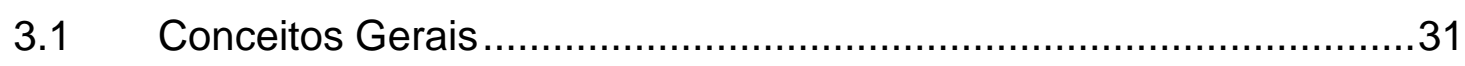

3.2 Problema Fundamental da Confiabilidade Estrutural .........................33

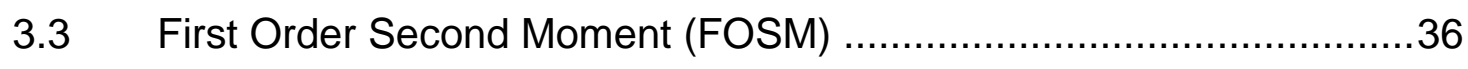

3.3.1 Transformação de Hasofer Lind.................................................37

3.3.2 Ponto de projeto e índice de confiabilidade para problemas $n$ -

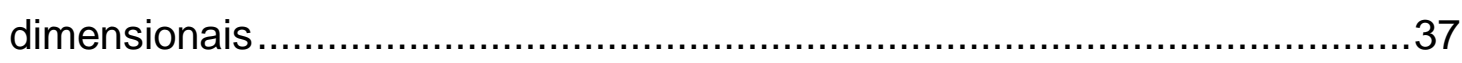


3.3.3 Método Lagrangiano para Problemas de Otimização com Restrições .38

3.3.4 Linearização da Equação de Estado Limite ................................39

3.3.5 O algoritmo Hasofer, Lind, Rackwitz and Fiessler (HLRF) ...........40

3.3.6 Sensibilidade e Relevância das Variáveis Aleatórias....................42

3.3.7 Transformação Hasofer-Lind matricial ...................................43

3.3.8 Método das Diferenças Finitas (DF) Aplicado em Problemas de Confiabilidade Estrutural....................................................................... 44

3.3.9 Exemplo de Aplicação do Método FOSM ................................45

3.4 Método de Monte Carlo Simples ..............................................46

3.4.1 Geração de amostras de Variáveis Aleatórias ...........................48

3.4.2 Exemplo de Aplicação do Método de Monte Carlo Simples..........52

3.5 Aplicação Conjunta dos Métodos MCS e FOSM ............................54

3.5.1 Problema simples de confiabilidade estrutural ........................54

3.5.2 Problema com diversas variáveis aleatórias e complexidade

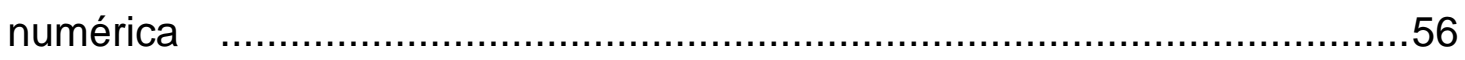

\section{MODELO DE INTERAÇÃO SOLO-FUNDAÇÃO-EDIFÍCIO......................64}

4.1 Modelo de Cálculo para Edifícios com Fundações..........................67

4.1.1 Hipótese de Winkler para Fundação Direta ..............................67

4.1.2 Hipótese de Winkler para Fundação Profunda ...........................68

4.1.3 Verificação do Programa de Edifícios com Estacas.....................71

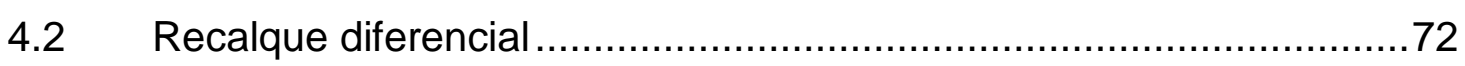

5 SIMULAÇÕES NUMÉRICAS ....................................................... 74

5.1 Edifício com 4 elementos de fundação direta via método MCS .........74

5.2 Edifício 9 elementos de fundação direta via método MCS com 19 variáveis aleatórias ........................................................................ 76 
5.3 Edifício com 9 elementos de fundação direta via método MCS e 38

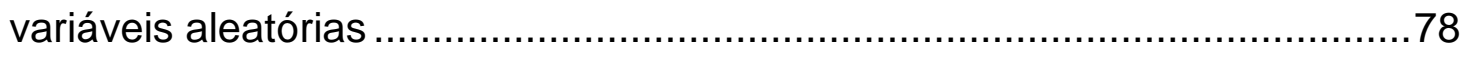

5.4 Edifício com 9 elementos de fundação direta avaliado pelo FOSM e 38 variáveis aleatórias

5.5 Edifício com 9 elementos de fundação direta avaliado pelo FOSM e 22 variáveis aleatórias

5.6 Edifício com 9 blocos de fundação com 4 estacas avaliado pelo FOSM e 22 variáveis aleatórias

5.7 Verificação em Estado Limite Último dos Pilares do Edifício TIPO-B.93

5.7.1 Verificação global com modelo engastado. .93

5.7.2 Verificação individual com modelo engastado e comparação com solo-estrutura

6 RESULTADOS E DISCUSSÕES 107 


\section{INTRODUÇÃO}

\subsection{Considerações Iniciais}

Na história, de maneira geral, o homem começou a desenvolver suas primeiras ferramentas e mecanismos motivados por suas necessidades diárias para sobrevivência, como conseguir alimentos e manter sua integridade física. Cada ferramenta, mecanismo ou abrigo primitivo pode ser considerado como um tipo de estrutura. Com a evolução das primeiras sociedades, advém a evolução da produção e desenvolvimento destas estruturas, à prima vista, de maneira grosseira e empírica. Em certo tempo, todo esse desenvolvimento passa a ser possível através de métodos numéricos dos quais foram se aprimorando com o decorrer dos anos, de modo que estruturas antes dimensionadas por modelos empíricos e, em geral, destrutivos, começam a ter a possibilidade de serem avaliadas numericamente de maneira mais eficiente e eficaz. Atualmente, certos fenômenos ainda são difíceis de serem previstos e devidamente calculados, de modo que são aplicados coeficientes de segurança, métodos probabilísticos, e ainda são utilizados modelos empíricos em determinadas análises. O solo, por exemplo, trata-se de um tipo de um material natural altamente heterogênea, de modo que na literatura são encontrados diversos métodos empíricos e semi-empíricos para a caracterização dos seus índices físicos tanto quando da previsão de seu comportamento mecânico.

Dentre os estudos de métodos estatísticos, confiabilidade é uma ciência que envolve resultados advindos de processos repetitivos que tem alguma relação com algum teste ou procedimento. Shewhart (1931) foi pioneiro na área com a publicação de um livro contendo métodos probabilísticos com foco em controle de fabricação de produtos. Nesta mesma época, estudos envolvendo análises probabilísticas foram amplamente desenvolvidos em função do contexto da segunda guerra mundial, na qual impulsionou e consolidou o conceito de confiabilidade na engenharia no início da década de 1940, época quando começaram a serem publicados trabalhos e desenvolvidos projetos no âmbito da confiabilidade estrutural.

Madsen et al. (1986) mencionam que existem diversos modos de se idealizar os modelos estruturais de confiabilidade, e muitas maneiras das quais é possível combinar idealizações diferentes para a análise de um problema específico. Então, 
propõe a importância de classificar os métodos de confiabilidade estrutural em níveis de acordo com a quantidade de informações que se dispõe do problema:

- Nível 0 - O método das tensões admissíveis: Trata-se da comparação entre a tensão gerada de cálculo $\left(\sigma_{s}\right)$ e a tensão admissível $\left(\sigma_{a d m}\right)$, de modo que a divisão $\sigma_{a d m} / \sigma_{s}$ representa um fator global de segurança.

- Nível I - Método dos Estados Limites: São métodos que envolvem apenas um valor característico de cada parâmetro aliado a fatores parciais de segurança. Este método é o mais utilizado nas normas Brasileiras.

- Nível II - Método do Índice de Confiabilidade: São métodos que aplicam dois parâmetros relativos à incerteza de cada variável, usualmente média e variância, com alguma medida de correlação entre as variáveis, geralmente a covariância.

- Nível III - Método da Probabilidade de Falha: Quando são calculadas as probabilidades de falha e, consequentemente, são conhecidas as distribuições conjuntas das variáveis. Este método é desenvolvido e aplicado neste trabalho.

- Nível IV - Método de Confiabilidade de Minimização de Custos: Métodos aplicados para estruturas de grande porte e complexidade, no qual analisa-se a otimização do custo da estrutura considerando fatores como custo benefício de construção, manutenção, reparo e risco.

Os níveis apresentados não são exclusivos, mas sim podem ter algumas informações a mais ou a menos, de modo que a classificação em níveis facilite a designação do conjunto de dados do problema.

Zhang et al. (1997) apresentam ainda que tentativas para métodos de combinação entre confiabilidade estrutural e Método dos Elementos Finitos (MEF) começaram a ser elaboradas a partir da década de 1980, para uma possível ferramenta unificada para análise de confiabilidade em sistemas estruturais complexos.

Colocados os conceitos introduzidos, em conjunto com ferramentas computacionais e da literatura, apresenta-se neste trabalho o propósito da elaboração de uma metodologia para a simulação em métodos estatísticos de uma estrutura modelada em elementos finitos (EF), no caso especifico de edifícios considerando a influência da sua interação com a fundação e solo. Tal proposta se baseia na introdução de modelos probabilísticos de análise do complexo problema de projeto 
que é a interação solo-estrutura, com ênfase nas análises levando-se em conta, principalmente as incertezas dos parâmetros do solo, simulado diretamente pelo método de Winkler, uma vez que são os valores de menor controle no projeto e podem levar a resultados no edifício de valores bem discrepantes para cada cenário.

\subsection{Objetivos}

Com a motivação de se fazer análises mais próximas da realidade, levando em conta a imponderabilidade dos parâmetros reais a partir de simulações numéricas, os métodos de confiabilidade introduzem os parâmetros estatísticos das variáveis que compõem as formulações do problema. Neste contexto, o método de Confiabilidade Estrutural é escolhido aqui para analisar as respostas relevantes de projeto que ocorrem em um edifício de vários andares, contemplando as variações dos coeficientes mais influentes do problema, no qual pode ser estendido a quaisquer tipos de estruturas. Neste trabalho, o comportamento de interação solo-estrutura é o principal fenômeno de estudo, aliado à importância e variabilidade dos diversos coeficientes mencionados e seus respectivos parâmetros estatísticos, de maneira a verificar a segurança da estrutura (coeficientes de segurança) em confronto aos métodos probabilísticos de confiabilidade (risco), para Estado Limite de Serviço (ELS) e Estado Limite Último (ELU).

\subsection{Justificativas}

Muito já tem sido estudado sobre o uso da confiabilidade estrutural, quer no tocante a sua aplicação nos parâmetros resistentes do concreto, aço, ou da madeira, no tocante a suas propriedades mecânicas, ou na sua variabilidade geométrica, como na verificação quando da mudança das seções, comprimento, na variação das ações permanentes e/ou acidentais. Portanto torna-se clara a necessidade de se abordar o tema de interação solo-estrutura considerando a variabilidade do maciço de solos que é o apoio final da estrutura. Acrescente-se também o fato que muitas vezes existe percolação de água em seu meio, falhas em forma de fratura em regiões de base de rochas sã, etc. Todas essas peculiaridades desse material, aliado à sua intrínseca 
geometria tridimensional e de domínio semi-infinito leva nos projetos a construção de modelos de análises bem como da definição de propriedades mecânicas muito simplificados. Devido a isso, coeficientes de segurança na majoração de ações e minoração de suas resistências são usados com valores muito elevados, em geral maiores que três (3), cada. Nesse sentido, devido aos modelos empregados, podemse cometer erros contra a segurança, além de elevar o custo final do projeto. Tais contrapontos podem ser estudados com maior refinamento utilizando-se métodos de confiabilidade.

Quanto ao uso de modelos de análise mais sofisticados, atualmente na Engenharia existem métodos numéricos e ferramentais de processamento que conseguem simular de maneira adequada seu comportamento físico, contudo o alto custo computacional devido a sua complexidade, muitas vezes inviabiliza o seu uso corrente na análise de projetos de obras civis. Por outro lado, caso se empreguem modelos de análises complexos, podem ocorrer erros grosseiros quando da escolha dos parâmetros mecânicos mais representativos desse meio. Em face disso, a confiabilidade estrutural é utilizada para a verificação da segurança dessa estrutura de base, o solo como elemento de assente das edificações, é muito adequado, uma vez que seja possível controlar de maneira mais precisa os parâmetros de modo a verificar a segurança dessa superestrutura.

\subsection{Materiais e métodos}

$\mathrm{Na}$ primeira etapa deste trabalho, foi elaborada uma revisão bibliográfica na qual envolvem os seguintes temas de maneira resumida: Confiabilidade Estrutural, Elementos Finitos, Interação solo-estrutura e Diferenças Finitas.

No projeto proposto, realiza-se a interação entre o modelo de análise de estruturas e o modelo de confiabilidade. $O$ modelo de edifícios usa o MEF com elementos de barra e casca e foi inicialmente desenvolvido por Almeida (2003), que contemplava a simulação de vigas, pilares e sapatas em elementos de casca. No trabalho de Aquino (2009) inseriu-se a análise não-linear geométrica dos pilares com formulação com rotações moderadas. O presente autor dessa dissertação inseriu o modelo de estacas. Neste trabalho, optou-se pela aplicação do método de Winkler 
para interação solo-estrutura devido à maior facilidade para aplicação e inserção das variáveis.

Para as formulações dos modelos de confiabilidade, foram desenvolvidos também nessa dissertação procedimentos que integrassem os temas mencionados, onde dois (2) modelos são feitos: First Order Second Moment (FOSM) e Monte Carlo Simples (MCS). Para o método FOSM, com a equação do estado limite que depende de um resultado implícito gerado pelo modelo, o que torna necessário o Método das Diferenças Finitas (DF) para aplicar a diferenciação do vetor gradiente dentro do método FOSM como explanado em Beck (1999). Neste trabalho, o método MCS é desenvolvido com funções densidade de probabilidade Normal e Lognormal. Os sistemas gerados executam externamente o programa de edifícios, para o cálculo das probabilidades de falha dos estados limite. Adiante, foi ainda inserida uma rotina no programa de edifícios para a possibilidade de modelagem de edifícios com fundações profundas. Vale destacar neste ponto a dificuldade em se encontrar na literatura trabalhos que contemplem uma análise geral de recalque por meio de métodos de confiabilidade aplicados em modelos de edifícios com interação solo/estrutura, seja com elementos de fundação rasa ou profunda. Seguidamente, desenvolveu-se particularmente um sistema semelhante ao anterior para executar um programa de análise de não linearidade física para pilares de concreto armado em flexocompressão (Pimenta, 2016) e posteriormente ao programa de edifícios. Foi ainda utilizado o método MCS para gerar amostragens de modo a verificar o comportamento probabilístico dos esforços solicitantes nos pilares.

Diversos exemplos numéricos foram elaborados com casos hipotéticos de edifícios de vários andares com fundação superficial e profunda projetados no Brasil para analisar e discutir os resultados posteriormente. Com esses resultados obtidos, uma interpretação apropriada é feita e comparada com as referências e entre si para se chegar em resultados e conclusões factíveis sobre os métodos e os próprios resultados.

\subsection{Organização da dissertação}

O presente trabalho está organizado da seguinte forma: Uma revisão bibliográfica na seção 2, explanação sobre Confiabilidade Estrutural e os métodos abordados na seção 3 , sendo apontados os temas do problema fundamental da 
confiabilidade estrutural, detalhes do método FOSM, o algoritmo de Hasofer, Lind, Rackwitz e Fiessler (HLRF), o método das diferenças finitas (DF) para confiabilidade estrutural, com exemplos para validação do modelo implementado para o método. Apresenta-se também o método de Monte Carlo simples, exemplo para verificação do algoritmo elaborado e, por fim, a aplicação conjunta dos métodos. Na seção 4 apresenta-se a interação do programa de edifícios em EF com os métodos de confiabilidade estrutural, apresentando os temas do modelo de cálculo, hipótese de Winkler para fundações diretas e profundas, exemplo de verificação para rotina implementada para fundações profundas e, por fim, o recalque diferencial. Os resultados obtidos com o programa proposto com a presente formulação são apresentados na seção 5 , e as conclusões na seção 6 . 


\section{REVISÃO BIBLIOGRÁFICA}

Melchers (1998), um dos pioneiros em publicações sobre confiabilidade estrutural, define em seu clássico trabalho que "A maneira que uma estrutura de engenharia vai responder aos carregamentos depende do tipo e magnitude da carga aplicada e na robustez e rigidez da estrutura. Se a resposta é considerada satisfatória depende das condições das quais devem ser satisfeitas. Estas incluem segurança da estrutura contra o colapso, limitações ao dano ou aos deslocamentos ou outros critérios". As condições mencionadas dizem respeito ao estado limite das quais a estrutura está sujeita de modo que não podem ser violadas. Ele aponta ainda estados limites típicos em estruturas, descritos na tabela 1.

Tabela 1 - Estados Limite típicos para estruturas, segundo Melchers (1998)

\begin{tabular}{|c|c|c|}
\hline Estados Limite & Descrição & Exemplos \\
\hline Último (segurança) & $\begin{array}{l}\text { Colapso de toda ou } \\
\text { parte da estrutura }\end{array}$ & $\begin{array}{l}\text { Escorregamento, ruptura, } \\
\text { colapso progressivo, } \\
\text { mecanismo plástico, } \\
\text { instabilidade, corrosão, fadiga, } \\
\text { deterioração, fogo }\end{array}$ \\
\hline $\begin{array}{l}\text { Dano (em geral, } \\
\text { incluído no caso } \\
\text { acima) }\end{array}$ & & $\begin{array}{l}\text { Fissuras excessivas ou } \\
\text { prematuras, deformação ou } \\
\text { deformação permanente } \\
\text { inelástica }\end{array}$ \\
\hline Serviço & $\begin{array}{l}\text { Complicação no uso } \\
\text { comum }\end{array}$ & $\begin{array}{l}\text { Deslocamento excessivo, } \\
\text { vibrações, dano local, etc. }\end{array}$ \\
\hline
\end{tabular}

Melchers (1999) diz também que é de conhecimento que poucas estruturas entram em colapso ou necessitam de reparos consideráveis, como de certo modo, intuitivamente entende-se que a violação dos estados limite ocorre raramente, porém quando ocorrem podem ter consequências desastrosas, como alguns casos de colapsos emblemáticos como a ponte Tay (carga de vento), edifício Ronan Point (explosão de gás), plataforma marítima de Kielland (problemas de carga local), terremoto Kobe (ductilidade), etc. Conclui ainda que o estudo da Confiabilidade 
Estrutural trata-se do cálculo e previsão da probabilidade da violação de um estado limite para um sistema estrutural dimensionado em qualquer estágio de sua vida útil.

Zhang et al. (1997) acrescentam ainda que a análise de confiabilidade com EF segue os seguintes 5 passos: (1) Modelagem dos materiais, geometrias, carregamentos em termos de variáveis aleatórias. (2) Modelagem da estrutura em termos de malha de EF e leis constitutivas. (3) Formulação dos termos de segurança da estrutura em termos de estados limite. (4) Processo de várias iterações de repetidas análises de EF por conjuntos variados de variáveis aleatórias. (5) Cálculo dos termos de sensibilidade para o método First Order Reliability Method (FORM).

Para que parâmetros estatísticos sejam inseridos em metodologias de concepção de projetos, O Joint Committee on Structural Safety (JCSS, 2001) traz um material que se destina a ajudar os engenheiros a projetar estruturas com o ponto de vista probabilístico. Tendo em vista as informações necessárias sobre o comportamento probabilístico das variáveis gerais, uma tentativa de trazê-los para o ambiente e os padrões brasileiros é elaborada, como alguns trabalhos recentes (Ramírez, 1998) (Santos et al., 2014) e a obra clássica (Hachich et al., 1998) aliado aos padrões técnicos brasileiros NBR8681: 2003, NBR6118: 2014, NBR6122: 2010 e NBR6123: 1988.

Para fazer um estudo estatístico é necessário um método probabilístico que, neste trabalho, foram utilizados os métodos First Order Second Moment (FOSM) e o Método de Monte Carlo Simples. De acordo com Beck (2015), o FOSM é um método mais simples, que é a base para os mais complexos de transformação, como o First Order Reliability Method (FORM) e o Second Order Reliability Method (SORM). O método de Monte Carlo Simples trata-se de um procedimento mais próximo da realidade e mais intuitivo. Outros métodos probabilísticos podem ser encontrados e estudados em Bjerager (1990), Melchers (1998), Zhang et al. (1997) e Madsen et al. (1986). Ainda assim, uma rotina de simulação é necessária para executar um modelo, portanto, em Almeida (2003) é possível simular a fundação superficial que interage com uma edificação de vários andares e a influência do solo por meio do MEF, com o último usando a hipótese clássica de Winkler.

Verzenhassi (2008) aborda o tema da otimização de risco estrutural, visando a minimização de custos, em que é procurado um coeficiente de segurança parcial ótimo que minimizaria o custo esperado total. Em seu trabalho, é elaborado um programa computacional em FORTRAN para a aplicação da otimização, que é 
acoplado a um programa de confiabilidade desenvolvido na Escola de Engenharia de São Carlos da Universidade de São Paulo (EESC/USP) e a um programa comercial de EF para a simulação do modelo mecânico. Além do desenvolvimento e apresentação do equacionamento de métodos de confiabilidade, também são abordados equacionamentos de métodos de otimização, de modo a particularizar algoritmos de Interpolação Quadrática e Regula Falsi. Ao final, com os exemplos elaborados, concluiu-se que quando parcelas não estruturais dominam o custo, um projeto superdimensionado não representa grande perda econômica, enquanto um projeto subdimensionado pode causar grandes prejuízos. Também é dito que a confiabilidade ótima é altamente dependente das consequências e custos de falha e mostra que casualidades que possuem grande incerteza e grandes consequências de falha tendem a dominar o projeto.

Khatibina et al. (2013) apresentam análise sísmica com confiabilidade para estruturas de concreto armado introduzindo o conceito de meta-modelos para reduzir o custo computacional ao aplicar o método de Monte Carlo. Tendo em vista esse contexto, um estudo é feito com exemplos numéricos confrontando modelos de edifícios em pórtico de base fixa e considerando a interação solo-estrutura, de modo que é concluído e evidenciado a importância da avaliação das probabilidades de falha da estrutura considerando a interação solo-estrutura mediante a divergência dos resultados entre este e o modelo de base fixa.

Souza Júnior (2008) em seu trabalho faz um estudo dos coeficientes parciais de segurança utilizados em normas de projeto estrutural. Utiliza-se dos métodos de confiabilidade estrutural de modo a atingir os coeficientes parciais e segurança a partir de valores de índice de confiabilidade alvo, para estruturas de aço, com calibração segundo normas americanas (ANSI/AISC). Os coeficientes obtidos são comparados com os da norma brasileira ABNT NBR8800:2008, de modo que se conclui que os coeficientes parciais da norma brasileira levam a uma variação significativa dos índices de confiabilidade, e é obtido um conjunto de coeficientes cujos quais diminuem essa variação. É recomendada, portanto, uma possível revisão desses coeficientes parciais da norma brasileira ABNT NBR8800:2008.

Bazán (2017) propõe uma formulação geral para a análise de fadiga de pórticos planos baseada na Mecânica do Dano Concentrado, contemplando as incertezas associadas às variáveis do problema através da confiabilidade estrutural com a aplicação do método de Monte Carlo Simples. Ao final, é constatada que a 
metodologia construída é eficiente, de modo que os resultados foram comparados a curvas normatizadas. Tessari (2016) faz uma abordagem da Engenharia de Ventos Baseada em Desempenho (Performance-based Wind Engineering - PBWE) no qual trata-se do projeto estrutural envolvendo atuação de ações do vento utilizando-se de métodos probabilísticos acoplado em torres metálicas. Neste trabalho são estudados quatro métodos para estimativa de ventos em torres metálicas, dois referentes às normas brasileiras e duas pela literatura. Concluindo-se, então, que ambos os métodos empregados conduziram a níveis de segurança de mesma ordem de grandeza, e que a elaboração de projetos de torres considerando a direção de incidência do vento atribuída a mais desfavorável para a estrutura é demasiadamente conservadora.

Mapa (2016) desenvolve um estudo de confiabilidade empregando os métodos FORM e Monte Carlo, em pórticos metálicos planos considerando não-linearidade geométrica e flexibilidade das ligações. É avaliado o desempenho da estrutura nos estados limites último e de serviço, de modo que é atestada através de exemplos numéricos a importância da consideração de ligações semi-rígidas e da nãolinearidade geométrica para o projeto de pórticos planos.

Ferreira (2016) em sua tese de Doutorado propõe um novo método de confiabilidade, nomeado de SORM DG, no qual propõe a aplicação da geometria diferencial para o cálculo das curvaturas principais de uma superfície genérica num ponto qualquer que, nesse caso, trata-se do ponto de projeto. Deste modo, obtêm-se através de análises de confiabilidade em superfícies como exemplo, valores mais acurados do que o método SORM, no tocante ao valor da probabilidade de falha.

Nietiedt (2018) traz um estudo da aplicação da teoria Bayesiana, na qual se trata da aplicação de conceitos da probabilidade condicional, na atualização da capacidade de carga de estacas metálicas. Em sua dissertação, foram estudadas e avaliadas estacas para a construção de uma estação de tratamento de esgoto, e aplicados diversos métodos, com os quais se obteve um elevado grau de confiabilidade nos resultados.

Coelho (2018) em sua dissertação de mestrado faz um estudo probabilístico de propagação de trincas, de modo que são propostos dois modelos de probabilidade baseados na Mecânica da Fratura, apresentados e comparados nessa análise. Foi aplicado o método de Monte Carlo para gerar as variáveis aleatórias e a teoria 
Bayesiana junto às curvas de probabilidade de detecção de trincas para consolidar os programas gerados no trabalho.

Silva (2017) estudou diversos casos de lajes sob efeito de puncionamento através da análise de confiabilidade, de modo a fazer dois procedimentos diversos para calcular os esforços, aplicando o método de Monte Carlo através de um pacote comercial acoplado ao software ANSYS. Com isso, concluiu-se que para lajes sem armadura de punção, o procedimento de cálculo da norma NBR6118:2014 obteve resultados seguros de acordo com os resultados gerados através da confiabilidade, porém para lajes com armadura de punção, os resultados não foram satisfatórios para os índices de confiabilidade.

Coelho (2011) em sua tese de doutorado efetuou um abrangente estudo de confiabilidade sobre vigas de concreto armado em estado limite de serviço utilizando o método de Monte Carlo Simples de modo a verificar as variações das flechas de acordo com o estado de fissuração e diferentes características do material e taxas de aço nas estruturas. Concluindo-se, então, que o procedimento orientado pela NBR6118 não produz resultados uniformes para o dimensionamento de vigas e estado limite de serviço.

Silva (2004) elaborou um vasto estudo sobre uma metodologia para projeto com estacas com aplicação da probabilidade de ruína, cuja qual envolve a aplicação de métodos de confiabilidade, na qual fora aplicada em um estudo de caso. Provouse que a metodologia desenvolvida pode ser aplicada em obras de fundações desta natureza, principalmente para a tomada de decisões.

Nos trabalhos de Iwamoto (2000), Aquino (2008) e Covas e Almeida (2006) a interação solo-estrutura é estudada e abordada de maneiras distintas, Iwamoto (2000) traz a modelagem de núcleos, para estrutura tridimensional considerando excentricidades nas vigas com os pilares e as lajes como diafragmas rígidos, de modo que a fundação é composta de blocos rígidos com estacas, com o objetivo de evidenciar a importância desta interação, é feito um processo iterativo de cargas. Aquino (2008) aplica os métodos de acoplamento do Método dos Elementos de Contorno (MEC), MEF e o de Winkler para a interação do solo com as sapatas, em um modelo de superestrutura de MEF para efetuar um confronto entre os esforços resultantes nas vigas e pilares. Covas e Almeida (2006) por sua vez abordam o desenvolvimento de um modelo pelo software TQS em diversos tipos de fundações. 
Entretanto, apesar da importância e complexidade de cada trabalho, não foi realizada uma análise de confiabilidade estrutural para esses modelos.

Nesse contexto, trabalhos como Bungenstab et al. (2012) e Naccache (2016) abordam métodos probabilísticos em estruturas de fundações para análises de estados limite de serviço e últimos das estruturas de fundação, de modo que em Bungenstab et al. (2012) há um método simplificado para análise probabilística para o estudo de recalque de sapatas em solos arenosos com equação de estado limite explícita e de maneira isolada. Naccache (2016) apresenta uma modelagem com acoplamento MEC/MEF onde se utilizada para simulação de grupos de estacas isoladas, aliado à uma verificação com mais variáveis aleatórias. Portanto, as análises da ação da superestrutura com os elementos de fundação são efetuadas separadamente.

Vale destacar que em Santos et al. (2014) os valores dos coeficientes e segurança das normas brasileiras são confrontados com análise de confiabilidade estrutural para uma análise de vigas em flexão pura, de modo que os parâmetros probabilísticos das variáveis aleatórias foram adaptados para projetos realizado no Brasil.

Lopes (2007) desenvolve um estudo de confiabilidade com vigas de concreto armado reforçadas para esforço cortante com compósitos de fibras de carbono pelo método FORM, tendo como índice de confiabilidade referenciado ao Eurocode EN1990. São obtidos os valores no ponto de projeto e os coeficientes parciais de segurança.

Eraso et al. (2011) elaboram um estudo em de confiabilidade em longarinas de concreto armado, na qual são verificados os Estados Limites Último e de Serviço segundo a NBR6118. As verificações em confiabilidade são feitas com aplicação dos métodos FORM e MCS desenvolvidos no software MATLAB. São analisados também os coeficientes de sensibilidade das variáveis aleatórias.

Rahul et al. (2016) e Pustka et al. (2008) desenvolvem análises probabilísticas em Estado Limite Último (ELU) em pilares de concreto armado através da elaboração de amostragens. O primeiro desenvolve um edifício em EF, de modo a gerar as amostragens de acordo com os resultados dos esforços solicitantes resultantes de diversas simulações com variáveis estabelecidas através da aplicação do método de MCS, para em seguida realizar a análise dos pilares em outro programa com a amostragem referida. Pustka et al. (2008) por sua vez fazem um estudo de pilares 
esbeltos, com a análise totalmente probabilística, atribuindo uma função apropriada de estado limite e gera amostragens de esforços críticos.

Aoki (2014) em seu minicurso apresenta fundamentos para análise de risco em fundações através da apresentação geral do cenário da análise de risco, construção e interpretação das curvas reais de solicitação e resistência, cálculo da probabilidade de ruína (probabilidade de falha), equacionamento da relação entre o fator de segurança global e probabilidade de ruína, determinação do risco geotécnico, procedimentos de cálculo e finalmente a colocação das exigências para o procedimento de cálculo de risco de uma fundação. 


\section{CONFIABILIDADE ESTRUTURAL}

\subsection{Conceitos Gerais}

Considerando um problema estrutural real têm-se diversos parâmetros, dentre eles geometria das seções, características físicas dos materiais, carregamentos, etc. dos quais podem ser caracterizados por variáveis aleatórias conforme a Figura 1, de modo que cada variável possa ser representada por uma função densidade de probabilidades $f_{X i}\left(x_{i}\right)$ e seus respectivos parâmetros.

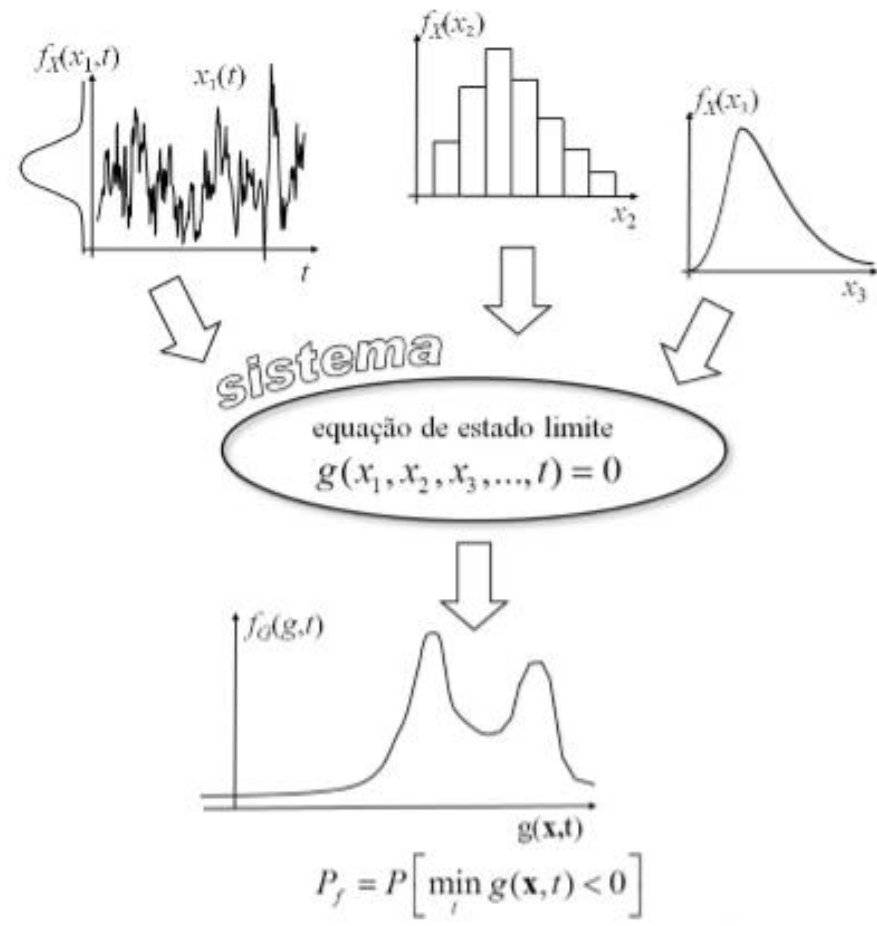

Figura 1 - Diagrama esquemático de um problema de confiabilidade estrutural (Fonte: Beck, 2015)

O vetor de variáveis aleatórias do problema é denominado por $\mathbf{X}$, a aplicação do modelo de cálculo utilizando um programa baseado no MEF, produzirá uma gama de respostas $s(\mathbf{x})$, uma vez que o vetor $\mathbf{x}$ trata-se das variáveis aleatórias em utilização, que podem ser deformações, tensões, deslocamentos, frequências naturais, esforços solicitantes ou quaisquer fenômenos cujos quais serão estudados, de acordo com um modo de falha estipulado (deslocamento excessivo, tensão limite, etc.), a função de estado limite é formulada em termos dos efeitos dos carregamentos no modelo e valores críticos (ou limites) $x_{\text {lim }}$ : 


$$
g\left(s(\mathbf{x}), x_{\text {lim }}\right)=0
$$

O valor limite de $x_{\text {lim }}$ pode ser aleatório ou determinístico, como um valor de tensão, ou valores limites normatizados, como deslocamentos controlados. Importante citar que a função dos efeitos do modelo $s(\mathbf{x})$ é explícita para os valores e estudo, mas contém implicitamente o vetor de variáveis $\mathbf{x}$, do qual é trabalhado pelo modelo numérico para a solução do problema.

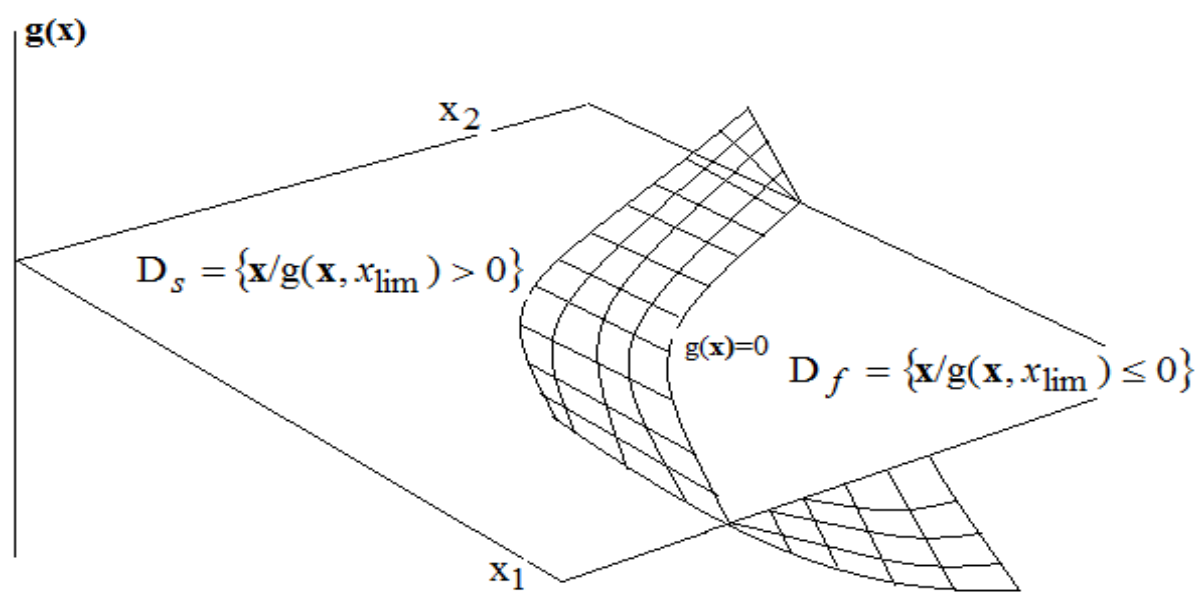

Figura 2 - Domínios da equação de estado limite (Beck, 2015, adaptado)

A função de estado limite é definida de tal maneira que é dividida em falha $D_{f}$ e de segurança $D_{s}$, expressa pela Equação 2:

$$
\begin{aligned}
& D_{f}=\left\{\mathbf{x} \mid g\left(\mathrm{x}, x_{\text {lim }}\right) \leq \mathbf{0}\right\} \\
& D_{s}=\left\{\mathbf{x} \mid g\left(\mathrm{x}, x_{\text {lim }}\right)>\mathbf{0}\right\}
\end{aligned}
$$

De maneira que a probabilidade de falha pode ser calculada da seguinte maneira:

$$
P_{f}=\int_{g\left(\mathrm{x}, x_{\lim }\right) \leq \mathbf{0}} f_{\boldsymbol{X}}(\mathbf{x}) d \mathrm{x}
$$

Onde $f_{\boldsymbol{X}}(\mathbf{x})$ é a função densidade de probabilidade conjunta das variáveis aleatórias, que geralmente é aproximada por funções de densidade de probabilidade. 
A integração da Equação 3 não é resolvida analiticamente, avaliada numericamente através da solução do modelo ou outro método qualquer, ou seja, para cada valor atribuído aos elementos de $\mathbf{x}$, obtém-se para a equação de estado limite resultados diferentes para o modelo, seja em deslocamentos, forças ou deformações. Seguindo esse processo iterativo, estipulam-se valores para $\mathbf{x}$, que são inseridos no modelo e ao final são utilizados os resultados para solução da Equação 3. Este processo, portanto, tem a facilidade da possibilidade de um algoritmo em que não seja necessário a alteração do código de EF, mas sim uma rotina externa que utiliza o programa para o uso dos resultados quantas vezes necessário.

Algumas das maneiras de solucionar a integração da Equação 3 é mediante os Método de Primeiro Momento e Segunda Ordem, do inglês, First Order Second Moment Method (FOSM) e Método de Monte Carlo Simples (MCS), de modo que o primeiro modo apresenta uma metodologia de resolução analítica e o segundo uma metodologia discreta.

Segundo Bjerager (1990), o método FOSM em geral é mais eficiente para pequenas probabilidades de falha e sua eficiência não depende da sua ordem de grandeza. O Método de Monte Carlo depende do número de simulações, de modo que quanto maior o número, maior a precisão e o resultado tende a convergir para um valor exato, porém sua eficiência depende da ordem de grandeza da probabilidade de falha, ou seja, quanto menor for a probabilidade de falha, maior o número de simulações necessárias.

Nos itens seguintes serão abordados ambos os métodos.

\subsection{Problema Fundamental da Confiabilidade Estrutural}

O principal problema da confiabilidade é a determinação da probabilidade de falha, de maneira a ser calculado pela Equação 3. De modo geral, tem-se uma parcela do estado limite referente a um valor limite ou resistente, e outra parcela a um valor solicitante ou resultante. Para um problema fundamental envolvendo duas variáveis aleatórias $R$ atribuído a um valor limite e $S$ a um valor solicitante, ambos com função densidade de probabilidade Normal, como apresentado na Figura 3. 


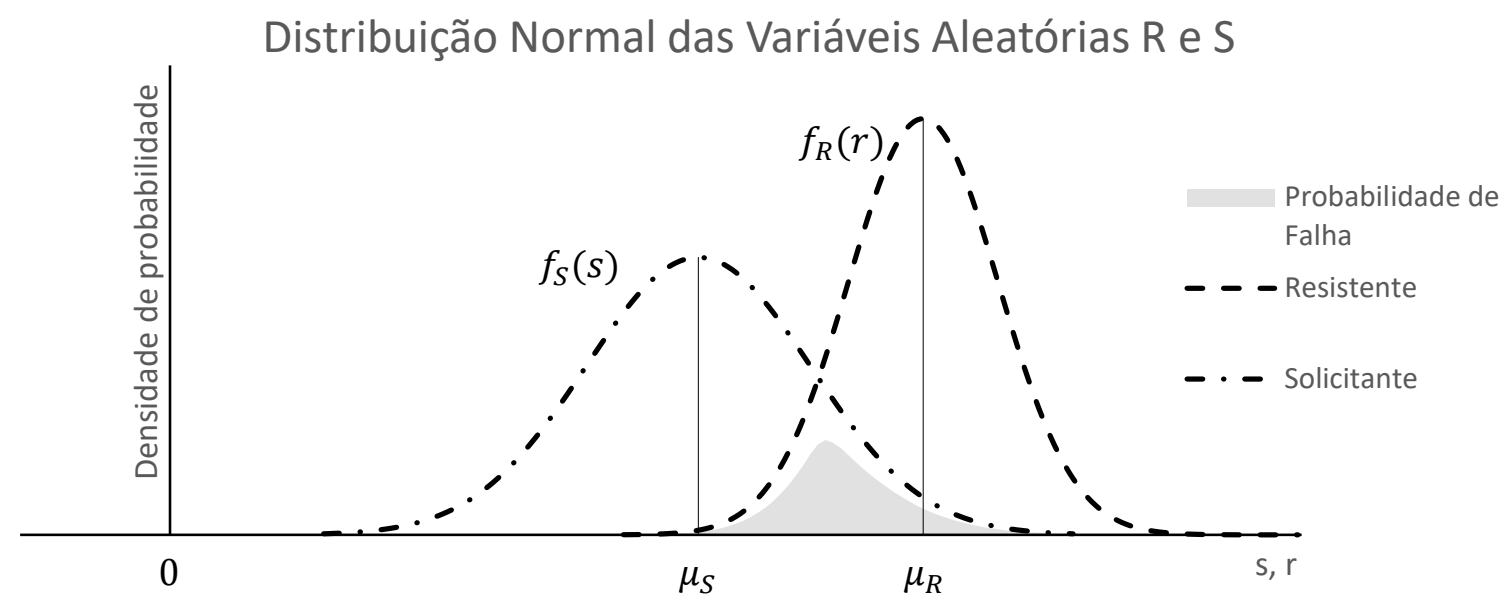

Figura 3 - Curvas de distribuição Normal para as variáveis aleatórias $\mathrm{R}$ e $\mathrm{S}$ (Fonte: Autor)

A configuração de cada curva é dada por dois parâmetros: a média e a variância. Mudando a média, é alterada a posição da distribuição, ver Figura 3. Mudando a variância, muda a dispersão da distribuição. A sobreposição das funções, dada por $M$, ver Figura 3, que representa a função de falha (função de estado limite) pode ser entendida como a probabilidade da carga máxima na estrutura, $S$, exceder a resistência da estrutura, $R$, durante a sua vida útil. A área hachurada do gráfico corresponde a probabilidade de falha $e$ pode ser calculada por $P_{f}=P[\{R \leq S\}]=\int_{-\infty}^{\infty} f_{S}(s)\left[\int_{-\infty}^{S} f_{R}(r) d r\right] d s$. Deste modo, pode-se considerar uma variável $M$ como margem de segurança, que será:

$$
M=R-\mathrm{S}
$$

Pode-se admitir que $M$ também será uma variável aleatória, então, é possível calcular a probabilidade de falha a partir de $M$, na qual corresponde a uma distribuição Normal com as respectivas média $\left(\mu_{M}\right)$ e desvio padrão $\left(\sigma_{M}\right)$ :

$$
\begin{gathered}
\mu_{M}=\mu_{\mathrm{R}}-\mu_{S} \\
\sigma_{M}=\sqrt{\sigma_{R}{ }^{2}+\sigma_{S}{ }^{2}}
\end{gathered}
$$

E sua curva pode ser caracterizada pela Figura 4: 


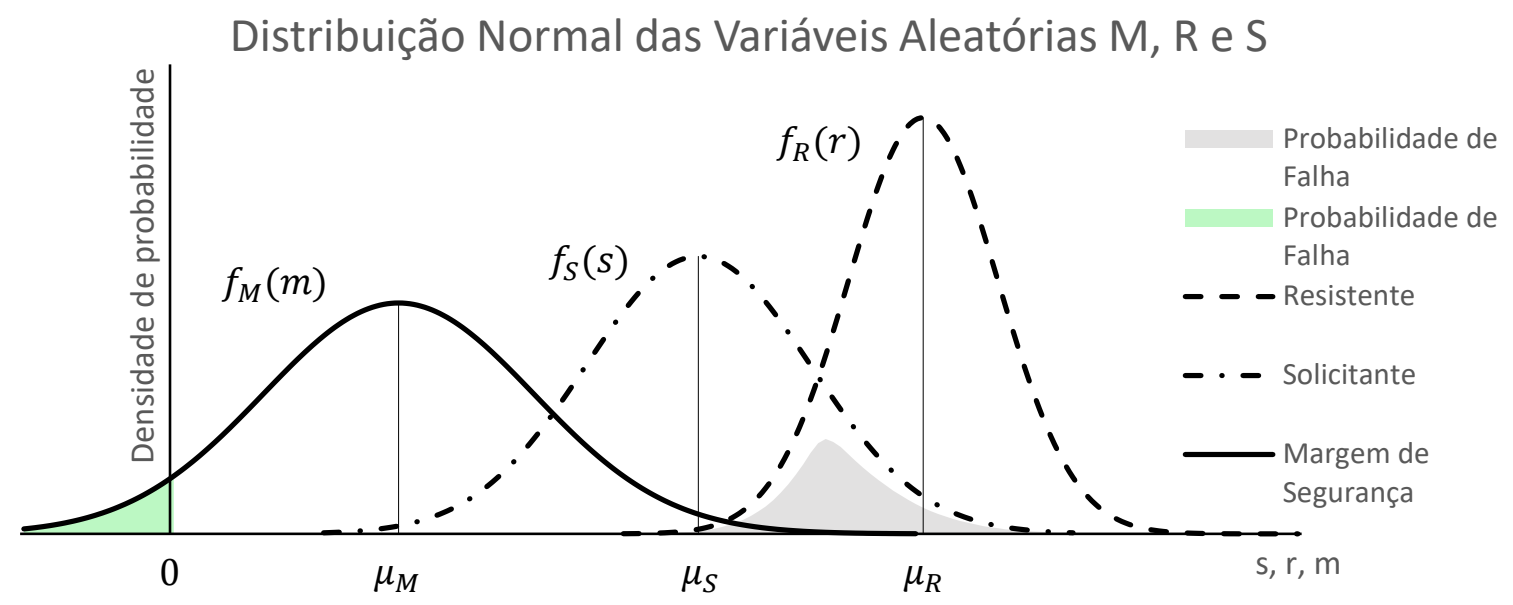

Figura 4 - Curva de distribuição Normal da Variável Aleatória M. (Fonte: Autor)

Nota-se que a região hachurada em verde corresponde a região de falha, ou seja, $S \geq R$ e consequentemente $M \leq 0$. A probabilidade de falha pode ser calculada pela equação:

$$
P_{f}=P[\{M \leq 0\}]=\int_{-\infty}^{0} f_{M}(r, s) d r d s
$$

A variável $M$ ainda pode ser transformada numa variável normal padrão no espaço $\mathbb{Y}$, com desvio padrão unitário e média nula, com a seguinte transformação:

$$
Y=\frac{M-\mu_{M}}{\sigma_{M}}
$$

Esta transformação permite avaliar as probabilidades associadas a $M$ através da função de distribuição cumulativa normal padrão que, em geral, é denominada $\phi()$, de maneira que probabilidade de falha resulta:

$$
P_{f}=P[\{M \leq 0\}]=P\left[\left\{M \leq-\frac{\mu_{M}}{\sigma_{M}}\right\}\right]=\phi\left(-\frac{\mu_{M}}{\sigma_{M}}\right)
$$

Deste modo, obtém-se o índice de confiabilidade $\beta$, no qual corresponde a distância entre o ponto de $M=0$ e a origem da distribuição normal padrão, que pode ser calculado usando a seguinte expressão: 


$$
\beta=\frac{\mu_{M}}{\sigma_{M}}=\frac{\mu_{R}-\mu_{S}}{\sqrt{\sigma_{R}^{2}+\sigma_{S}^{2}}}
$$

O índice de confiabilidade $\beta$ é igual ao número de desvios padrão para o valor da média da distribuição de $M$ ser menor ou igual a zero. Assim, é possível expressar a probabilidade de falha pela equação e sua representação geométrica está indicada na Figura 5, tendo em vista que a área hachurada corresponde a probabilidade de falha:

$$
P_{f}=\phi\left(-\frac{\mu_{M}}{\sigma_{M}}\right)=\phi(-\beta)
$$

\section{Distribuição Normal Padrão da Margem de}

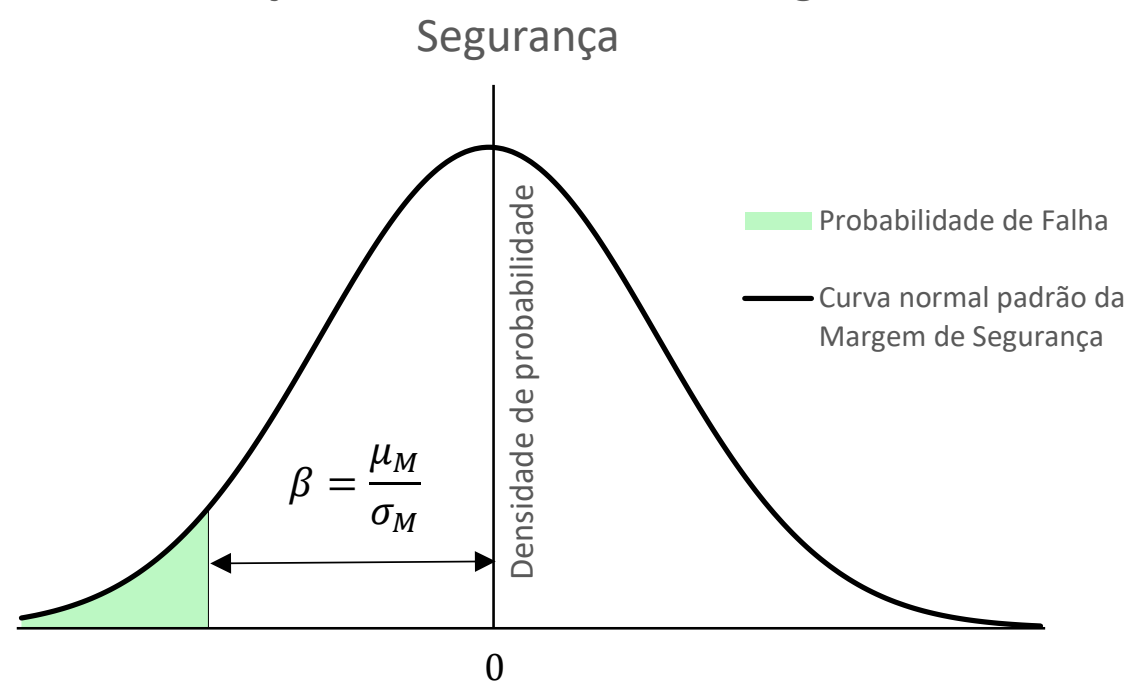

Figura 5 - Curva de distribuição Normal Padrão da Variável Aleatória M. (Fonte: Autor)

\subsection{First Order Second Moment (FOSM)}

De acordo com Beck (2015), resolver um problema de confiabilidade estrutural envolve a determinação da aproximação da função de densidade conjunta de probabilidade $f_{X i}\left(x_{i}\right)$, então o método denominado de FOSM (First Order Second Moment Method) é um método de transformação, que aproxima a função de estado limite para uma função linear, restringindo os valores estatísticos de média e desvio padrão para construir $f_{X i}\left(x_{i}\right)$. 


\subsubsection{Transformação de Hasofer Lind}

Os métodos de transformação, como o FOSM, baseiam-se na transformação de Hasofer e Lind, que transforma o vetor de variáveis Gaussianas $\boldsymbol{X}$, com as respectivas média e desvio padrão, num ponto $Y$ de variáveis aleatórias normais com média nula e desvio padrão:

$$
Y_{i}=\frac{X_{i}-\mu_{X_{i}}}{\sigma_{X_{i}}}
$$

A Figura 6 mostra a transformação de uma função de estado limite $g(\mathbf{y})=R-$ $S$, como uma função generalizada, assumindo $R=Y_{1}$ e $S=Y_{2}$.
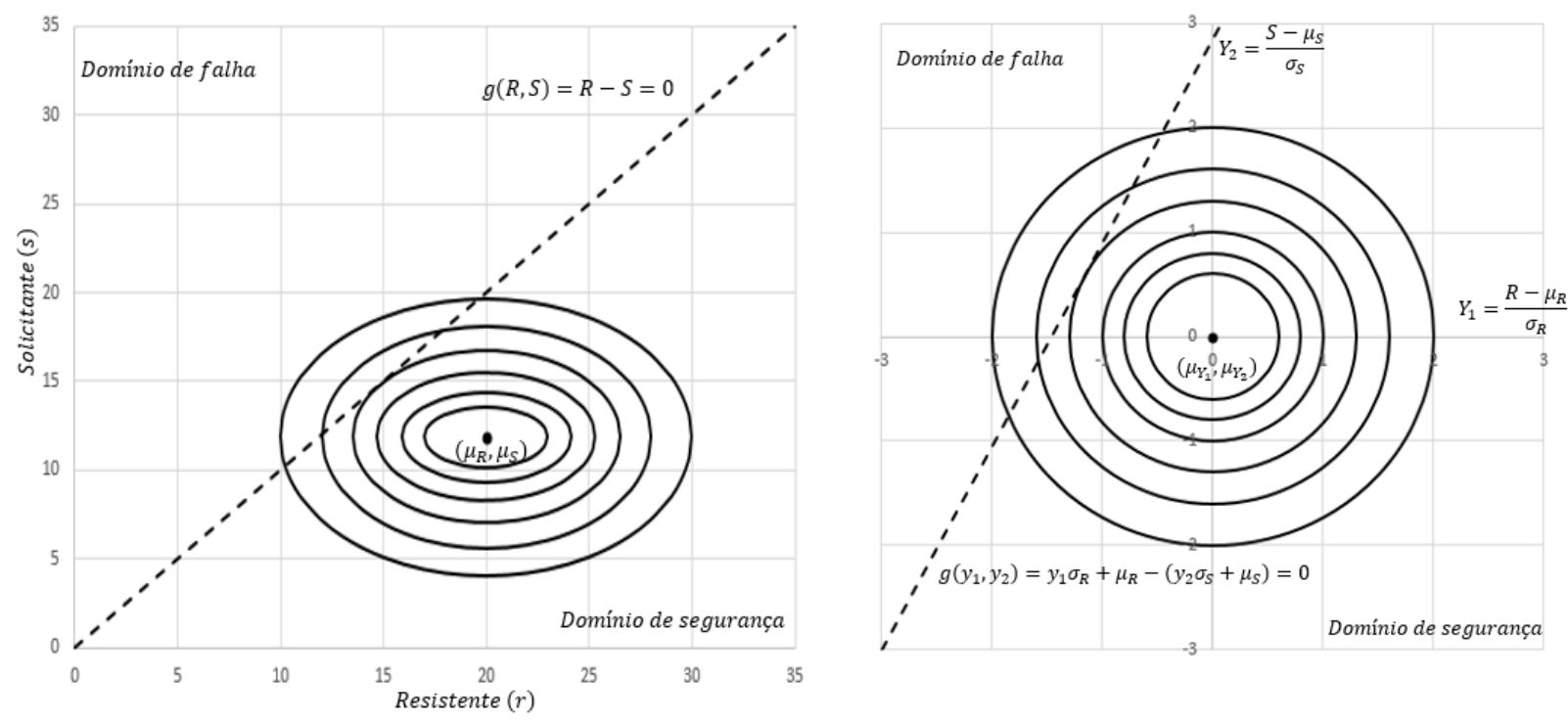

Figura 6 - Transformação de Hasofer Lind do espaço $\mathbb{X}$ para $\mathbb{Y}$ (Fonte: Autor)

\subsubsection{Ponto de projeto e índice de confiabilidade para problemas n- dimensionais}

O índice de confiabilidade $\beta$ pode ser obtido aplicando-se a transformação de Hasofer Lind (Equação 12) no problema principal (Equação 3) e resolvendo o 
problema de otimização encontrando o ponto de projeto $\mathbf{y}^{*}$ que minimiza $d=\|\mathbf{y}\|$ e zera a função de estado-limite $g(\mathbf{y})$. Onde $d$ é a distância entre o ponto y a qualquer origem, portanto, trata-se de um problema de minimização com restrições, então $\beta$ é a distância mínima:

$$
d=\|\boldsymbol{y}\|=\sqrt{\boldsymbol{y} *^{T} \bullet \boldsymbol{y} *}
$$

E o vetor gradiente da equação de estado limite é dado por:

$$
\nabla g(\boldsymbol{y})=\left\{\frac{\partial g}{\partial y_{1}}, \frac{\partial g}{\partial y_{2}}, \ldots, \frac{\partial g}{\partial y_{n}}\right\}^{T}
$$

Os cossenos diretores de quaisquer pontos na função de estado limite podem ser obtidos:

$$
\alpha(\boldsymbol{y})=\frac{\nabla g(\boldsymbol{y})}{\|\nabla g(\boldsymbol{y})\|}
$$

Finalmente, o ponto de projeto $\mathbf{y}^{*}$ é o ponto da função de estado limite mais próximo à origem do espaço $\mathbb{Y}$, portanto nesse ponto a função de estado limite é projetada como segue:

$$
\boldsymbol{y}^{*}=-\alpha \beta
$$

Onde $\beta=\left\|\mathbf{y}^{*}\right\|$ é a distância entre $\mathbf{y}^{*}$ e a origem do espaço $\mathbb{Y}$.

É entendido, portanto, que o ponto de projeto é o ponto da função de estado limite $g(\mathbf{y})$ onde ocorre a maior probabilidade de falha possível, de maneira que $g\left(\mathbf{y}^{*}\right)=0$.

\subsubsection{Método Lagrangiano para Problemas de Otimização com Restrições}

A otimização pode ser feita através do método de Lagrange, aplicando-se o multiplicador de Lagrange $\lambda$, segue a langrangiana do problema: 


$$
\mathcal{L}(\mathrm{y}, \lambda)=\sqrt{\boldsymbol{y}^{T} \cdot \boldsymbol{y}}+\lambda g(\boldsymbol{y})
$$

Um ponto estacionário pode ser obtido para a Equação 17:

$$
\begin{gathered}
\frac{\partial \mathcal{L}}{\partial y}=\mathbf{y} d^{-1}+\lambda \nabla g(\mathbf{y})=0 \\
\frac{\partial \mathcal{L}}{\partial \lambda}=g(\mathbf{y})=0
\end{gathered}
$$

A Equação 18 é satisfeita se y estiver na equação de estado limite, e determina as coordenadas do ponto estacionário, e assumindo que este e o ponto de projeto, isto é, um ponto de mínimo, então se tem:

$$
d_{\text {min }}=-\frac{\nabla g(\boldsymbol{y})}{\|\nabla g(\boldsymbol{y})\|} \cdot \mathbf{y}^{*}=-\boldsymbol{\alpha}^{T} \cdot \mathbf{y}^{*}
$$

\subsubsection{Linearização da Equação de Estado Limite}

Uma expansão da equação de estado limite num ponto qualquer $y^{p}$, em série de Taylor até termos lineares:

$$
\tilde{g}(\mathbf{y}) \cong g\left(\mathbf{y}^{\boldsymbol{p}}\right)+\nabla g^{p} \cdot\left(\mathbf{y}-\mathbf{y}^{\boldsymbol{p}}\right) \cong 0
$$

Para o valor esperado:

$$
E[\tilde{g}(\mathbf{y})] \cong g\left(\mathbf{y}^{\boldsymbol{p}}\right)-\nabla g^{T} \cdot \mathbf{y}^{\boldsymbol{p}}
$$

E a variância:

$$
\operatorname{Var}[\tilde{g}(\mathbf{y})] \cong \nabla g^{T} \cdot \nabla g
$$

Pela definição de $\beta$, com a Equação 22 e a Equação 23: 


$$
\beta \cong \frac{E[\tilde{g}(\mathbf{y})]}{\sqrt{\operatorname{Var}[\tilde{g}(\mathbf{y})]}} \cong-\boldsymbol{\alpha}^{T} \cdot \mathbf{y}^{p}
$$

Portanto, se $\mathbf{y}^{\mathbf{p}}=\mathbf{y}^{*}$ a Equação 24 é igual a Equação 20, provando que a distância entre o ponto de projeto e a origem do espaço representa o índice de confiabilidade.

\subsubsection{O algoritmo Hasofer, Lind, Rackwitz and Fiessler (HLRF)}

O algoritmo HLRF foi desenvolvido especificamente para a solução de problemas de confiabilidade estrutural. Seja $\mathbf{y}_{k}$ qualquer ponto fora da superfície de falha, mas candidato a ponto de projeto, uma expansão de Taylor de $g\left(\mathbf{y}_{k+1}\right)$ para termos lineares é dada por:

$$
\tilde{g}\left(\mathbf{y}_{k+1}\right) \cong g\left(\mathbf{y}_{k}\right)+\nabla g\left(\mathbf{y}_{k}\right)^{T} \cdot\left(\mathbf{y}_{k+1}-\mathbf{y}_{k}\right) \cong 0
$$

Um novo ponto é obtido, em que $\tilde{g}\left(\boldsymbol{y}_{k+1}\right)=0$. Assumindo que $\beta_{k}=\sqrt{\boldsymbol{y}_{k}^{T} \cdot \boldsymbol{y}_{k}}$ em conjunto com a equação 16 aplicando na Equação 25 resulta:

$$
\nabla g\left(\mathbf{y}_{k}\right)^{T} \cdot \mathbf{y}_{k+1} \cong-\nabla g\left(\mathbf{y}_{k}\right)^{T} \cdot\left(\boldsymbol{\alpha}_{k} \beta_{k}\right)-g\left(\mathbf{y}_{k}\right)
$$

Enquanto que o cosseno diretor de comprimento unitário pode ser inserido na Equação 26 sem alterações:

$$
\boldsymbol{\alpha}_{k}^{T} \cdot \boldsymbol{\alpha}_{k}=\frac{\nabla g\left(\mathbf{y}_{k}\right)^{T} \cdot\left(\boldsymbol{\alpha}_{k}\right)}{\left\|\nabla g\left(\mathbf{y}_{k}\right)\right\|}=1
$$

Portanto, aplicando na Equação 26, tem-se:

$$
\nabla g\left(\mathbf{y}_{k}\right)^{T} \cdot \mathbf{y}_{k+1}=-\nabla g\left(\mathbf{y}_{k}\right)^{T} \cdot\left(\boldsymbol{\alpha}_{k} \beta_{k}\right)-\frac{\nabla g\left(\mathbf{y}_{k}\right)^{T} \cdot\left(\boldsymbol{\alpha}_{k}\right)}{\left\|\nabla g\left(\mathbf{y}_{k}\right)\right\|} g\left(\mathbf{y}_{k}\right)
$$

Rearranjando a Equação 28, chega-se a: 


$$
\mathbf{y}_{k+1}=-\boldsymbol{\alpha}_{k}\left[\beta_{k}+\frac{g\left(\mathbf{y}_{k}\right)}{\left\|\nabla g\left(\mathbf{y}_{k}\right)\right\|}\right]
$$

A Figura 7 ilustra a interpretação geométrica do processo iterativo:

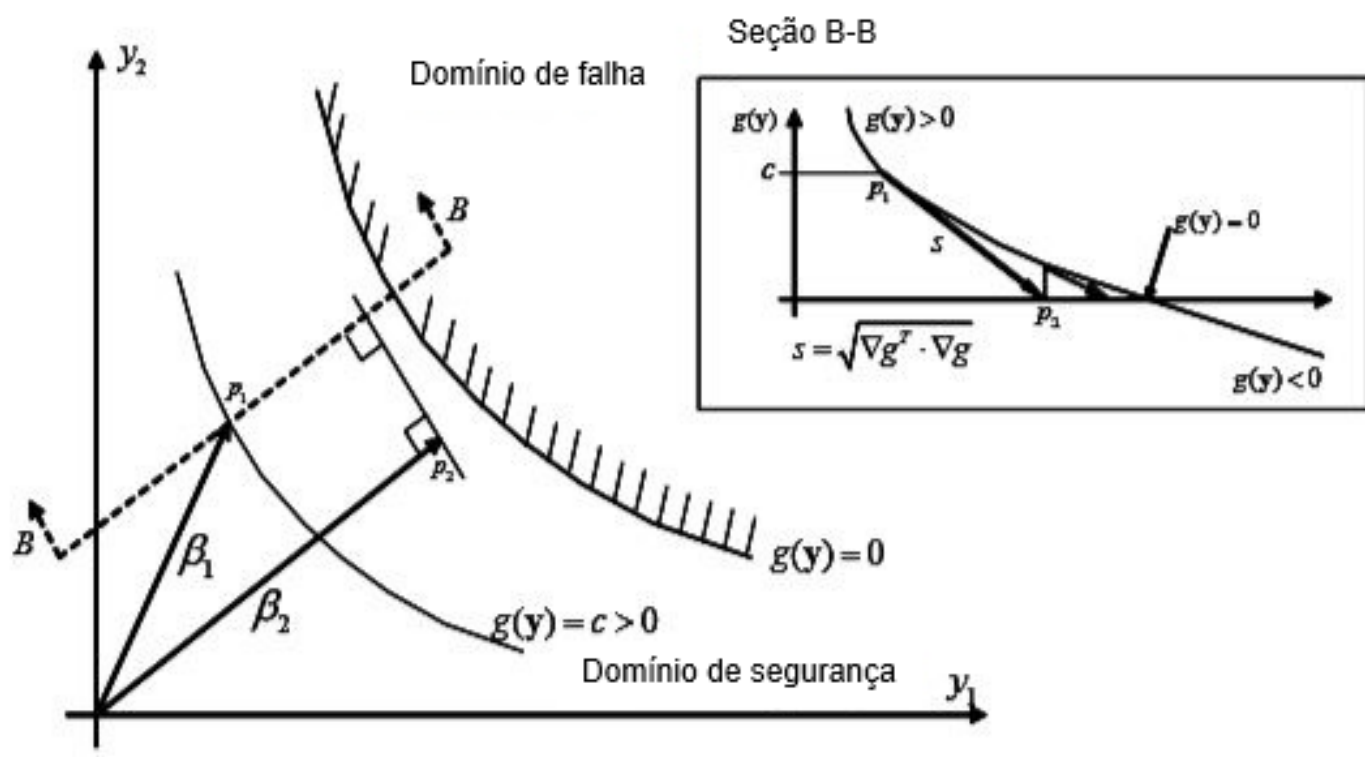

Figura 7 -Interpretação geométrica do algoritmo iterativo HLFR (Beck, 2015, adaptado)

Outra função pode ser determinada através da Equação 26:

$$
\begin{aligned}
\nabla g\left(\mathbf{y}_{k}\right)^{T} \cdot \mathbf{y}_{k+1}= & {\left[\nabla g\left(\mathbf{y}_{k}\right)^{T} \cdot \mathbf{y}_{k}-g\left(\mathbf{y}_{k}\right)\right]-\frac{\nabla g\left(\mathbf{y}_{k}\right)^{T} \cdot \boldsymbol{\alpha}_{k}}{\left\|\nabla g\left(\mathbf{y}_{k}\right)\right\|} } \\
& =\frac{\nabla g\left(\mathbf{y}_{k}\right)^{T} \cdot \mathbf{y}_{k}-g\left(\mathbf{y}_{k}\right)}{\left\|\nabla g\left(\mathbf{y}_{k}\right)\right\|^{2}} \cdot \nabla g\left(\mathbf{y}_{k}\right)^{T} \cdot \nabla g\left(\mathbf{y}_{k}\right)
\end{aligned}
$$

Finalmente, reescrevendo a equação 30:

$$
\mathbf{y}_{k+1}=\frac{\nabla g\left(\mathbf{y}_{k}\right)^{T} \cdot \mathbf{y}_{k}-g\left(\mathbf{y}_{k}\right)}{\left\|\nabla g\left(\mathbf{y}_{k}\right)\right\|^{2}} \cdot \nabla g\left(\mathbf{y}_{k}\right)
$$

A convergência pode ser satisfeita se: 


$$
\left\{1-\left|\frac{\nabla g\left(\mathbf{y}_{k+1}\right) \cdot \mathbf{y}_{k+1}}{|| \nabla g\left(\mathbf{y}_{k+1}\right)\|\cdot\| \mathbf{y}_{k+1} \|}\right|<\varepsilon\right.
$$

De modo que $\epsilon$ e $\delta$ representam valores de tolerância ou residuais, cujos quais devem ser próximos à zero, como valores de $10^{-3}$ ou $10^{-6}$ por exemplo.

\subsubsection{Sensibilidade e Relevância das Variáveis Aleatórias}

Derivando-se a aproximação de primeira ordem da probabilidade de falha (Equação 11), em relação às variáveis aleatórias no espaço normal padrão, é possível obter fatores relativos a contribuição de cada variável aleatória na composição do valor de $P_{f}$ :

$$
\left.\frac{\partial P_{f}}{\partial \mathbf{y}}\right|_{\mathbf{y}=\mathbf{y}^{*}}=\left.\frac{\partial \phi(-\beta)}{\partial \beta} \frac{\partial \beta}{\partial \mathbf{y}}\right|_{\mathbf{y}=\mathbf{y}^{*}}=-\left.\phi(-\beta) \frac{\partial \beta}{\partial \mathbf{y}}\right|_{\mathbf{y}=\mathbf{y}^{*}}
$$

Com as Equações 16 e 15 tem-se:

$$
\left.\frac{\partial \beta}{\partial \mathbf{y}}\right|_{\mathbf{y}=\mathbf{y}^{*}}=-\alpha\left(\mathbf{y}^{*}\right)=-\frac{\nabla g\left(\mathbf{y}^{*}\right)}{\left\|\nabla g\left(\mathbf{y}^{*}\right)\right\|}
$$

Combinando as equações 33 e 34 :

$$
\left.\frac{\partial P_{f}}{\partial \mathbf{y}}\right|_{\mathbf{y}=\mathbf{y}^{*}}=\phi(-\beta) \alpha\left(\mathbf{y}^{*}\right)
$$

Nota-se que na Equação 35 o termo $\phi(-\beta)$ é constante e o vetor $\alpha$ é unitário, então, como $\sum \alpha_{i}{ }^{2}=1$ entende-se que os valores de $\alpha_{i}{ }^{2}$ são fatores cujos quais indicam uma contribuição relativa Da variável aleatória $Y_{i}$ e, consequentemente, $X_{i}$ para a probabilidade de falha. Portanto assume-se que quanto menor o valor de $\alpha_{i}^{2}$, menor é a contribuição da variável aleatória $X_{i}$ para a probabilidade de falha da 
estrutura, de modo que eventualmente possa ser substituída por uma variável determinística.

\subsubsection{Transformação Hasofer-Lind matricial}

Para se trabalhar com múltiplas variáveis, é necessário efetuar diversas transformações $\mathbb{X} \rightarrow \mathbb{Y}$ e $\mathbb{Y} \rightarrow \mathbb{X}$, então se torna conveniente à introdução de variáveis matriciais. Primeiramente, introduzindo o vetor de médias $\mathbf{M}$ e a matriz diagonal de desvios padrão D:

$$
\begin{gathered}
M=\left\{\mu_{x_{1}}, \mu_{x_{2}}, \ldots, \mu_{x_{n}}\right\} \\
D=\left[\begin{array}{cccc}
\sigma_{X_{1}} & 0 & \ldots & 0 \\
0 & \sigma_{X_{2}} & \ldots & 0 \\
\ldots & \ldots & \ldots & \ldots \\
0 & 0 & \ldots & \sigma_{X_{n}}
\end{array}\right] \Rightarrow D^{-1}=\left[\begin{array}{cccc}
\frac{1}{\sigma_{X_{1}}} & 0 & \ldots & 0 \\
0 & \frac{1}{\sigma_{X 2}} & \ldots & 0 \\
\ldots & \ldots & \ldots & \ldots \\
0 & 0 & \ldots & \frac{1}{\sigma_{X_{n}}}
\end{array}\right]
\end{gathered}
$$

Então, a transformação de Hasofer-Lind em forma matricial é dada por:

$$
\begin{aligned}
& \boldsymbol{x}=J_{x y} \cdot \boldsymbol{y}+M, \quad \mathrm{~J}_{x y}=\left[\frac{\partial x_{i}}{\partial y_{j}}\right]_{i=1,2, \ldots, n ; j=1,2, . ., n}=D \\
& \boldsymbol{y}=J_{y x} \cdot\{\boldsymbol{x}-M\}, \quad \mathrm{J}_{y x}=\left[\frac{\partial y_{i}}{\partial x_{j}}\right]_{i=1,2, \ldots, n ; j=1,2, ., n}=D^{-1}
\end{aligned}
$$

Fazendo-se o vetor gradiente da função de estado limite no espaço $\mathbb{Y}$ :

$$
\nabla g(\boldsymbol{y})=\left\{\sum_{j=1}^{n} \frac{\partial g}{\partial x_{i}} \frac{\partial x_{i}}{\partial y_{j}}\right\}_{j=1,2, \ldots, n}=\left(J_{x y}\right)^{-1} \cdot \nabla g(\boldsymbol{x})
$$




\subsubsection{Método das Diferenças Finitas (DF) Aplicado em Problemas de Confiabilidade Estrutural}

Como mencionado anteriormente, uma vez que a função de estado limite tem resultados implícitos obtidos pelo MEF, a diferenciação direta de g(x) não é possível, impossibilitando o cálculo do vetor gradiente $\nabla g(\mathbf{x})$, de acordo com a Equação 39 . Para resolver esse problema, o método das diferenças finitas pode ser um meio para executar uma diferenciação aproximada da função de estado limite através do método da diferença progressiva, aplicando uma pequena diferença $\Delta x$ para cada variável aleatória, com a seguinte aproximação:

$$
\frac{\partial g}{\partial x_{i}} \approx \frac{g\left(\boldsymbol{x}+\Delta x_{i}\right)-g(\boldsymbol{x})}{\Delta x_{i}}
$$

Entende-se então que para cada diferenciação da função de estado limite pelo valor correspondente do vetor $\mathbf{X}$ na i-ésima posição, é somado um valor $\Delta x$ na posição i para o cálculo de $\mathrm{g}\left(\mathbf{x}+\Delta x_{i}\right)$.

Segundo Beck (2003), é conveniente adotar $\Delta x$ como uma porcentagem do desvio padrão representada pelo fator $p$ :

$$
\Delta x_{i}=p \sigma_{x_{i}}
$$

Portanto, para cada valor de aproximação do vetor gradiente da função de estado limite no espaço $\mathbb{X}$, é necessário efetuar o cálculo com o auxílio do programa MEF. 


\subsubsection{Exemplo de Aplicação do Método FOSM}

O exemplo abordado neste item é apresentado por Du (2005), cujo qual a função objetivo é na verificação do deslocamento na extremidade de uma viga em balanço:

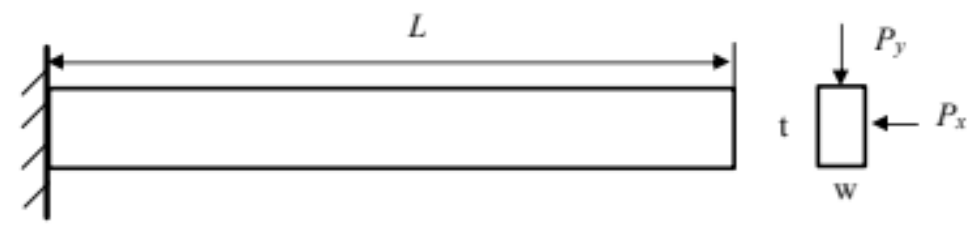

Figura 8 - Modelo do exemplo proposto. (Fonte: Du, 2005)

De modo que a equação de estado limite seja:

$$
g(\mathbf{x})=D_{0}-\frac{4 L^{3}}{E w t} \sqrt{\left(\frac{P_{y}}{t^{2}}\right)^{2}+\left(\frac{P_{x}}{w^{2}}\right)^{2}}
$$

Para este exemplo, são determinadas as variáveis aleatórias e determinísticas de acordo com a Tabela 2 e Tabela 3 respectivamente:

Tabela 2 - Variáveis Aleatórias

\begin{tabular}{ccccc}
\hline Variável & Símbolo & $\mu_{X_{i}}$ & $\sigma_{X_{i}}$ & Unidade \\
\hline Carga aplicada em x & $P_{x}$ & 500 & 100 & $\mathrm{l} b$ \\
Carga aplicada em y & $P_{y}$ & 1000 & 100 & $\mathrm{l} b$ \\
\hline
\end{tabular}

Tabela 3 - Variáveis Determinísticas

\begin{tabular}{cccc}
\hline Variável & Símbolo & Valor & Unidade \\
\hline $\begin{array}{c}\text { Deslocamento limite } \\
\text { Módulo de }\end{array}$ & $D_{0}$ & 3 & pol. \\
Elasticidade & $\mathrm{E}$ & $30 \times 10^{6}$ & $\mathrm{psi}$ \\
Comprimento & $\mathrm{L}$ & 100 & $\mathrm{pol}$. \\
Largura da seção & $\mathrm{w}$ & 2 & pol. \\
Altura da seção & $\mathrm{t}$ & 4 & pol. \\
\hline
\end{tabular}


Neste caso, o método é aplicado na referência pela diferenciação direta da equação de estado limite, de modo que é obtido o valor da probabilidade de falha após 3 iterações. Segue o histórico de valores obtidos na Tabela 4:

Tabela 4 - Resultados obtidos para o ponto de projeto, segundo Du (2005)

\begin{tabular}{ccccc}
\hline Iteração & $\beta$ & $\mathrm{g}$ & $\nabla g$ & $\left(P_{x_{Y}}, P_{y_{Y}}\right)$ \\
\hline 0 & 0 & 0,67076 & $(-0,37268-0,046585)$ & $(1,77220,22152)$ \\
1 & 1,7859 & $-0,015931$ & $(-0,38984-0,036775)$ & $(1,73750,16391)$ \\
2 & 1,7453 & $-0,00032102$ & $(-0,38986-0,036758)$ & $(1,73670,16375)$ \\
3 & 1,7444 & $-2,60 \times 10^{-9}$ & $(-0,38986-0,036761)$ & $(1,73670,16376)$ \\
\hline
\end{tabular}

Com o valor de $\beta$ obtido, tem-se uma probabilidade de falha equivalente a $P_{f}=$ $4,05 \times 10^{-2}$.

Na rotina desenvolvida neste trabalho, a diferenciação da equação de estado limite é feita pelo método das diferenças finitas, e foram obtidos os resultados para a procura do ponto de projeto na Tabela 5:

Tabela 5 - Resultados obtidos para o ponto de projeto, de acordo com o presente modelo

\begin{tabular}{|c|c|c|c|}
\hline Iteração & $\beta$ & g & $\left(P_{x_{Y}}, P_{y_{Y}}\right)$ \\
\hline 1 & 1,7856 & $-0,0158$ & $(1,77180,2215)$ \\
\hline 2 & 1,7453 & $-0,0003$ & $(1,73750,1640)$ \\
\hline 3 & 1,7444 & $-2,0 \times 10^{-9}$ & $\left(\begin{array}{lll}1,7367 & 0,1638\end{array}\right)$ \\
\hline
\end{tabular}

Deste modo, como o valor de $\beta$ e os valores das variáveis aleatórias no domínio $\mathbb{Y}$ são iguais ao valor obtido em Du (2005), então tem-se uma probabilidade de falha equivalente a $P_{f}=4,05 \times 10^{-2}$.

Portanto pode-se verificar a eficácia da rotina elaborada em conjunto com método das Diferenças Finitas introduzido.

\subsection{Método de Monte Carlo Simples}

Um método de simples aplicação e mais preciso quanto maior a incerteza do problema, o método visa sumariamente em adotar valores aleatórios das variáveis do 
problema, a partir das respectivas funções de densidade de probabilidade, e com esses valores resolver as equações de estado limite quantas vezes for necessário. Como será utilizado uma rotina externa de EF, os valores das variáveis aleatórias são inseridos no programa de análise estrutural, de modo que os resultados são empregados nas equações de estado limite.

O cálculo do $P_{f}$ é feito com as variáveis que são geradas de acordo com a função conjunta de densidade de probabilidade $f_{X}(\mathbf{x})$ e em conjunto com uma função indicadora $I[g(\mathbf{x})]$ de tal maneira que:

$$
P_{f}=\int_{D_{f}} I[g(\mathbf{x})] f_{X}(\mathbf{x}) d \mathbf{x}
$$

Uma vez que, para os valores obtidos de $g(\mathbf{x})$ :

$$
\begin{aligned}
& I\left[g\left(\mathbf{x}_{i}\right)\right]=1 \text { se } g\left(\mathbf{x}_{i}\right) \leq 0 \\
& I\left[g\left(\mathbf{x}_{i}\right)\right]=0 \text { se } g\left(\mathbf{x}_{i}\right)>0
\end{aligned}
$$

Portanto, a probabilidade de falha é aproximada de acordo com o número de simulações e as equações 43 e 44 :

$$
P_{f} \approx \overline{P_{f}}=\frac{\sum_{i=1}^{n_{S}} I\left[g\left(\mathbf{x}_{i}\right)\right]}{n_{S}}
$$

E a respectiva variância que pode ser determinada por:

$$
\operatorname{Var}\left[\overline{P_{f}}\right]=\frac{\sum_{i=1}^{n_{S}}\left(I\left[g\left(\mathbf{x}_{i}\right)\right]-\overline{P_{f}}\right)^{2}}{\left(n_{s}-1\right)}
$$

A variância corresponde a incerteza ou erro estatístico da simulação, de modo que quando $n_{s} \rightarrow \infty$, a variância tende a zero. Há também a dependência da ordem de grandeza da $P_{f}$, ou seja, para uma menor probabilidade de falha faz-se necessário um maior número de simulações $n_{s}$.

Como para as estruturas é interessante que a probabilidade de falha seja baixa, há necessidade de um número grande de simulações para que possa ser obtido uma 
variância pequena. Como é apresentado por Bjerager (1990), uma boa estimativa para o número de simulações $n_{s}$, cujo qual depende da ordem de grandeza da probabilidade de falha $P_{f}$, com um número de simulações para ter resultados mais confiáveis por volta de $100 / P_{f}$.

É possível ainda determinar o intervalo de confiança da probabilidade de falha obtida, na qual depende do nível de confiança do intervalo. Segundo Sigman (2007), é comum estimar-se um intervalo de confiança de $95 \%$, de modo que o intervalo pode ser obtido com a equação 47:

$$
\overline{P_{f}}-1,96 \frac{\sigma_{\overline{P_{f}}}}{\sqrt{n_{s}}}<P_{f}<\overline{P_{f}}+1,96 \frac{\sigma_{\overline{P_{f}}}}{\sqrt{n_{s}}}
$$

Com $\sigma_{\overline{P_{f}}}=\sqrt{\operatorname{Var}\left[\overline{P_{f}}\right]}$, correspondente ao desvio padrão da probabilidade de falha.

\subsubsection{Geração de amostras de Variáveis Aleatórias}

Como se apresentou anteriormente, o método baseia-se num número de simulações, que para problemas de confiabilidade estrutural, resultam em valores de probabilidade de falha da ordem de $10^{-3}$ a $10^{-6}$. E então se concluiu que é necessário um número elevado de simulações, e para cada simulação é necessário gerar os valores das variáveis aleatórias de acordo com o tipo de função de densidade de probabilidade de falha e os parâmetros probabilísticos como média e desvio padrão, de maneira aleatória. Esses valores podem ser obtidos da seguinte maneira:

- Gerar um número aleatório entre 0 e 1. Há métodos para a geração de uma amostragem aleatória não viciada como algoritmo gerador linear congruencial, do qual pode ser visto com mais detalhes em Beck (2015). Existem também funções para valores aleatórios em linguagens de programação, neste trabalho, utilizou-se do da própria função do MATLAB para gerar esses valores de maneira aleatória.

- Através da equação cumulativa inversa de probabilidades, com o valor obtido no passo anterior, extrai-se o valor requerido para a variável aleatória. 
Por mais que o procedimento se aparenta simples, há uma certa complexidade para obter-se valores numéricos para a função cumulativa inversa de probabilidades. Neste trabalho, foi utilizado uma aproximação proposta por Beck (2015) para a equação cumulativa inversa de probabilidades para uma distribuição normal padrão, cujos parâmetros são média 0 e desvio padrão unitário, e à posteriori transforma-se para a distribuição da variável aleatória. Aqui serão abordadas distribuições do tipo Normal e Lognormal.

De acordo com Beck (2015), uma aproximação numérica eficiente para obtenção da função cumulativa inversa $y_{i}=\phi^{-1}\left[u_{i}\right]$, atribuído o fato de que o número aleatório $u$ varia entre 0 e 1 , tem-se os intervalos abaixo.

Para $0 \leq u_{i} \leq 0,5$ :

$$
\begin{gathered}
z_{i}=\sqrt{\ln \left(\frac{1}{u_{i}^{2}}\right)} \\
y_{i}=-z_{i}-\frac{p_{1}+z_{i}\left(p_{2}+z_{i}\left(p_{3}+z_{i}\left(p_{4}+z_{i}\left(p_{5}\right)\right)\right)\right)}{q_{1}+z_{i}\left(q_{2}+z_{i}\left(q_{3}+z_{i}\left(q_{4}+z_{i}\left(q_{5}\right)\right)\right)\right)}
\end{gathered}
$$

Para $0,5 \leq u_{i} \leq 1.0$ :

$$
\begin{gathered}
z_{i}=\sqrt{\ln \left(\frac{1}{\left(1-u_{i}\right)^{2}}\right)} \\
y_{i}=z_{i}+\frac{p_{1}+z_{i}\left(p_{2}+z_{i}\left(p_{3}+z_{i}\left(p_{4}+z_{i}\left(p_{5}\right)\right)\right)\right)}{q_{1}+z_{i}\left(q_{2}+z_{i}\left(q_{3}+z_{i}\left(q_{4}+z_{i}\left(q_{5}\right)\right)\right)\right)}
\end{gathered}
$$

Para os valores de $p_{n}$ e $q_{n}$ de acordo com os respectivos índices dos vetores:

$$
\mathbf{p}=\left[\begin{array}{c}
-0,3222324310880 \\
-1,0000000000000 \\
-0,3422422088547 \\
-0,2042312102450 \times 10^{-1} \\
-0,4536422101480 \times 10^{-4}
\end{array}\right] \quad \mathbf{q}=\left[\begin{array}{c}
0,9934846260600 \times 10^{-1} \\
0,5885815704950 \\
0,5311034623660 \\
0,1035377528500 \\
0,3856070063400 \times 10^{-2}
\end{array}\right]
$$




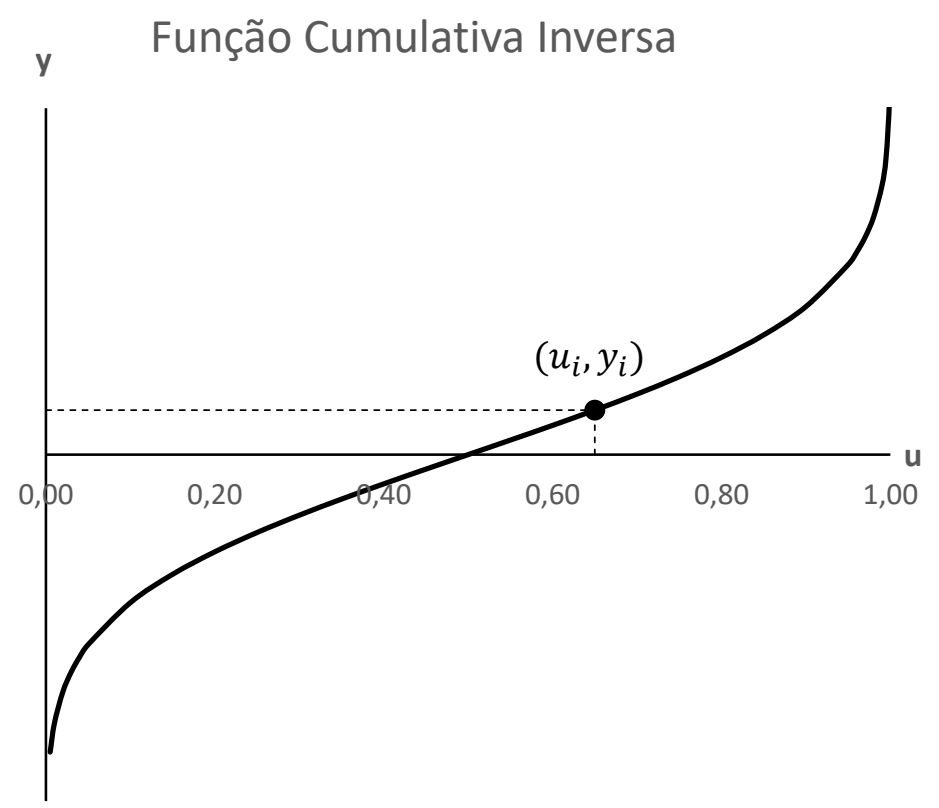

Figura 9 - Função cumulativa inversa de probabilidade proposta por Beck (2015) com valores y e u para a i-ésima variável aleatoria. (Fonte: Autor)

Assim, é obtido o valor da variável correspondente a uma distribuição normal padrão. Então, através a transformação de Hasofer-Lind (Equação 12) é possível calcular a variável aleatória no espaço $\mathbb{X}$ desejado:

$$
x_{i}=y_{i} \sigma_{X_{i}}+\mu_{X_{i}}
$$

De modo a obter-se o valor da variável aleatória de acordo com a curva esperada, apresentada na Figura 10: 
Distribuição Normal Padrão e Normal da V.A.

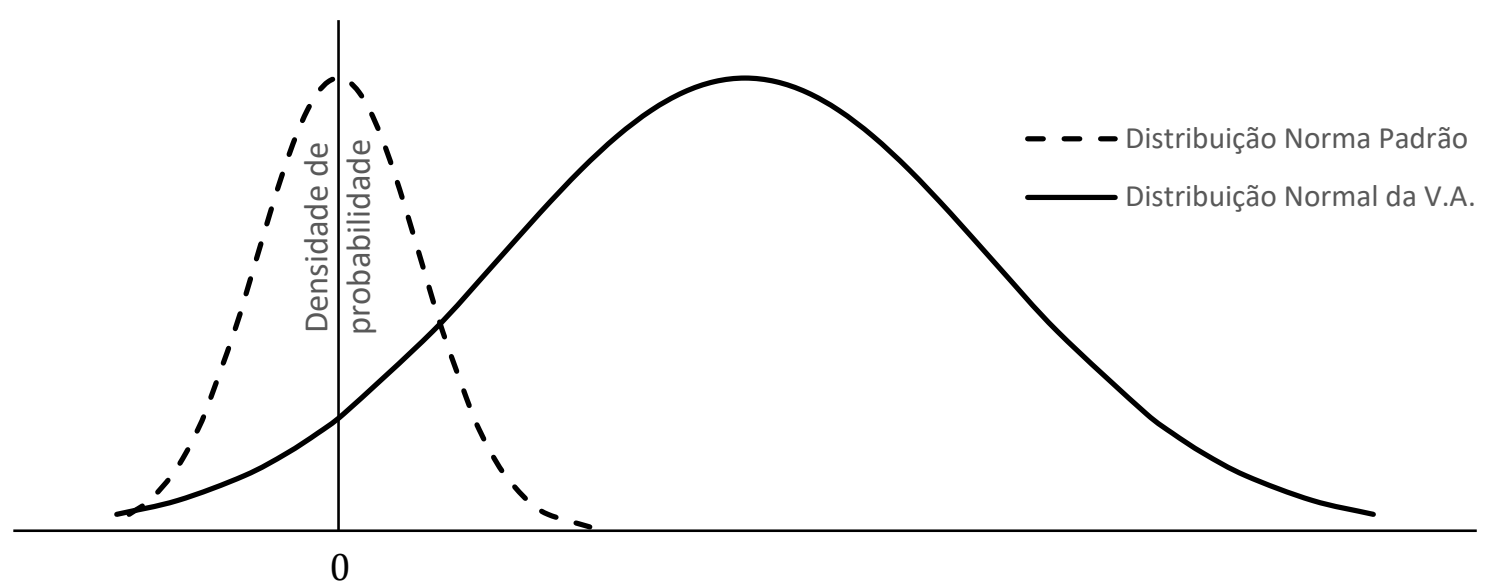

Figura 10 - Transformação da Distribuição Normal Padrão para Normal da Variável Aleatória. (Fonte: Autor)

Já para variáveis com distribuição Lognormal é possível calcular as variáveis no espaço $\mathbb{X}$ com média e desvio padrão aplicando as seguintes transformações, após obter-se o valor de $y$ :

$$
\begin{gathered}
\xi_{X_{i}}=\sqrt{\ln \left(1+\left(\frac{\sigma_{X_{i}}}{\mu_{X_{i}}}\right)^{2}\right)} \\
\lambda_{X_{i}}=\ln \mu_{X_{i}}-0.5 \xi_{X_{i}}^{2} \\
x_{i}=e^{\left(y_{i} \xi_{X_{i}}+\lambda_{X_{i}}\right)}
\end{gathered}
$$

Dessa maneira, é possível obter a variável aleatória numa distribuição Lognormal através de uma distribuição normal padrão, conforme a Figura 11: 
Distribuição Normal Padrão e Distribuição Lognormal da V.A.

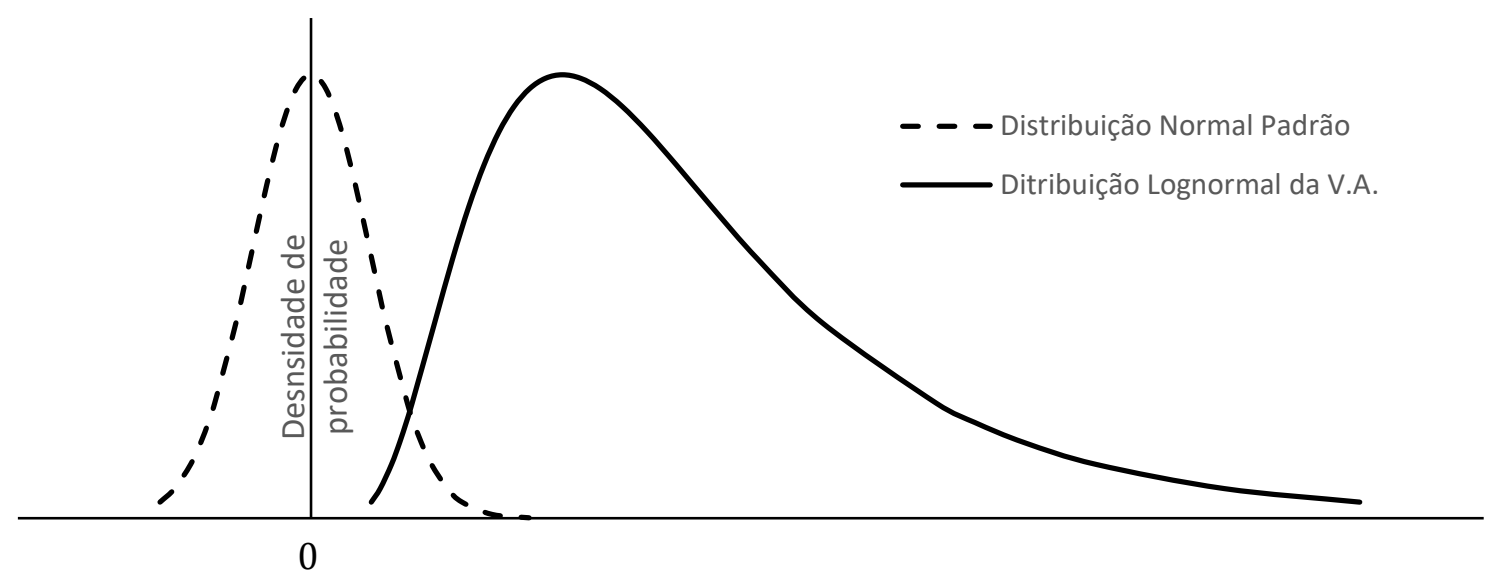

Figura 11 - Transformação da Distribuição Normal Padrão para Lognormal da Variável Aleatória. (Fonte: Autor)

\subsubsection{Exemplo de Aplicação do Método de Monte Carlo Simples}

Neste exemplo, o método desenvolvido neste trabalho, é retirado do manual do software StRAnD (Beck, 2008). Trata-se do problema de uma coluna sob ação de uma carga centrada, onde são consideradas por variáveis aleatórias o raio da seção transversal e a carga aplicada. Seguem as variáveis nas tabelas Tabela 6 e Tabela 7:

Tabela 6 - Variáveis Aleatórias

\begin{tabular}{cccccc}
\hline Variável & Símbolo & Distribuição & $\mu_{X_{i}}$ & $\sigma_{X_{i}}$ & Unidade \\
\hline Raio da Seção & $r$ & Lognormal & 20 & 0.8 & $\mathrm{~mm}$ \\
Carga Centrada & $P$ & Lognormal & 100 & 25 & $k N$ \\
\hline
\end{tabular}

Tabela 7 - Variáveis Determinísticas

\begin{tabular}{|c|c|c|c|}
\hline Variável & Símbolo & Valor & Unidade \\
\hline Tensão de Escoamento & $S_{y}$ & 240 & $M P a$ \\
\hline Módulo de Elasticidade & E & 70 & $G P a$ \\
\hline Comprimento & $L$ & 500 & $\mathrm{~mm}$ \\
\hline
\end{tabular}

Para as equações de Estado Limite são consideradas a falha por esmagamento e a falha por instabilidade elástica (carga de Euler) respectivamente: 


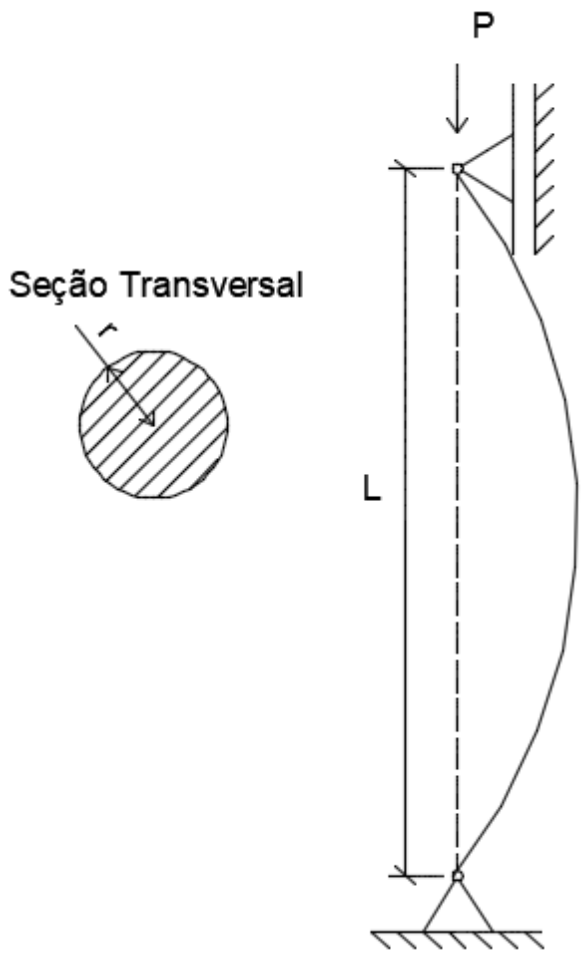

Figura 12 - Modelo do exemplo proposto por Beck, 2008 (Fonte: Autor)

$$
\begin{aligned}
& g_{1}(\mathbf{x})=\pi r^{2} S_{y}-10^{3} P \\
& g_{2}(\mathbf{x})=E \pi^{3} r^{4}-4 P L^{2}
\end{aligned}
$$

Com as informações obtidas, foi aplicado o método de Monte Carlo para essas equações de Estado Limite variando-se o número de simulações $n_{s}$ de modo a se consolidar uma convergência no resultado para a probabilidade de falha em cada situação limite:

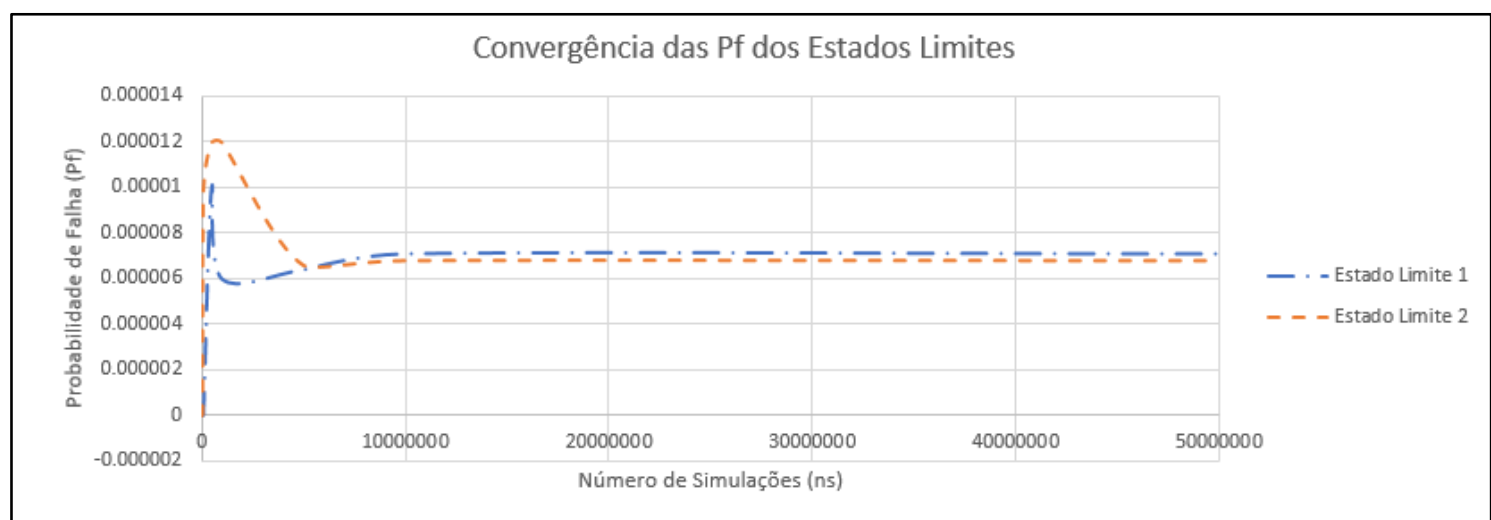

Figura 13 - Gráfico de convergência das probabilidades de falha dos estados limites (Fonte:

Autor) 
Com base nas informações do gráfico da Figura 13, é possível aferir que a probabilidade de falha do estado limite 1 converge para $P_{f, 1} \approx 7,10 \times 10^{-6}$ e a probabilidade de falha do estado limite 2 converge para $P_{f, 2} \approx 6,80 \times 10^{-6}$. Considerando confiança de $95 \%$, tem-se a probabilidade de falha para o estado limite 1 entre o intervalo $6,36 \times 10^{-6}<P_{f, 1}<7,84 \times 10^{-6}$

O resultado apresentado no manual do software StRAnD (Beck, 2008), apresentou resultados para a probabilidade de falha do estado limite 1 para $n_{s}=$ 1.000.000, que resultou em $P_{f, 1}=1,60 \times 10^{-5}$. Considerando-se a variância, a probabilidade de falha encontra-se no intervalo $8,16 \times 10^{-6}<P_{f, 1}<2,38 \times 10^{-5}$.

Como apontado anteriormente por Bjerager (1990), um número eficiente simulações para o MCS seria por volta de $n_{s}=100 / P_{f}$, portanto nesse exemplo, de acordo com o resultado atingido pelo estado limite 1 , um número de simulações eficiente seria no entorno de $n_{s} \approx 1,40 \times 10^{7}$, o que é possível se confirmar de acordo com o gráfico da Figura 13, onde a convergência é obtida para um número de simulações próximo. Desse modo, é possível, inclusive, justificar a divergência entre o resultado obtido, para o valor médio, neste trabalho e no manual do StRAnD (Beck, 2008) para a probabilidade de falha do estado limite 1 , uma vez que o número de simulações no referido material é menor daquele recomendado por Bjerager (1990). Nota-se que, se considerarmos o intervalo de confiança, ambos os resultados se tornam muito próximos, variando em cerca de $4 \%$.

\subsection{Aplicação Conjunta dos Métodos MCS e FOSM}

Neste item, serão abordados exemplos dos quais ambos os métodos são aplicados de modo a compará-los.

\subsubsection{Problema simples de confiabilidade estrutural}

Este exemplo trata-se de um caso proposto por Du (2005), no qual é estudado um caso genérico em componentes mecânicos, onde tem-se um caso de estado limite para as variáveis aleatórias: 
Tabela 8 - Variáveis Aleatórias

\begin{tabular}{cccccc}
\hline Variável & Símbolo & Distribuição & $\mu_{X_{i}}$ & $\sigma_{X_{i}}$ & Unidade \\
\hline $\begin{array}{c}\text { Tensão } \\
\text { resistente }\end{array}$ & $X_{1}$ & Normal & 200 & 20 & $M P a$ \\
Tensão aplicada & $X_{2}$ & Normal & 150 & 10 & $M P a$ \\
\hline
\end{tabular}

Assim, segue a equação de estado limite:

$$
g(\mathbf{x})=X_{1}-X_{2}
$$

Inicialmente, consideremos os valores obtidos com a aplicação do FOSM:

Tabela 9 - Resultados obtidos para o ponto de projeto, de acordo com a rotina elaborada

\begin{tabular}{|c|c|c|c|}
\hline Iteração & $\beta$ & $g$ & $\left(P_{x_{Y}}, P_{y_{Y}}\right)$ \\
\hline 1 & 2,2361 & $-2,84 \times 10^{-12}$ & $(-2,00001,0000)$ \\
\hline
\end{tabular}

Para o valor encontrado de $\beta$ atribui-se um valor de probabilidade de falha de $P_{f, F O S M} \approx 1,25 \times 10^{-2}$. Nota-se que foi necessário apenas uma iteração para a solução do problema, isso se deve a linearidade da equação de estado limite. Para o fator de importância das variáveis aleatórias:

Tabela 10 - Fatores de importância obtidos

\begin{tabular}{cccc}
\hline Var. & Símbolo & Atribuição & Fator de Importância Resultante \\
\hline 1 & $X_{1}$ & Tensão resistente & 0,8944 \\
2 & $X_{2}$ & Tensão aplicada & $-0,4472$ \\
\hline
\end{tabular}

Neste caso, obviamente, era de se esperar que os fatores de importância das variáveis tivessem valores expressivos. A seguir, para os valores obtidos pelo método MCS: 


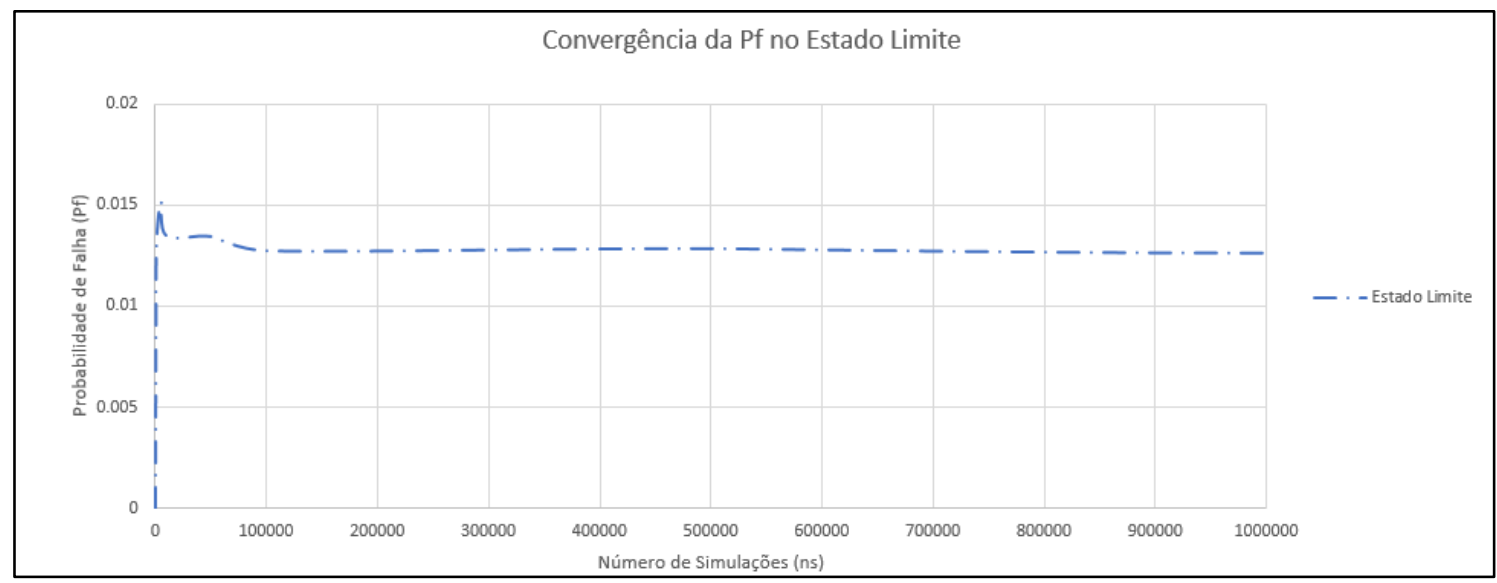

Figura 14 - Gráfico de convergência da probabilidade de falha do estado limites. (Fonte:

Autor)

Portanto é possível aferir que o valor da probabilidade de falha nesse caso é $P_{f, M C} \approx 1,26 \times 10^{-2}$, de maneira que, considerando uma confiança de $95 \%$, a probabilidade de falha varia de $1,26 \times 10^{-2}<P_{f, M C S}<1,27 \times 10^{-2}$.

Conforme esperado, os valores foram muito próximos variando em menos de $1 \%$, de modo que o exemplo estudado se assemelha à introdução e desenvolvimento do equacionamento do método FOSM, de maneira que a aplicação do método resultaria na solução exata do problema.

\subsubsection{Problema com diversas variáveis aleatórias e complexidade numérica}

Este exemplo trata-se de outro caso proposto por Du (2005) no qual é feita a verificação da tensão admissível de uma viga simplesmente apoiada de seção transversal composta por uma seção de madeira e uma chapa de alumínio, na seção crítica M-M, com 6 cargas aplicadas em diferentes distâncias conforme a Figura 15: 

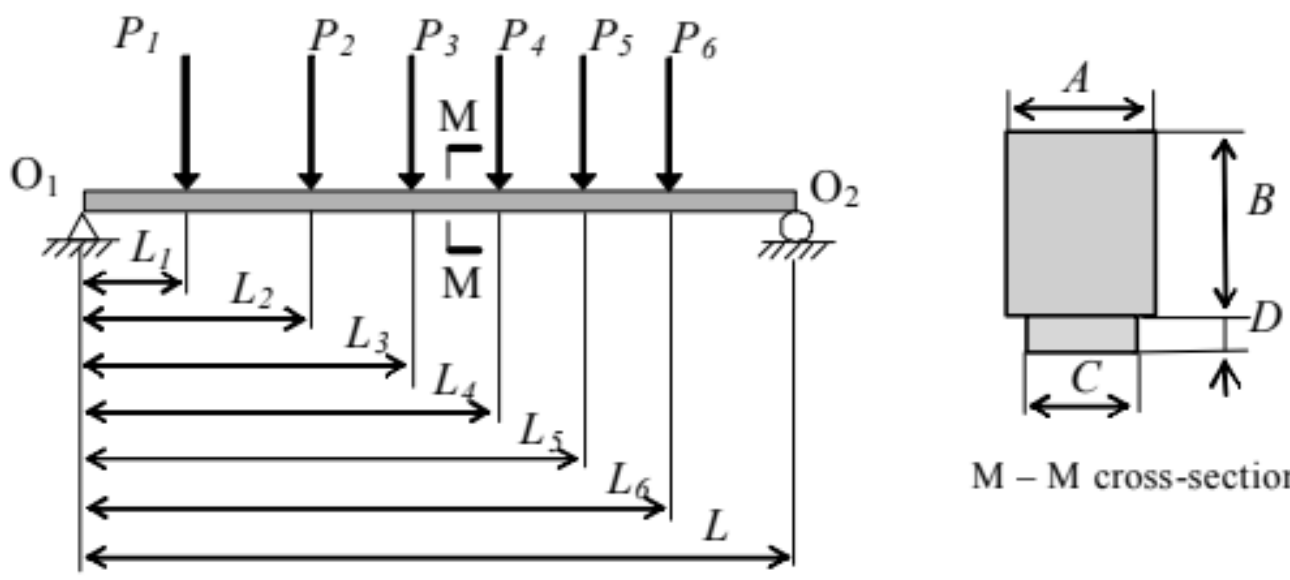

$\mathrm{M}-\mathrm{M}$ cross-section

Figura 15 - Modelo da viga mista do exemplo proposto. (Fonte: Du, 2005)

Dessa vez, todas as variáveis do problema serão aleatórias, resultando em 20 no total, conforme a Tabela 11:

Tabela 11 - Variáveis Aleatórias

\begin{tabular}{|c|c|c|c|c|c|c|}
\hline Variável & Símbolo & Atribuição & Distribuição & Unidade & $\overline{\mu_{X_{i}}}$ & $\overline{\sigma_{X_{i}}}$ \\
\hline 1 & $A$ & Medida A & Normal & $\mathrm{mm}$ & 100 & 0,2 \\
\hline 2 & $B$ & Medida B & Normal & $\mathrm{mm}$ & 200 & 0,2 \\
\hline 3 & C & Medida C & Normal & $\mathrm{mm}$ & 80 & 0,2 \\
\hline 4 & $D$ & Medida D & Normal & $\mathrm{mm}$ & 20 & 0,2 \\
\hline 5 & $L_{1}$ & Distância 1 & Normal & $\mathrm{mm}$ & 200 & 1 \\
\hline 6 & $L_{2}$ & Distância 2 & Normal & $\mathrm{mm}$ & 400 & 1 \\
\hline 7 & $L_{3}$ & Distância 3 & Normal & $\mathrm{mm}$ & 600 & 1 \\
\hline 8 & $L_{4}$ & Distância 4 & Normal & $\mathrm{mm}$ & 800 & 1 \\
\hline 9 & $L_{5}$ & Distância 5 & Normal & $\mathrm{mm}$ & 1000 & 1 \\
\hline 10 & $L_{6}$ & Distância 6 & Normal & $\mathrm{mm}$ & 1200 & 1 \\
\hline 11 & $L$ & $\begin{array}{c}\text { Comprimento } \\
\text { total }\end{array}$ & Normal & $\mathrm{mm}$ & 1400 & 2 \\
\hline 12 & $P_{1}$ & Força aplicada 1 & Lognormal & $k N$ & 15 & 1,5 \\
\hline 13 & $P_{2}$ & Força aplicada 2 & Lognormal & $k N$ & 15 & 1,5 \\
\hline 14 & $P_{3}$ & Força aplicada 3 & Lognormal & $k N$ & 15 & 1,5 \\
\hline 15 & $P_{4}$ & Força aplicada 4 & Lognormal & $k N$ & 15 & 1,5 \\
\hline 16 & $P_{5}$ & Força aplicada 5 & Lognormal & $k N$ & 15 & 1,5 \\
\hline
\end{tabular}




\begin{tabular}{|c|c|c|c|c|c|c|}
\hline Variável & Símbolo & Atribuição & Distribuição & Unidade & $\mu_{X_{i}}$ & $\sigma_{X_{i}}$ \\
\hline 17 & $P_{6}$ & Força aplicada 6 & Lognormal & $k N$ & 15 & 1,5 \\
\hline 18 & $E_{a}$ & $\begin{array}{c}\text { Mod. De Elast. } \\
\text { Alumínio }\end{array}$ & Lognormal & $G P a$ & 70 & 7 \\
\hline 19 & $E_{w}$ & $\begin{array}{c}\text { Mod. De Elast. } \\
\text { Madeira }\end{array}$ & Lognormal & $G P a$ & 8,75 & 0,875 \\
\hline 20 & $S$ & $\begin{array}{c}\text { Tensão } \\
\text { Resistente }\end{array}$ & Lognormal & $M P a$ & 25,5 & 3,825 \\
\hline
\end{tabular}

Finalmente, para a tensão atuante $\sigma$ na seção segue a equação 55:

$$
\sigma=\frac{\left[\frac{\sum_{i=1}^{6} P_{i}\left(L-L_{i}\right)}{L} L_{3}-P_{1}\left(L_{2}-L_{1}\right)-P_{2}\left(L_{3}-L_{2}\right)\right]\left[\frac{0,5 A B^{2}+\frac{E_{a}}{E_{w}} D C(B+D)}{A B+\frac{E_{a}}{E_{w}} D C}\right]}{\frac{1}{12} A B^{3}+A B\left\{\left[\frac{0,5 A B^{2}+\frac{E_{a}}{E_{w}} D C(B+D)}{A B+\frac{E_{a}}{E_{w}} D C}\right]-0,5 B\right\}^{2}+\frac{1}{12} \frac{E_{a}}{E_{w}} C D^{3}+\frac{E_{a}}{E_{w}} C D\left\{0,5 D+B-\left[\frac{0,5 A B^{2}+\frac{E_{a}}{E_{w}} D C(B+D)}{A B+\frac{E_{a}}{E_{w}} D C}\right]\right\}^{2}}
$$

E, portanto, a equação de estado limite:

$$
g(\mathbf{x})=S-1000 \sigma
$$

Inicialmente, obtendo-se os resultados para método FOSM, tem-se $\beta=1,6415$, que equivale a uma probabilidade de falha $P_{f . F O S M}=5,05 \times 10^{-2}$. Seguem os valores das variáveis aleatórias no ponto de projeto e os fatores de importância nas tabelas Tabela 12 e Tabela 13:

Tabela 12 - Variáveis Aleatórias no ponto de projeto

\begin{tabular}{ccccc}
\hline Variável & Símbolo & Atribuição & Unidade & $\begin{array}{c}\text { Valor no Ponto } \\
\text { de Projeto }\end{array}$ \\
\hline 1 & $A$ & Medida A & $m m$ & 100 \\
2 & $B$ & Medida B & $m m$ & 200 \\
3 & $C$ & Medida C & $m m$ & 80 \\
4 & $D$ & Medida D & $m m$ & 20 \\
5 & $L_{1}$ & Distância 1 & $m m$ & 200 \\
6 & $L_{2}$ & Distância 2 & $m m$ & 400
\end{tabular}




\begin{tabular}{|c|c|c|c|c|}
\hline Variável & Símbolo & Atribuição & Unidade & $\begin{array}{c}\text { Valor no Ponto } \\
\text { de Projeto }\end{array}$ \\
\hline 7 & $L_{3}$ & Distância 3 & $m m$ & 600 \\
\hline 8 & $L_{4}$ & Distância 4 & $\mathrm{~mm}$ & 800 \\
\hline 9 & $L_{5}$ & Distância 5 & $m m$ & 1000 \\
\hline 10 & $L_{6}$ & Distância 6 & $m m$ & 1200 \\
\hline 11 & $L$ & $\begin{array}{c}\text { Comprimento } \\
\text { total }\end{array}$ & $\mathrm{mm}$ & 1400 \\
\hline 12 & $P_{1}$ & Força aplicada 1 & $k N$ & 15,3 \\
\hline 13 & $P_{2}$ & Força aplicada 2 & $k N$ & 15,2 \\
\hline 14 & $P_{3}$ & Força aplicada 3 & $k N$ & 15,3 \\
\hline 15 & $P_{4}$ & Força aplicada 4 & $k N$ & 15,2 \\
\hline 16 & $P_{5}$ & Força aplicada 5 & $k N$ & 15,1 \\
\hline 17 & $P_{6}$ & Força aplicada 6 & $k N$ & 15,1 \\
\hline 18 & $E_{a}$ & $\begin{array}{c}\text { Mod. De Elast. } \\
\text { Alumínio }\end{array}$ & $G P a$ & 69,0 \\
\hline 19 & $E_{w}$ & $\begin{array}{c}\text { Mod. De Elast. } \\
\text { Madeira }\end{array}$ & $G P a$ & 8,9 \\
\hline 20 & $S$ & $\begin{array}{c}\text { Tensão } \\
\text { Resistente }\end{array}$ & $M P a$ & 19,4 \\
\hline
\end{tabular}

Tabela 13 - Fatores de Importância das Variáveis Aleatórias

\begin{tabular}{cccc}
\hline Variável & Símbolo & Atribuição & $\begin{array}{c}\text { Fator de } \\
\text { Importância }\end{array}$ \\
\hline 1 & $A$ & Medida A & 0,0082 \\
2 & $B$ & Medida B & 0,0087 \\
3 & $C$ & Medida C & 0,0021 \\
4 & $D$ & Medida D & 0,0115 \\
5 & $L_{1}$ & Distância 1 & $-0,0020$ \\
6 & $L_{2}$ & Distância 2 & 0,0015 \\
7 & $L_{3}$ & Distância 3 & $-0,0055$ \\
8 & $L_{4}$ & Distância 4 & 0,0015 \\
9 & $L_{5}$ & Distância 5 & 0,0015 \\
10 & $L_{6}$ & Distância 6 & 0,0015
\end{tabular}




\begin{tabular}{cccc}
\hline Variável & Símbolo & Atribuição & $\begin{array}{c}\text { Fator de } \\
\text { Importância }\end{array}$ \\
\hline 11 & $L$ & Comprimento total & $-0,0090$ \\
12 & $P_{1}$ & Força aplicada 1 & $-0,1089$ \\
13 & $P_{2}$ & Força aplicada 2 & $-0,0792$ \\
14 & $P_{3}$ & Força aplicada 3 & $-0,1188$ \\
15 & $P_{4}$ & Força aplicada 4 & $-0,0891$ \\
16 & $P_{5}$ & Força aplicada 5 & $-0,0594$ \\
17 & $P_{6}$ & Força aplicada 6 & $-0,0297$ \\
18 & $E_{a}$ & Mod. De Elast. & 0,0842 \\
& & Alumínio & $-0,0823$ \\
19 & $E_{w}$ & Mod. De Elast. & Madeira \\
20 & $S$ & Tensão Resistente & 0,9701 \\
\hline
\end{tabular}

E então, para a aplicação do método MCS, obtém-se a convergência:

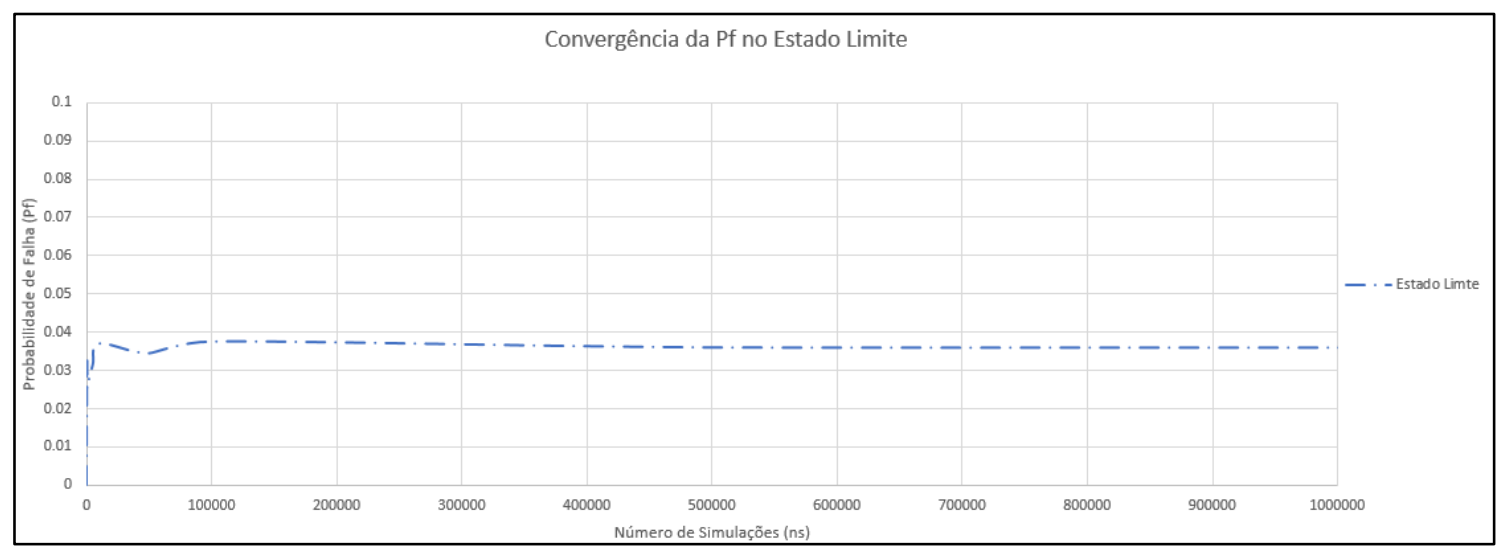

Figura 16 - Gráfico de convergência da probabilidade de falha do estado limite (Fonte: Autor)

De acordo com o valor convergido, admitindo um intervalo com $95 \%$ de confiança, obtém-se a probabilidade de falha $P_{f . M C S}=3,60 \times 10^{-2} \pm 3,65 \times 10^{-4}$.

Desta vez, aplicam-se ambos os métodos, porém, removendo as variáveis aleatórias cujos fatores de importância foram menores que 0,0100. Então, as variáveis aleatórias consideradas: 
Tabela 14 - Variáveis Aleatórias do novo caso

\begin{tabular}{ccccccc}
\hline Variável & Símbolo & Atribuição & Distribuição & Unidade & $\mu_{X_{i}}$ & $\sigma_{X_{i}}$ \\
\hline 1 & $D$ & Medida D & Normal & $m m$ & 20 & 0,2 \\
2 & $P_{1}$ & Força aplicada 1 & Lognormal & $k N$ & 15 & 1,5 \\
3 & $P_{2}$ & Força aplicada 2 & Lognormal & $k N$ & 15 & 1,5 \\
4 & $P_{3}$ & Força aplicada 3 & Lognormal & $k N$ & 15 & 1,5 \\
5 & $P_{4}$ & Força aplicada 4 & Lognormal & $k N$ & 15 & 1,5 \\
6 & $P_{5}$ & Força aplicada 5 & Lognormal & $k N$ & 15 & 1,5 \\
7 & $P_{6}$ & Força aplicada 6 & Lognormal & $k N$ & 15 & 1,5 \\
8 & $E_{a}$ & Mod. De Elast. & Lognormal & $G P a$ & 70 & 7 \\
9 & $E_{w}$ & Mod. De Elast. & Lognín & & & \\
10 & $S$ & Tensão Resistente & Lognormal & $M P a$ & 25,5 & 3,825 \\
\hline
\end{tabular}

Após a simulação, obtiveram-se os resultados para método $\mathrm{FOSM}, \beta=1,6417$, que equivale a uma probabilidade de falha $P_{f . F O S M}=5,05 \times 10^{-2}$. Seguem os valores das variáveis aleatórias no ponto de projeto e os fatores de importância nas Tabela 15 e Tabela 16 respectivamente:

Tabela 15 - Variáveis Aleatórias no ponto de projeto

\begin{tabular}{|c|c|c|c|c|}
\hline Variável & Símbolo & Atribuição & Unidade & $\begin{array}{c}\text { Valor no Ponto } \\
\text { de Projeto }\end{array}$ \\
\hline 1 & $D$ & Medida D & $\mathrm{mm}$ & 20 \\
\hline 2 & $P_{1}$ & Força aplicada 1 & $k N$ & 15,3 \\
\hline 3 & $P_{2}$ & Força aplicada 2 & $k N$ & 15,2 \\
\hline 4 & $P_{3}$ & Força aplicada 3 & $k N$ & 15,3 \\
\hline 5 & $P_{4}$ & Força aplicada 4 & $k N$ & 15,2 \\
\hline 6 & $P_{5}$ & Força aplicada 5 & $k N$ & 15,1 \\
\hline 7 & $P_{6}$ & Força aplicada 6 & $k N$ & 15,1 \\
\hline 8 & $E_{a}$ & $\begin{array}{c}\text { Mod. De Elast. } \\
\text { Alumínio }\end{array}$ & $G P a$ & 69,0 \\
\hline
\end{tabular}




\begin{tabular}{ccccc}
\hline Variável & Símbolo & Atribuição & Unidade & $\begin{array}{c}\text { Valor no Ponto } \\
\text { de Projeto }\end{array}$ \\
\hline 9 & $E_{w}$ & $\begin{array}{c}\text { Mod. De Elast. } \\
\text { Madeira }\end{array}$ & $G P a$ & 8,9 \\
10 & $S$ & Tensão Resistente & $M P a$ & 19,4 \\
\hline
\end{tabular}

Tabela 16 - Fatores de Importância das Variáveis Aleatórias

\begin{tabular}{|c|c|c|c|c|}
\hline Variável & Símbolo & Atribuição & Unidade & $\begin{array}{c}\text { Fator de } \\
\text { Importância }\end{array}$ \\
\hline 1 & $D$ & Medida D & $\mathrm{mm}$ & 0,0115 \\
\hline 2 & $P_{1}$ & Força aplicada 1 & $k N$ & $-0,1089$ \\
\hline 3 & $P_{2}$ & Força aplicada 2 & $k N$ & $-0,0792$ \\
\hline 4 & $P_{3}$ & Força aplicada 3 & $k N$ & $-0,1188$ \\
\hline 5 & $P_{4}$ & Força aplicada 4 & $k N$ & $-0,0891$ \\
\hline 6 & $P_{5}$ & Força aplicada 5 & $k N$ & $-0,0594$ \\
\hline 7 & $P_{6}$ & Força aplicada 6 & $k N$ & $-0,0297$ \\
\hline 8 & $E_{a}$ & $\begin{array}{c}\text { Mod. De Elast. } \\
\text { Alumínio }\end{array}$ & $G P a$ & 0,0842 \\
\hline 9 & $E_{w}$ & $\begin{array}{c}\text { Mod. De Elast. } \\
\text { Madeira }\end{array}$ & $G P a$ & $-0,0823$ \\
\hline 10 & $S$ & $\begin{array}{c}\text { Tensão } \\
\text { Resistente }\end{array}$ & $M P a$ & 0,9703 \\
\hline
\end{tabular}

E então para o método MCS:

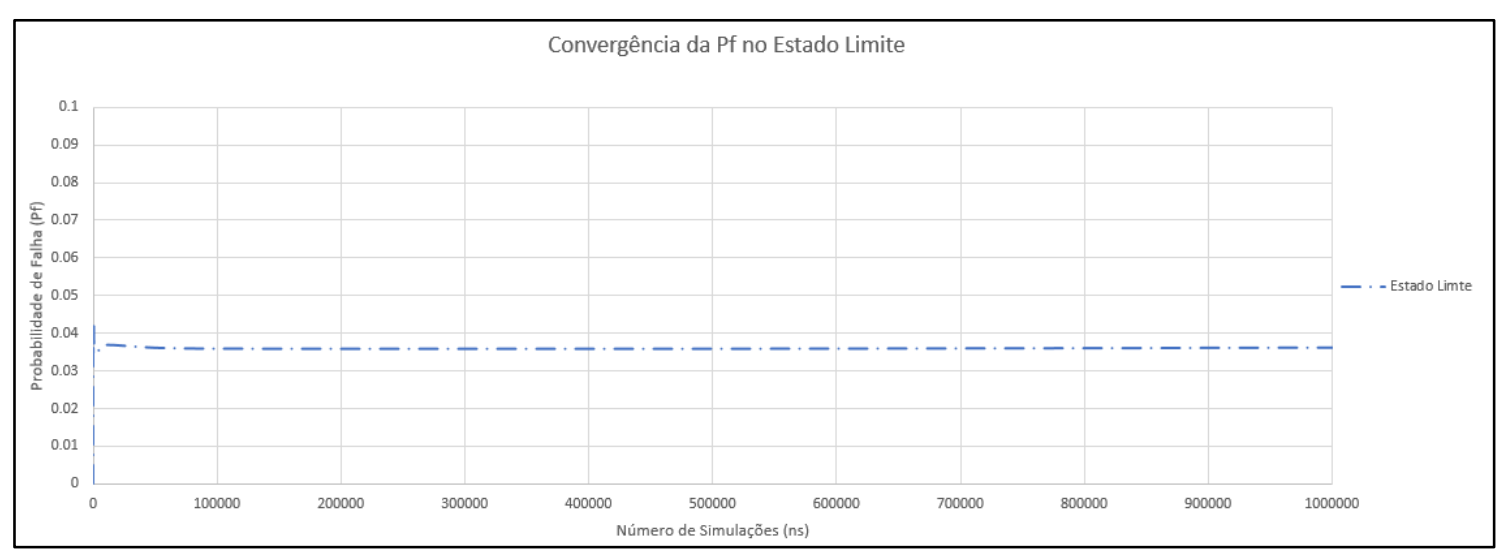

Figura 17 - Gráfico de convergência da probabilidade de falha do estado limite (Fonte: Autor) 
De modo que se evidenciou o mesmo valor para a probabilidade de falha anterior, ou seja, $P_{f . M C S}=3,60 \times 10^{-2} \pm 3,65 \times 10^{-4}$.

Considerando os valores obtidos neste item, notou-se que os coeficientes de importância tomam como destaque na consideração de se reduzirem as variáveis aleatórias do problema, ou seja, tornar o estudo mais enxuto com a necessidade de controle de variáveis reduzida, de modo que os resultados obtidos contemplem a mesma precisão, como ocorrido com ambos os métodos. É observado que os resultados de ambos os métodos divergiram conforme esperado, devido a não linearidade da equação de estado limite.

Neste caso, a equação de estado limite é de certa complexidade na qual suas derivadas parciais ficam difíceis de se obterem, revelando mais uma vantagem do método das DF incluído no FOSM, cujo qual não depende da derivação explicita parcial da equação de estado limite.

Vale destacar ainda que, devido às DF aplicado no FOSM, um reduzido número de variáveis aleatórias implica em um menor número de operações para o cálculo do vetor gradiente, de modo a diminuir o esforço computacional do processo, portanto, a ideia permeia em controlar a variáveis de acordo com a ordem de grandeza dos valores obtidos dos coeficientes de importância. 


\section{MODELO DE INTERAÇÃO SOLO-FUNDAÇÃO-EDIFÍCIO}

O modelo utilizado para este estudo foi proposto por Almeida (2003), o qual é baseado no MEF, com formulação lagrangiana, que utiliza elementos de barra e de casca, para simulações lineares e com não linearidade geométrica formulada nas barras do edifício. Permite a inserção de fundação direta via elemento de casca, que fora resultante do acoplamento dos EF de membrana - proposto por Bergan e Felippa (1985) - e de flexão - desenvolvido por Batoz e Dhatt (1979) e a interação soloestrutura pela hipótese clássica e simplificada de Winkler, que representam o solo como um conjunto de molas translacionais ou pelo acoplamento entre EF e elementos de contorno, que simula efetivamente o meio contínuo. Foram necessários algoritmos adicionais para acoplar os métodos de confiabilidade com o programa MEF. Os fluxogramas para integração com o programa relativo aos métodos FOSM e MCS são ilustrados, respectivamente, na Figura 18 e Figura 19 


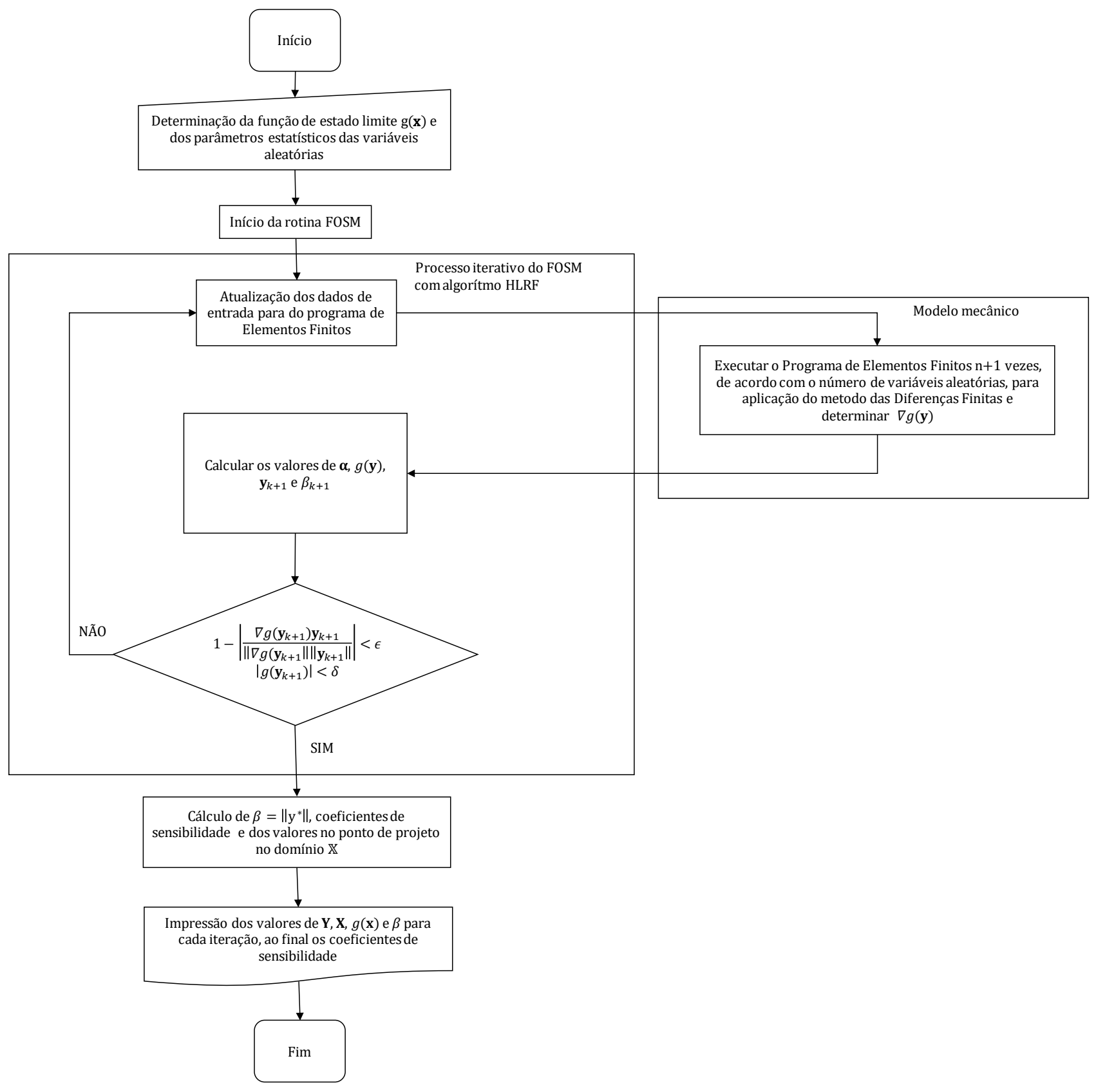

Figura 18 - Fluxograma do procedimento de cálculo desenvolvido para o método FOSM (Fonte: Autor) 


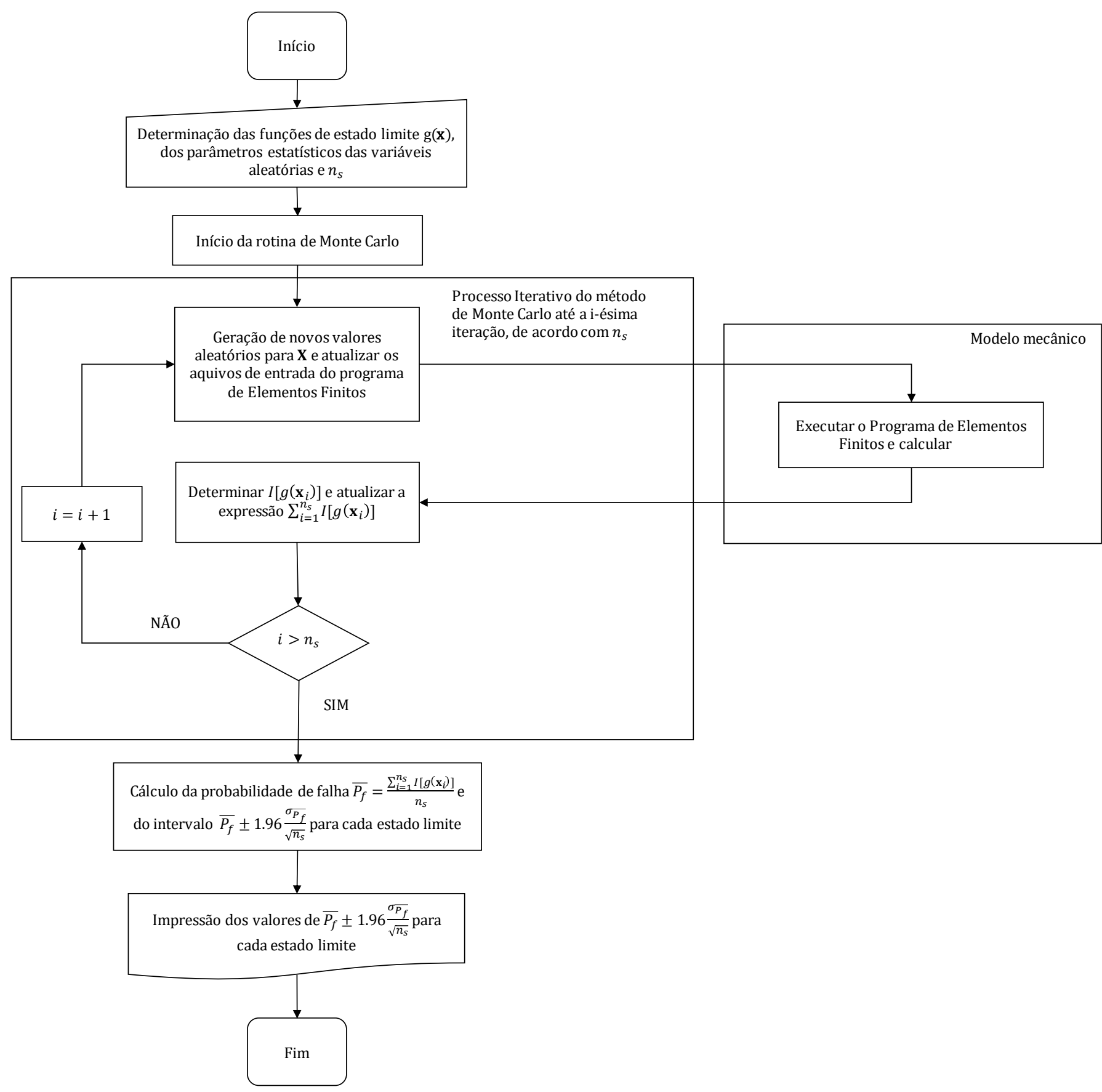

Figura 19 - Fluxograma do procedimento de cálculo desenvolvido para o método de Monte Carlo (Fonte: Autor)

Destaca-se, conforme explanado anteriormente, que os fluxogramas apresentados dependem do programa de EF apenas para o cálculo dos estados limite, ou seja, o corpo principal dos algoritmos não depende do programa para cálculo de edifícios, de modo que este pode estar contido e ser executado na rotina dos estados limites de maneira independente. Neste trabalho, este foi o procedimento adotado, isto é, a rotina para aplicação dos métodos apresentados é executada com uma rotina 
externa de estados limite, de modo que a execução do programa de EF ocorre nesta. Entende-se, também, que para o método FOSM, a aplicação do método das DF não depende da rotina dos estados limite, tornando a rotina do FOSM eficaz para quaisquer rotinas de estados limite, possibilitando o cálculo do vetor gradiente para funções implícitas, e tornando desnecessária a diferenciação para funções explícitas.

\subsection{Modelo de Cálculo para Edifícios com Fundações}

\subsubsection{Hipótese de Winkler para Fundação Direta}

Para considerar a influência do solo junto à fundação, partiu-se da hipótese de Winkler, onde se estabelece que as tensões aplicadas no solo sejam proporcionais, em uma relação escalar ao recalque mobilizado. Não havendo influência entre o ponto de aplicação desta tensão com sua vizinhança, estabelece uma relação pontual entre fundação-solo, mediante a definição de uma constante de mola que representará a rigidez do maciço. Para isto, é necessário definir os valores de $K_{v}$ e $K_{h}$, os quais são denominados respectivamente de módulo de reação vertical e horizontal, com unidade de $\mathrm{FL}^{-3}$. Estes são valores escalares que representam os coeficientes de rigidez que o solo possui para resistir ao deslocamento mobilizado por uma tensão imposta. Eles são análogos ao coeficiente de mola $\left(\mathrm{FL}^{-1}\right)$, mas não relacionado a uma força, mas sim a uma pressão a qual advêm das ações ativas de uma fundação superficial. Os trabalhos de Morais (1981), Morrison (1993), Cintra et al. (2003), Velloso e Lopes (1996), Terzaghi (1955), Calavera (2000) e Bowles (1997) apresentam várias metodologias para o cálculo dos módulos de reações.

Para o caso do acoplamento entre a fundação superficial e o solo simulado pela hipotese de Winkler, a aplicação é imediata. Transformam-se os módulos de reações em constantes elásticas de molas. É relevante afirmar, que esses coeficientes de reação vertical são obtidos de maneira simplificada, multiplicando este valor pela área de cada elemento superficial, ou seja:

$$
\bar{k}^{i}=k_{v} \cdot A^{i} \quad\left(F L^{-1}\right) \quad(i=1, \text { número total de elemento fundação })
$$


Em seguida, é considerado um valor médio deste coeficiente em cada nó do elemento de fundação, dividindo-se este valor pelo número total de nós $(N t)$ deste elemento, ou seja:

$$
k^{i}=\bar{k}^{i} / N t_{i}\left(F L^{-1}\right) \quad(i=1, \text { número total de elemento fundação })
$$

Já o coeficiente de mola horizontal foi estipulado como um percentual do coeficiente de mola vertical, este percentual pode ser atribuído com valores estimados nas referências mencionadas. Assim, a expressão final neste modelo é indicada por:

$$
\overline{\mathbf{K}}_{\text {mef }} \cdot \mathbf{U}_{\text {mef }}=\mathbf{F}_{\text {mef }}
$$

Onde $\overline{\mathbf{K}}_{\text {mef }}$ já incorpora as influências dos coeficientes de mola nas respectivas posições dos nós de contato com o solo.

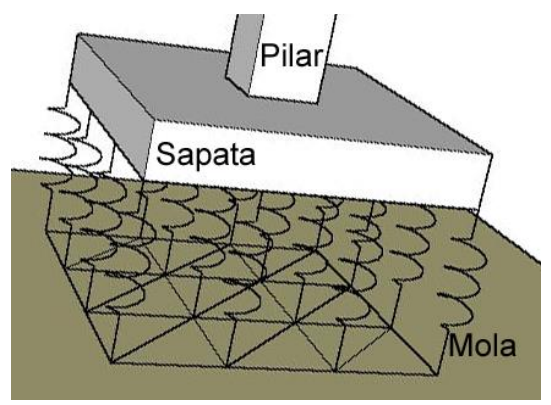

Figura 20 - Acoplamento entre sapata e solo via hipótese de Winkler (Fonte: Almeida, 2003)

\subsubsection{Hipótese de Winkler para Fundação Profunda}

Sabe-se que o uso de elementos de fundação direta no projeto de edifícios não é muito frequente, onde de modo geral, em função das características resistentes do solo em conjunto com os esforços que são transmitidos às fundações, é imprescindível usar elementos de fundação profunda (estacas, tubulões). Assim, parte da proposta deste trabalho, envolve também um estudo de fundações profundas, para este fim foi inserido uma formulação para a simulação de edifícios com blocos de fundação com estacas no modelo de Almeida (2003). Desse modo, adotou-se um 
procedimento de cálculo de condensação estática da rigidez de cada estaca e adicionado o efeito no local correspondente na matriz de rigidez dos blocos, calculados com elementos de casca que já está acoplada com todo o edifício.

A influência das rigidezes relativas ao solo, tanto na horizontal, eixo x e y, como na vertical, são definidas em cada análise mediante a introdução desses valores por nó e por bloco. A Figura 21 ilustra o modelo a ser discretizado em MEF, com barras verticais, divididas em $n$ elementos de comprimento unitário.

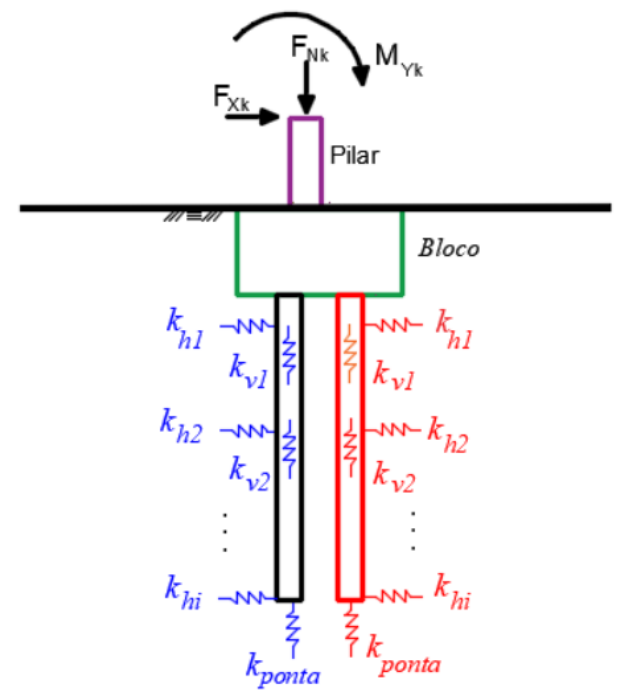

Figura 21 - Modelo de estaca com as molas representando o solo (Fonte: Autor)

Assim, considerando uma estaca discretizada em $n$ elementos de barra, podese dividir a sua matriz em dois blocos de matrizes, um subloco nomeado com índice 2, onde pega-se os nós da estaca que devem ser condensados, que são os nós que não estão em contato com o nó do bloco, e chamando de nó 1, o nó em contato com esse, tem-se as equações de equilíbrio dividida em sub-matrizes e sub-vetores como:

$$
\left[\begin{array}{ll}
\mathbf{k}_{11} & \mathbf{k}_{12} \\
\mathbf{k}_{21} & \mathbf{k}_{22}
\end{array}\right]\left\{\begin{array}{l}
\mathbf{U}_{1} \\
\mathbf{U}_{2}
\end{array}\right\}=\left\{\begin{array}{l}
\mathbf{F}_{1} \\
\mathbf{F}_{2}
\end{array}\right\} \Rightarrow\left\{\begin{array}{l}
\mathbf{k}_{11} \mathbf{U}_{1}+\mathbf{k}_{12} \mathbf{U}_{2}=\mathbf{F}_{1} \\
\mathbf{k}_{21} \mathbf{U}_{1}+\mathbf{k}_{22} \mathbf{U}_{2}=\mathbf{F}_{2}
\end{array}\right.
$$

Portanto, com a segunda linha do sistema da equação 60, tem-se:

$$
\mathbf{U}_{2}=\mathbf{k}_{22}{ }^{-1}\left\{F_{2}-\mathbf{k}_{21} \mathbf{U}_{1}\right\}
$$


Substituindo a equação 58 na primeira linha do sistema linear da equação 60, sabendo-se que $\mathbf{F}_{\mathbf{2}}=\mathbf{0}$, uma vez que esse vetor representa as forças nodais aplicadas ao longo dos nós do fuste da estaca, que é considerado nulo obtém-se:

$$
\left[\mathbf{k}_{11}-\mathbf{k}_{12} \mathbf{k}_{22}{ }^{-1} \mathbf{k}_{21}\right] \mathbf{U}_{1}=F_{1} \Rightarrow \mathbf{k}_{\mathrm{bl}}=\left[\mathbf{k}_{11}-\mathbf{k}_{12} \mathbf{k}_{22}{ }^{-1} \mathbf{k}_{21}\right]
$$

Onde $\mathbf{U}_{\mathbf{1}}$ indica o vetor de incógnitas dos deslocamentos pertencentes aos nós do topo de cada estaca. Desse modo, com a representação de cada estaca pela matriz $\mathbf{k}_{\mathbf{b l}}$, Equação 62, é imediato somar sua parcela na matriz de rigidez do nó de referência do topo de cada estaca de cada bloco, ou seja, o sistema linear da equação 60 é obtido já com a influência das estacas no modelo, conforme visualizado nas Figuras $22 \mathrm{a}$ e $22 \mathrm{~b}$.

O procedimento desenvolvido, resumido pelas Equações de 60 a 62, embora tenha um processo de alto custo computacional, que é a inversão da matriz [k] matrizes, ele se torna interessande no modelo qunado a análise não-linear geometrica é realizada. Isso pois as alterações das matrizes de rigidezes são apenas realizadas nos elementos do edificio, assim, não modificando as parcelas devidoa fundação, assim não é necessario recalcular as matriz da parcela da fundação-solo, tanto para as sapatas como para o conjunto bloco/estaca ao longo do processo incrementaliterativo.
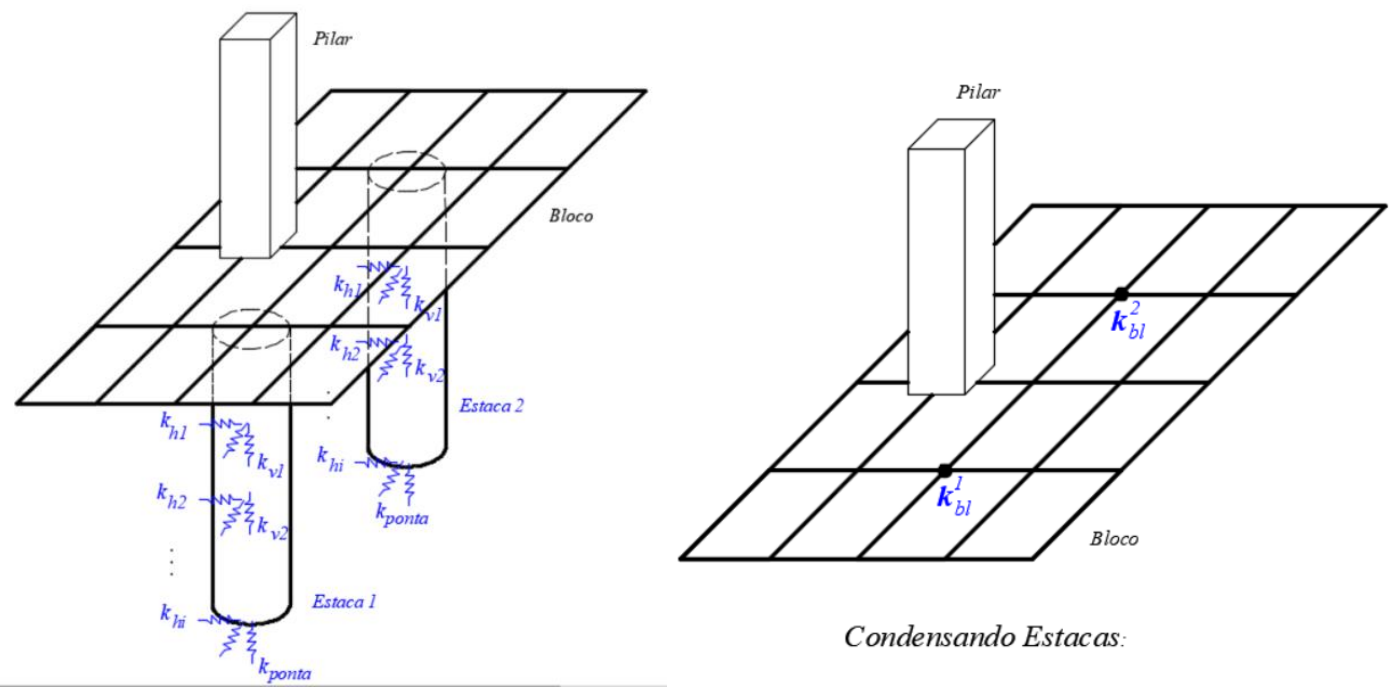

Condensando Estacas:

Figura 22 - a) Representação explícita dos elementos de estaca com mola, bloco e pilar; b) Representação condensada das estacas e molas (Fonte: Autor) 


\subsubsection{Verificação do Programa de Edifícios com Estacas}

De modo a se verificar a precisão dos resultados do programa de edifícios com a implementação da rotina de condensação das estacas, elaborou-se um exemplo teste com um edifício de 2 andares com pavimento tipo de $4 \times 4 \mathrm{~m}$, vigas $20 \times 55 \mathrm{~cm}$ e pilares $20 \times 70 \mathrm{~cm}$, quatro blocos de $2 \times 2 \times 0,5 \mathrm{~m}$, estacas de diâmetro de $40 \mathrm{~cm}$ e $6 \mathrm{~m}$ de comprimento. Ao longo da estaca foram adotados os coeficientes para o $1^{\circ}$ metro $k_{\text {solo }}=1000 \mathrm{kN} / \mathrm{m}$, de 2 a 3 metros $k_{\text {solo }}=2000 \mathrm{kN} / \mathrm{m}$, de 4 a $5 k_{\text {solo }}=3000 \mathrm{kN} / \mathrm{m}$ e no 6을 $k_{\text {solo }}=5000 \mathrm{kN} / \mathrm{m}$.

Fora elaborado um modelo do STRAP para confrontar os resultados do programa de edifícios com a nova rotina inserida, com cargas aplicadas de $50 \mathrm{kN} / \mathrm{m}$ em cada viga e $100 \mathrm{kN}$ de carga resultante de vento para cada pavimento.
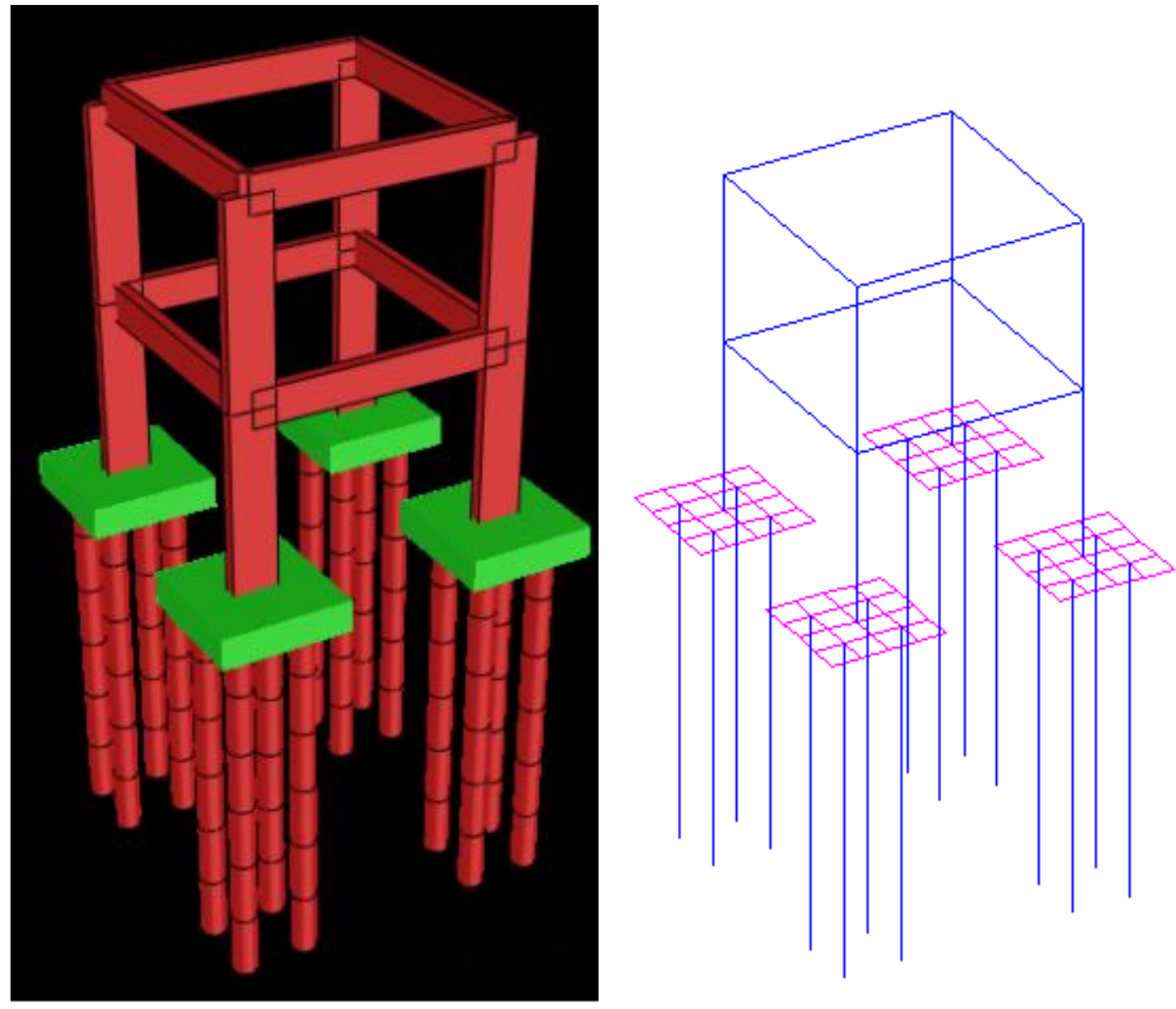

Figura 23 - Modelo renderizado e em frames no STRAP. (Fonte: Autor) 
Tabela 17 - Valores dos recalques obtidos no presente modelo e pelo STRAP

\begin{tabular}{ccccc}
\hline Coord. X & Coord. Y & $d_{z}$ STRAP $(\mathrm{cm})$ & $d_{z}$ Programa $(\mathrm{cm})$ & Diferença (\%) \\
\hline 0,0 & 0,0 & 0,5235 & 0,5386 & 2,80 \\
0,0 & 4,0 & 0,5235 & 0,5386 & 2,80 \\
4,0 & 6,0 & 0,7558 & 0,7413 & 1,96 \\
4,0 & 0,0 & 0,7558 & 0,7413 & 1,96 \\
\hline
\end{tabular}

$\mathrm{Na}$ Tabela 17 apresentam-se os resultados obtidos por ambos os modelos e as diferenças relativas demonstram pequena divergência, possivelmente em decorrentes ou pelo uso de diferente discretização do bloco e do tipo de EF usado e pelo erro numérico gerado pelo presente modelo em decorrência do processo de condensação estática. Entende-se, portanto, que a rotina gera resultados confiáveis para as análises que serão elaboradas neste trabalho.

\subsection{Recalque diferencial}

O recalque diferencial trata-se da diferença entre as cotas dos recalques das estruturas, dos quais acrescentam esforços nos elementos através dos deslocamentos que possivelmente serão responsáveis por patologias no edifício. Essas patologias podem ser classificadas da seguinte maneira:

- Danos arquitetônicos ou à aparência visual da edificação: Patologias que podem ser visíveis por qualquer um que podem causar um certo desconforto, como trincas nas paredes e recalque de pisos;

- Danos causados à funcionalidade ou ao uso da edificação: Problemas como inversão da declividade de pisos e desaprumo do edifício;

- Danos estruturais: Patologias que podem ocorrer nos elementos estruturais do edifício, podendo comprometer sua segurança. 


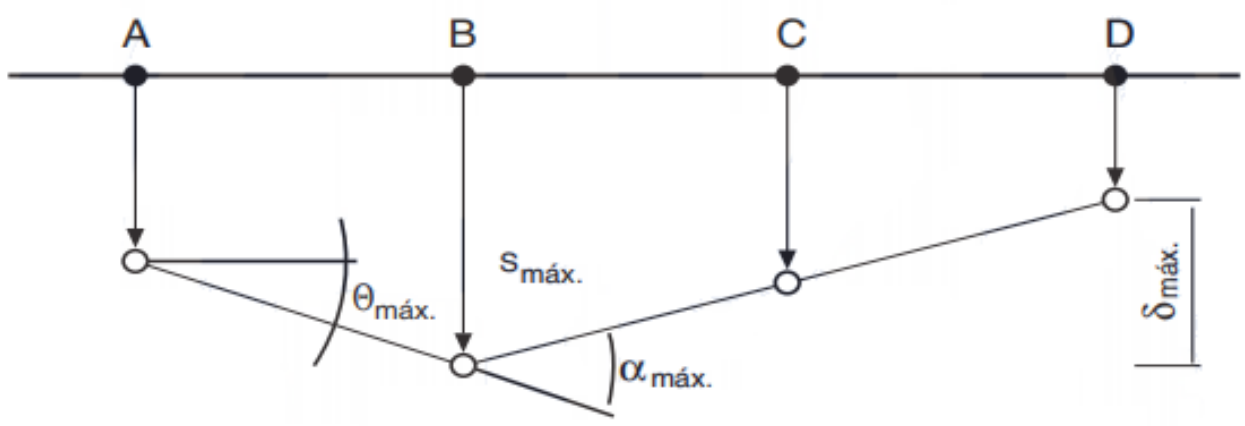

Figura 24 - Desenho esquemático de movimentos na fundação (NBR6122, 2010)

A NBR6122 (2010) apresenta índices de movimentações nas fundações, a Figura 24 ilustra dentre outras o recalque diferencial que é de maior interesse neste trabalho. As variáveis representam:

Tabela 18 - Valores das variáveis relativas aos movimentos das fundações de acordo com a NBR6122(2010)

\begin{tabular}{cc}
\hline Variável & Representação física \\
\hline$\theta$ & Rotação relativa \\
$s$ & Recalque total \\
$\alpha$ & Deformação angular \\
$\delta$ & Recalque diferencial \\
\hline
\end{tabular}

Em complemento aos índices mencionados pela norma, Hachich et. al (1998) trazem valores máximos recomendados para o recalque diferencial em função do tipo de solo que ocorrem, conforme indicado na Tabela 19.

Tabela 19 - Valores de recalque diferencial máximo $\left(\delta_{\text {máx }}\right)$ de acordo com a literatura

\begin{tabular}{cc}
\hline Tipo de Solo & $\delta_{\text {máx }}$ \\
\hline Areias & $25 \mathrm{~mm}$ \\
Argilas & $40 \mathrm{~mm}$ \\
\hline
\end{tabular}

Para outros tipos de solo não há recomendações, a não ser o devido estudo do recalque em função da estrutura em questão. Esses valores valem para estruturas de convencionais de aço ou concreto, não se aplicam para estruturas de alvenaria estrutural. 


\section{SIMULAÇÕES NUMÉRICAS}

Nesta seção serão apresentados algumas simulações e os resultados obtidos. Para todos os exemplos estudados, é adotado uma porcentagem $p=10 \%$ para aplicação do Método das Diferenças Finitas.

Os valores de coeficientes de variação e desvios padrão adotados foram baseados no Joint Committee on Structural Safety, (JCSS, 2001), no qual se trata de um comitê internacional que, através de um estudo conjunto de normatizações de diversos países, estipulam recomendações para valores em análises estruturais probabilísticas, incluindo demais referências neste trabalho. Como tal comitê não contempla formulações das normas brasileiras, certas adaptações foram adotadas para alguns coeficientes.

Entre as variáveis manipuladas, destaca-se ainda a dificuldade de se considerar uma curva estatística para aplicação dos valores de velocidade básica do vento e respectivos coeficientes nas normas brasileiras. Portanto adotou-se recomendações do JCSS (2001) para tais variáveis.

Todos os modelos estudados são hipotéticos, portanto propriedades geométricas dos edifícios e rigidez do solo são arbitrárias. Inclui-se, também, que para as simulações foi utilizado um computador com processador Intel Core i3 $(1.9 \mathrm{GHz}$, 3MB L3 cache) com memória RAM de 4GB DDR3 L.

O programa de edifícios utilizado não considera a rigidez das lajes no modelo de cálculo, de modo que os carregamentos oriundos das lajes são aplicados diretamente nas vigas.

$\mathrm{O}$ autor destaca que todos os algoritmos utilizados e gerados neste trabalho podem ser disponibilizados, com exceção do programa de cálculo de edifícios, por não ter sua autoria.

\subsection{Edifício com 4 elementos de fundação direta via método MCS}

Os primeiros resultados obtidos foram relativos a uma edificação de pavimentos tipo quadrados de $4 \times 4 \mathrm{~m}$ com 4 elementos de fundação direta de $1,5 \times 1,5 \times 0,5 \mathrm{~m}$, vigas e pilares de seção $20 \times 20 \mathrm{~cm}$. Modelo em EF na Figura 25. 


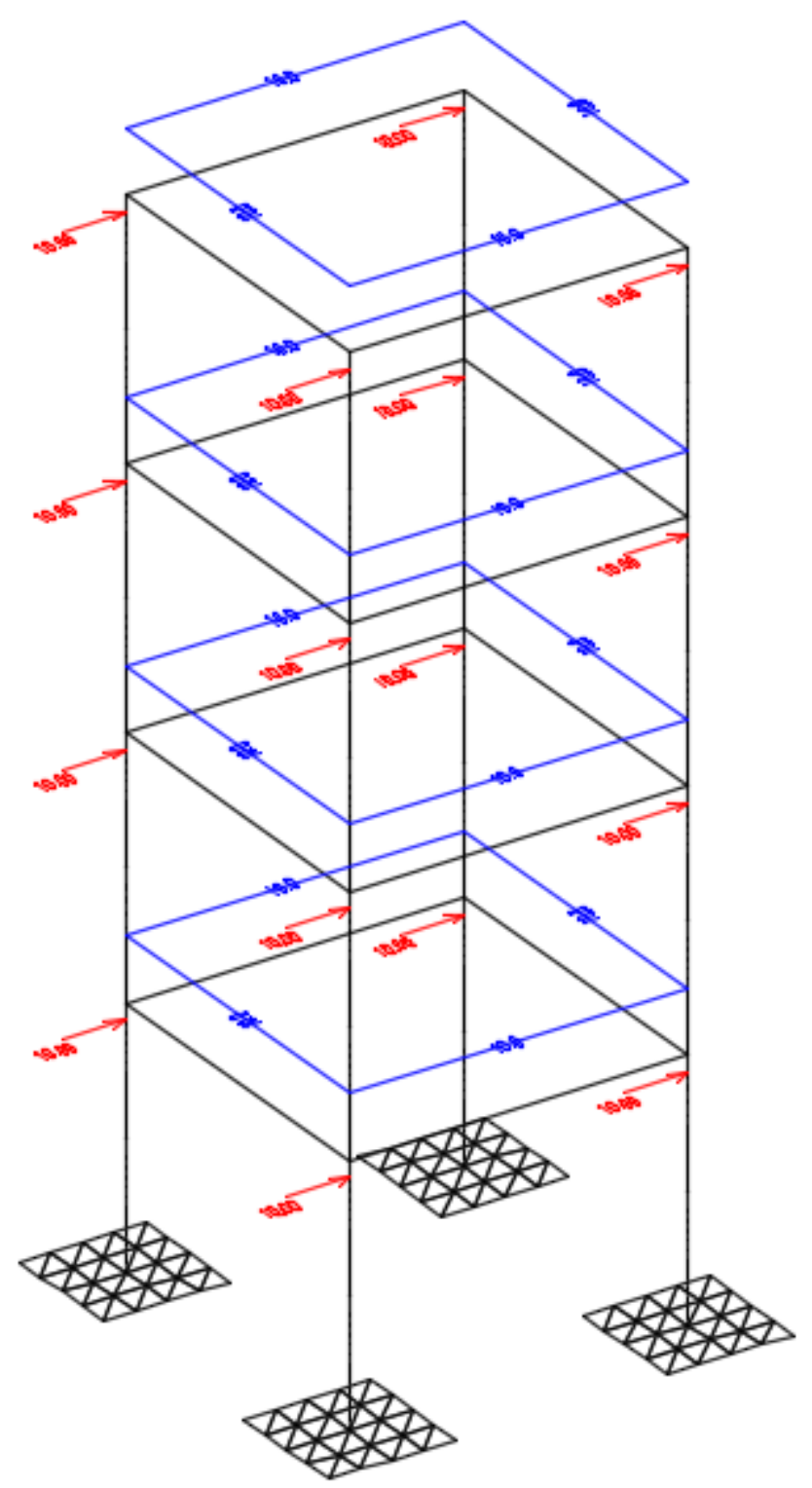

Figura 25 - Modelo do edifício gerado (Fonte: Autor)

Os resultados obtidos são referentes a um edifício de 4 andares, com variações apenas na rigidez do solo, sendo médias iguais a $K_{\text {solo }}=1000 \mathrm{kN} / \mathrm{m}^{3}$ e desvios padrão de $500 \mathrm{kN} / \mathrm{m}^{3}$, em cada elemento de fundação. Os valores iniciais estimados não tiveram nenhuma referência específica, valor que pode representar um solo com SPT em torno de 2. Foram aplicados carregamentos de $10 \mathrm{kN} / \mathrm{m}$ em todas as vigas e cargas resultantes de vento de $40 \mathrm{kN}$ em cada pavimento de valores nao de projeto.

Nessa simulação, definiram-se 2 possibilidades de falha: $P_{f, 1}$ referente ao recalque total limite de $3 \mathrm{~cm}$ para qualquer elemento de fundação (nó central de cada sapata), $P_{f, 2}$ referente ao recalque diferencial limite de $2,5 \mathrm{~cm}$ entre quaisquer sapatas (comparações entre os nós centrais de cada sapata). Os resultados atingidos dizem 
respeito ao número de 500 simulações $(n s)$, onde o número de falhas ocorridas foram de 69 e $63(n f)$ para cada probabilidade de falha respectivamente, com intervalo de $95 \%$ de confiança, e por fim os valores de $P_{f, 1}=1,38 \times 10^{-1} \pm 3,03 \times 10^{-2}$ e $P_{f, 2}=$ $1,26 \times 10^{-1} \pm 2,91 \times 10^{-2}$.

Como a rigidez adotada ao solo pode ser atribuída à um solo de SPT baixo, e as cargas horizontais relativamente altas, era de se esperar uma probabilidade de falha elevada. Esta simulação demorou cerca de 4 horas.

\subsection{Edifício 9 elementos de fundação direta via método MCS com 19 variáveis aleatórias}

Neste exemplo foram feitos 2 casos em que são consideradas as variações nos coeficientes das cargas de vento, que são calculadas pela rotina de confiabilidade segundo a NBR6123, com os parâmetros de variação baseando-se no JCSS (2001) compatibilizando com os métodos de cálculo da norma mencionada.

Os resultados obtidos nesse modelo foram relativos à uma edificação de pavimentos tipo quadrados de 6x6 m com 9 elementos de fundação direta de 2,0x2,0 $\mathrm{m}$, edifício de 10 andares, com vigas $20 \times 30 \mathrm{~cm}$ e pilares de $60 \times 120 \mathrm{~cm}$. Ao edifício é atribuído o nome TIPO-A, conforme modelo em EF na Figura 26. 


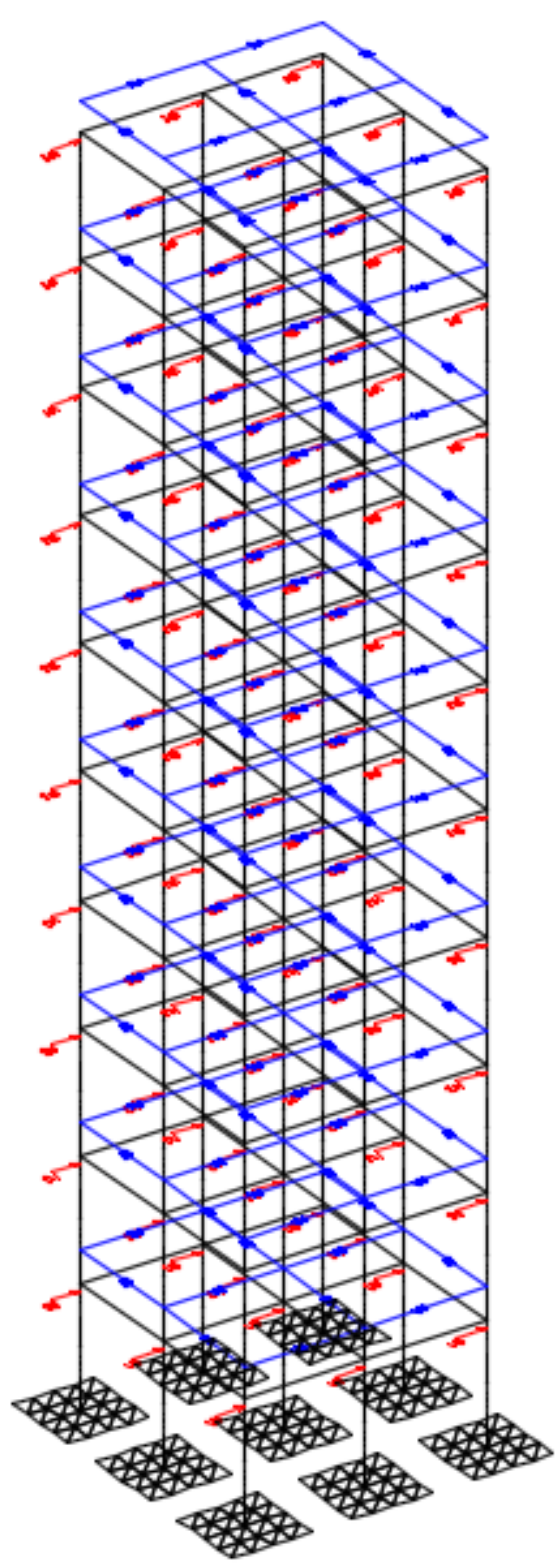

Figura 26 - Modelo do edifício TIPO-A gerado (Fonte: Autor)

Lembrando-se de que os valores do vento variam para cada iteração, e para os valores da rigidez do solo foi adotada distribuição normal e dos fatores do vento lognormal.

Com isso, para calcular os esforços do vento, temos a entrada da velocidade básica, fator $S_{1}$ e fator $S_{2}$, de maneira que estamos fazendo uma análise estatística, não foi inserido o valor de $S_{3}$ por se tratar de um coeficiente relativo a fatores estatísticos. Relativo ao fator $S_{2}$ adotou-se um para cada andar já que dependem da altura que devem ser inseridos com as devidas medias e desvios padrão, portanto eles vão variar independentemente para cada andar. 
As simulações foram feitas considerando $V_{0}=45 \mathrm{~m} / \mathrm{s}$ (variação $30 \%$ ), $S_{1}=1$ (variação 20\%) e o $S_{2}$ classe B categoria IV (variação 20\%). A primeira simulação o solo com o coeficiente de reação vertical $K_{\text {solo }}=3000 \mathrm{kN} / \mathrm{m}^{3}$, para cada sapata (variação de $50 \%$ ). Já na segunda simulação, o solo com $K_{\text {solo }}=5000 \mathrm{kN} / \mathrm{m}^{3}$ para cada sapata (variação de 50\%).

Foram 100 simulações, com $P_{f}$ de recalque total $P_{f, 1}=1,50 \times 10^{-1} \pm$ $7,03 \times 10^{-2}, \quad P_{f}$ de recalque diferencial $P_{f, 2}=9,00 \times 10^{-2} \pm 5,64 \times 10^{-2}$. Estas simulações demoraram em torno de 13 horas cada.

Para a segunda simulação, foram obtidos resultados equivalentes para as probabilidades de falha, de modo que $P_{f, 1}=P_{f, 2}=1,00 \times 10^{-2} \pm 1,96 \times 10^{-2}$.

Considerando que o primeiro valor de rigidez adotado poderia ser atribuído a um SPT de 2 e o segundo para um SPT de 5 (ambos para solos arenosos) era de se esperar que as probabilidades de falha relativas ao recalque fossem maiores no solo com a menor rigidez.

\subsection{Edifício com 9 elementos de fundação direta via método MCS e 38 variáveis aleatórias}

No exemplo elaborado, é aplicado o método MCS utilizando 38 variáveis aleatórias e 1000 simulações.

Foi adotado um edifício hipotético de 8 pavimentos $6 \times 6$ com fundação em sapatas com dimensões $2 \times 2 \times 1 \mathrm{~m}$, vigas $20 \times 55 \mathrm{~cm}$, pilares de $70 \times 20 \mathrm{~cm}$, concreto $\mathrm{C} 25$ para toda a estrutura. $O$ vento está atuando na direção $X$ conforme o eixo coordenado na Figura 27 com os respectivos parâmetros de acordo com a NBR 6123, para região de São Paulo capital. Ao edifício foi atribuído o nome TIPO-B, cujo qual é apresentado na Figura 27. 

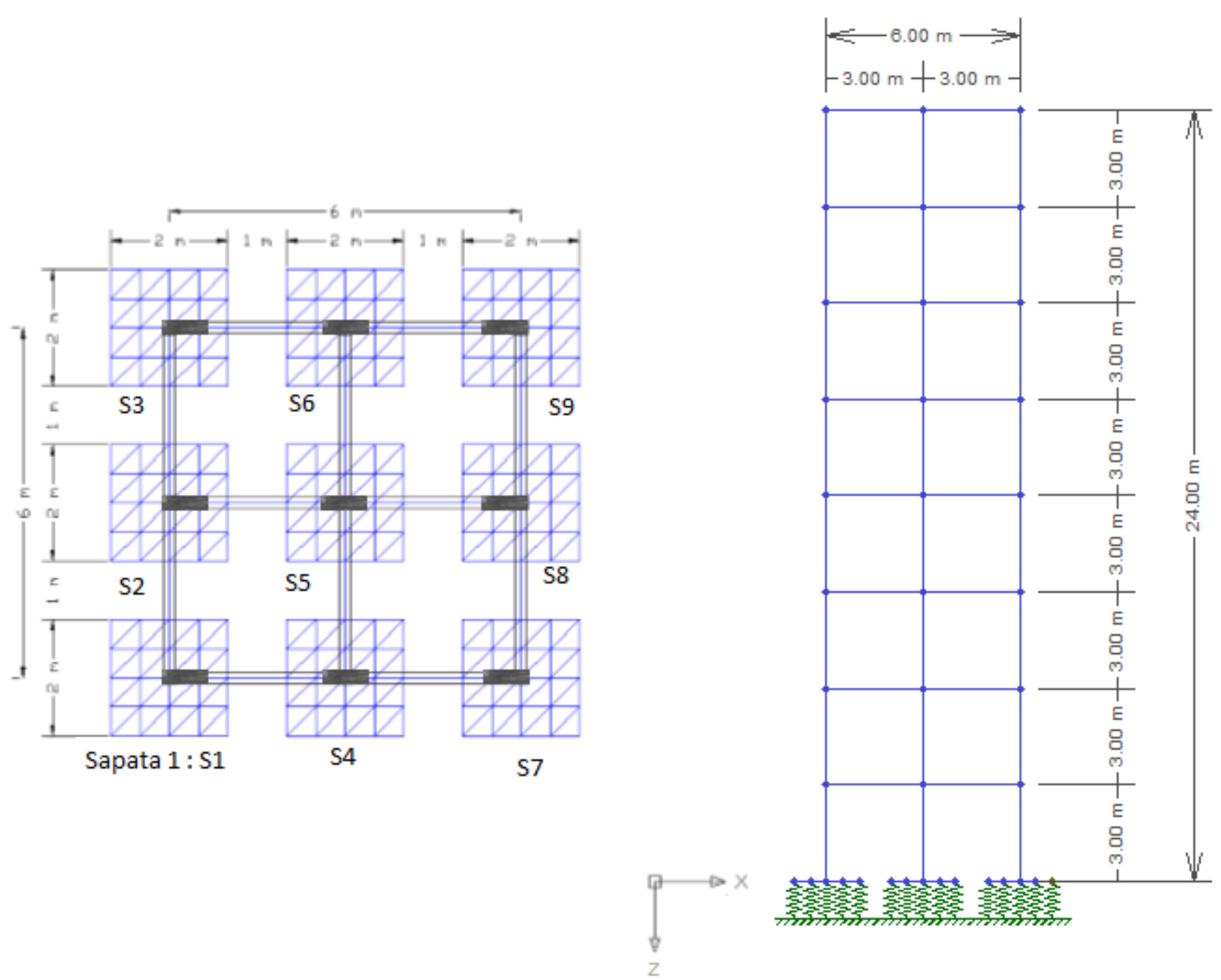

Figura 27 - Planta do edifício TIPO-B à esquerda e seção transversal no plano ZX à direita. (Fonte: Autor)

O estudo a seguir contempla a análise do recalque diferencial entre as estruturas de fundação direta, com a interação solo estrutura pelo modelo de Winkler, sendo adotado, a título de estudo, solo arenoso com uma rigidez de $K_{\text {solo }}=$ $3000 \mathrm{kN} / \mathrm{m}^{3}$, suposto para uma faixa de SPT entre 2 e 5 de acordo com a literatura, para todas a sapatas.

Tabela 20 - Variáveis aleatórias aplicadas na simulação

\begin{tabular}{cccccccc}
\hline Var. & Símbolo & Atribuição & $\begin{array}{c}\text { Tipo de } \\
\text { Distribuição }\end{array}$ & Unid. & Média & $\begin{array}{c}\text { Taxa de } \\
\text { Variação }\end{array}$ & $\begin{array}{c}\text { Desv. } \\
\text { Pad. }\end{array}$ \\
\hline 1 & $V_{0}$ & $\begin{array}{c}\text { Velocidade } \\
\text { básica }\end{array}$ & Lognormal & $m / s$ & 45 & 0,15 & 6,75 \\
2 & $C_{P}$ & $\begin{array}{c}\text { Coef. pressão } \\
2\end{array}$ & Normal & adim. & 1,4 & 0,15 & 0,21
\end{tabular}




\begin{tabular}{|c|c|c|c|c|c|c|c|}
\hline Var. & Símbolo & Atribuição & $\begin{array}{c}\text { Tipo de } \\
\text { Distribuição }\end{array}$ & Unid. & Média & $\begin{array}{l}\text { Taxa de } \\
\text { Variação }\end{array}$ & $\begin{array}{c}\text { Desv. } \\
\text { Pad. }\end{array}$ \\
\hline 3 & $S_{1}$ & Fator $S_{1}$ & Normal & adim. & 1 & 0,15 & 0,15 \\
\hline 4 & $S_{2,1}$ & $\begin{array}{c}\text { Fator } S_{2} \text { do } 1^{\circ} \\
\text { andar }\end{array}$ & Normal & adim. & 0,72 & 0,15 & 0,11 \\
\hline 5 & $S_{2,2}$ & $\begin{array}{c}\text { Fator } S_{2} \text { do } 2^{\circ} \\
\text { andar }\end{array}$ & Normal & adim. & 0,78 & 0,15 & 0,12 \\
\hline 6 & $S_{2,3}$ & $\begin{array}{c}\text { Fator } S_{2} \text { do } 3^{\circ} \\
\text { andar }\end{array}$ & Normal & adim. & 0,82 & 0,15 & 0,12 \\
\hline 7 & $S_{2,4}$ & $\begin{array}{c}\text { Fator } S_{2} \text { do } 4^{\circ} \\
\text { andar }\end{array}$ & Normal & adim. & 0,85 & 0,15 & 0,13 \\
\hline 8 & $S_{2,5}$ & $\begin{array}{c}\text { Fator } S_{2} \text { do } 5^{\circ} \\
\text { andar }\end{array}$ & Normal & adim. & 0,88 & 0,15 & 0,13 \\
\hline 9 & $S_{2,6}$ & $\begin{array}{c}\text { Fator } S_{2} \text { do } 6^{\circ} \\
\text { andar }\end{array}$ & Normal & adim. & 0,9 & 0,15 & 0,14 \\
\hline 10 & $S_{2,7}$ & $\begin{array}{c}\text { Fator } S_{2} \text { do } 7^{\circ} \\
\text { andar }\end{array}$ & Normal & adim. & 0,91 & 0,15 & 0,14 \\
\hline 11 & $S_{2,8}$ & $\begin{array}{c}\text { Fator } S_{2} \text { do } 8^{\circ} \\
\text { andar }\end{array}$ & Normal & adim. & 0,93 & 0,15 & 0,14 \\
\hline 12 & $\gamma_{c a, p}$ & $\begin{array}{l}\text { Peso esp. c.a. } \\
\text { do prédio }\end{array}$ & Normal & $\mathrm{kN} / \mathrm{m}^{3}$ & 25 & 0,03 & 0,75 \\
\hline 13 & $\gamma_{a l v}$ & $\begin{array}{l}\text { Peso esp. } \\
\text { alvenaria }\end{array}$ & Normal & $k N / m^{3}$ & 13 & 0,05 & 0,65 \\
\hline 14 & $\gamma_{c s}$ & $\begin{array}{l}\text { Peso esp. } \\
\text { regularização }\end{array}$ & Normal & $\mathrm{kN} / \mathrm{m}^{3}$ & 21 & 0,03 & 0,63 \\
\hline 15 & $\gamma_{p i s o}$ & Peso esp. piso & Normal & $k N / m^{3}$ & 28 & 0,05 & 1,4 \\
\hline 16 & $\gamma_{\text {gesso }}$ & $\begin{array}{l}\text { Peso esp. } \\
\text { gesso }\end{array}$ & Normal & $k N / m^{3}$ & 12,5 & 0,05 & 0,625 \\
\hline 17 & $h_{\text {laje }}$ & Altura da laje & Normal & $m$ & 0,1 & 0,025 & 0,0025 \\
\hline 18 & $h_{r}$ & $\begin{array}{c}\text { Altura da } \\
\text { camada de reg. }\end{array}$ & Normal & $m$ & 0,02 & 0,025 & 0,0005 \\
\hline 19 & $h_{\text {piso }}$ & Altura do piso & Normal & $m$ & 0,02 & 0,025 & 0,0005 \\
\hline
\end{tabular}




\begin{tabular}{|c|c|c|c|c|c|c|c|}
\hline Var. & Símbolo & Atribuição & $\begin{array}{c}\text { Tipo de } \\
\text { Distribuição }\end{array}$ & Unid. & Média & $\begin{array}{l}\text { Taxa de } \\
\text { Variação }\end{array}$ & $\begin{array}{c}\text { Desv. } \\
\text { Pad. }\end{array}$ \\
\hline 20 & $h_{\text {gesso }}$ & $\begin{array}{c}\text { Altura da } \\
\text { camada de } \\
\text { gesso }\end{array}$ & Normal & $m$ & 0,02 & 0,025 & 0,0005 \\
\hline 21 & $b_{\text {viga }}$ & $\begin{array}{l}\text { Dimensão b } \\
\text { das vigas }\end{array}$ & Normal & $m$ & 0,2 & 0,004 & 0,0008 \\
\hline 22 & $h_{v i g a}$ & $\begin{array}{l}\text { Dimensão h } \\
\text { das vigas }\end{array}$ & Normal & $m$ & 0,55 & 0,011 & 0,00605 \\
\hline 23 & $q_{s o b}$ & Carga acidental & Lognormal & $k N / m^{2}$ & 3 & 0,7 & 2,1 \\
\hline 24 & $f_{c k, p}$ & $\begin{array}{l}\text { Res. carac. do } \\
\text { c.a. do prédio }\end{array}$ & Lognormal & $M P a$ & 25 & 0,17 & 4,25 \\
\hline 25 & $b_{\text {pilar }}$ & $\begin{array}{l}\text { Dimensão b } \\
\text { dos pilares }\end{array}$ & Normal & $m$ & 0,7 & 0,014 & 0,0098 \\
\hline 26 & $h_{\text {pilar }}$ & $\begin{array}{l}\text { Dimensão } \mathrm{h} \\
\text { dos pilares }\end{array}$ & Normal & $m$ & 0,2 & 0,004 & 0,0008 \\
\hline 27 & $\gamma_{c a, s}$ & $\begin{array}{l}\text { Peso esp. c.a. } \\
\text { da sapata }\end{array}$ & Normal & $k N / m^{3}$ & 25 & 0,03 & 0,75 \\
\hline 28 & $f_{c k, p}$ & $\begin{array}{l}\text { Res. carac. do } \\
\text { c.a. das } \\
\text { sapatas }\end{array}$ & Lognormal & $M P a$ & 25 & 0,17 & 4,25 \\
\hline 29 & $k_{1}$ & $\begin{array}{l}\text { Rigidez do solo } \\
\text { na sapata } 1\end{array}$ & Lognormal & $k N / m^{3}$ & 3000 & 0,6 & 1800 \\
\hline 30 & $k_{2}$ & $\begin{array}{l}\text { Rigidez do solo } \\
\text { na sapata } 2\end{array}$ & Lognormal & $k N / m^{3}$ & 3000 & 0,6 & 1800 \\
\hline 31 & $k_{3}$ & $\begin{array}{c}\text { Rigidez do solo } \\
\text { na sapata } 3\end{array}$ & Lognormal & $k N / m^{3}$ & 3000 & 0,6 & 1800 \\
\hline 32 & $k_{4}$ & $\begin{array}{l}\text { Rigidez do solo } \\
\text { na sapata } 4\end{array}$ & Lognormal & $k N / m^{3}$ & 3000 & 0,6 & 1800 \\
\hline 33 & $k_{5}$ & $\begin{array}{l}\text { Rigidez do solo } \\
\text { na sapata } 5\end{array}$ & Lognormal & $k N / m^{3}$ & 3000 & 0,6 & 1800 \\
\hline 34 & $k_{6}$ & $\begin{array}{l}\text { Rigidez do solo } \\
\text { na sapata } 6\end{array}$ & Lognormal & $k N / m^{3}$ & 3000 & 0,6 & 1800 \\
\hline
\end{tabular}




\begin{tabular}{|c|c|c|c|c|c|c|c|}
\hline Var. & Símbolo & Atribuição & $\begin{array}{c}\text { Tipo de } \\
\text { Distribuição }\end{array}$ & Unid. & Média & $\begin{array}{l}\text { Taxa de } \\
\text { Variação }\end{array}$ & $\begin{array}{l}\text { Desv. } \\
\text { Pad. }\end{array}$ \\
\hline 35 & $k_{7}$ & $\begin{array}{l}\text { Rigidez do solo } \\
\text { na sapata } 7\end{array}$ & Lognormal & $k N / m^{3}$ & 3000 & 0,6 & 1800 \\
\hline 36 & $k_{8}$ & $\begin{array}{c}\text { Rigidez do solo } \\
\text { na sapata } 8\end{array}$ & Lognormal & $k N / m^{3}$ & 3000 & 0,6 & 1800 \\
\hline 37 & $k_{9}$ & $\begin{array}{l}\text { Rigidez do solo } \\
\text { na sapata } 9\end{array}$ & Lognormal & $k N / m^{3}$ & 3000 & 0,6 & 1800 \\
\hline 38 & $\theta_{s}$ & $\begin{array}{l}\text { Fator de erro } \\
\text { para recalque }\end{array}$ & Normal & adim. & 1 & 0,25 & 0,25 \\
\hline
\end{tabular}

A análise trivial para o recalque diferencial do edifício geralmente é efetuada com os esforços característicos atuantes. Esses valores são obtidos executando o programa de EF com as médias apresentadas na tabela, que são valores correntes em projetos de edifícios, de acordo com as normas brasileiras. Na Tabela 21 apresentam-se os deslocamentos nos nós centrais das sapatas.

\begin{tabular}{ccc} 
Tabela $21-$ Resultados de recalques obtidos pelo \\
\cline { 2 - 3 } Coord. X & Coord. Y & $d_{z}(\mathrm{~mm})$ \\
\hline 0,0 & 0,0 & 15,11 \\
0,0 & 3,0 & 17,78 \\
0,0 & 6,0 & 15,00 \\
3,0 & 0,0 & 20,96 \\
3,0 & 3,0 & 24,26 \\
3,0 & 6,0 & 20,92 \\
6,0 & 0,0 & 22,59 \\
6,0 & 3,0 & 25,33 \\
6,0 & 6,0 & 22,57 \\
\hline
\end{tabular}

De acordo com os resultados obtidos, o maior valor de recalque diferencial obtido é de $\delta=10,33 \mathrm{~mm}$, portanto está dentro do limite apresentado anteriormente para solos arenosos de $\delta_{\text {máx }}=25 \mathrm{~mm}$. 
Após o estudo trivial, será apresentada a análise com a aplicação da rotina de confiabilidade com base no método MCS, e para tal determina-se uma equação de estado limite:

$$
g(\mathbf{x})=\min \left[\delta_{\text {máx }}-\theta_{s} \delta_{i}\right]
$$

Dessa maneira, verifica-se para cada ponto de $\mathbf{x}$ se ocorre em pelo menos algum par de sapatas um recalque diferencial maior que $\delta_{\text {máx }}$ determinado. Nota-se que há um coeficiente $\theta_{s}$ presente na Equação 63, que se trata do coeficiente de incertezas de modelagem para recalque apresentado previamente na tabela 19, recomendado pela JCSS (2001) para que seja inserido variações físicas presentes no modelo de EF em comparação ao comportamento estrutural real. Como $\delta_{\text {máx }}$ é um valor determinístico independente do modelo de cálculo, permanece constante.

Para o estudo de confiabilidade, determinou-se um valor $n s=1.000$, isto é, a rotina inicia-se e o programa para cálculo de edifícios é executado 1.000 vezes e assim são trabalhados os resultados obtidos de cada simulação para o cálculo da $P_{f}$. Finalmente, o resultado obtido para 1000 simulações, considerando um intervalo de confiança de $95 \%$, é de $P_{f}=1,46 \times 10^{-1} \pm 2,19 \times 10^{-2}$. Esta simulação demorou em torno de 31 horas.

Tendo em vista a resposta da análise trivial dentro do limite, a probabilidade de falha é relativamente alta, o que será discutido a frente.

\subsection{Edifício com 9 elementos de fundação direta avaliado pelo FOSM e 38 variáveis aleatórias}

Neste caso, foi feita a análise utilizando o método FOSM aplicado no mesmo exemplo anterior. Outra questão na aplicação deste método, é que a análise é feita apenas para o recalque diferencial $\delta_{\text {nós }}$ entre os centros das sapatas S2 e S8, vide Figura 27, ou seja, entre os nós de coordenadas $(0 ; 3)$ e $(6 ; 3)$, com a equação semelhante ao método anterior, porém considerando-se apenas a diferença entre esses dois nós:

$$
g(\mathbf{x})=\delta_{\text {máx }}-\theta_{s} \delta_{\text {nós }}
$$


Com a aplicação do método, além da probabilidade de falha, é possível extrair o fator de importância de cada variável, uma das vantagens do método, de modo a mensurar o quanto cada variável influencia nos resultados da função de estado limite. Nesse caso, na Tabela 22 foram obtidos os valores de importância.

Tabela 22 - Fatores de importância obtidos

\begin{tabular}{|c|c|c|c|}
\hline Var. & Símbolo & Atribuição & Fator de Importância Resultante \\
\hline 1 & $V_{0}$ & Velocidade básica & $-0,3459$ \\
\hline 2 & $C_{P}$ & Coef. pressão & $-0,2018$ \\
\hline 3 & $S_{1}$ & Fator $S_{1}$ & $-0,3459$ \\
\hline 4 & $S_{2,1}$ & Fator $S_{2}$ do $1^{\circ}$ andar & $-0,0865$ \\
\hline 5 & $S_{2,2}$ & Fator $S_{2}$ do $2^{\circ}$ andar & $-0,0769$ \\
\hline 6 & $S_{2,3}$ & Fator $S_{2}$ do $3^{\circ}$ andar & $-0,0576$ \\
\hline 7 & $S_{2,4}$ & Fator $S_{2}$ do $4^{\circ}$ andar & $-0,0576$ \\
\hline 8 & $S_{2,5}$ & Fator $S_{2}$ do $5^{\circ}$ andar & $-0,0384$ \\
\hline 9 & $S_{2,6}$ & Fator $S_{2}$ do $6^{\circ}$ andar & $-0,0384$ \\
\hline 10 & $S_{2,7}$ & Fator $S_{2}$ do $7^{\circ}$ andar & $-0,0192$ \\
\hline 11 & $S_{2,8}$ & Fator $S_{2}$ do $8^{\circ}$ andar & 0,0000 \\
\hline 12 & $\gamma_{c a, p}$ & Peso esp. c.a. do prédio & 0,0000 \\
\hline 13 & $\gamma_{a l v}$ & Peso esp. alvenaria & 0,0000 \\
\hline 14 & $\gamma_{c S}$ & Peso esp. regularização & 0,0000 \\
\hline 15 & $\gamma_{\text {piso }}$ & Peso esp. piso & 0,0000 \\
\hline 16 & $\gamma_{\text {gesso }}$ & Peso esp. gesso & 0,0000 \\
\hline 17 & $h_{\text {laje }}$ & Altura da laje & 0,0000 \\
\hline 18 & $h_{r}$ & Altura da camada de reg. & 0,0000 \\
\hline 19 & $h_{\text {piso }}$ & Altura do piso & 0,0000 \\
\hline 20 & $h_{\text {gesso }}$ & Altura da camada de gesso & 0,0000 \\
\hline 21 & $b_{\text {viga }}$ & Dimensão b das vigas & 0,0000 \\
\hline 22 & $h_{\text {viga }}$ & Dimensão h das vigas & 0,0000 \\
\hline 23 & $q_{s o b}$ & Carga acidental & $-0,0096$ \\
\hline 24 & $f_{c k, p}$ & Res. carac. do c.a. do prédio & 0,0000 \\
\hline 25 & $b_{\text {pilar }}$ & Dimensão b dos pilares & 0,0000 \\
\hline
\end{tabular}




\begin{tabular}{cccc}
\hline Var. & Símbolo & Atribuição & Fator de Importância Resultante \\
\hline 26 & $h_{\text {pilar }}$ & Dimensão h dos pilares & 0,0000 \\
27 & $\gamma_{c a, s}$ & Peso esp. c.a. da sapata & 0,0000 \\
28 & $f_{c k, s}$ & Res. carac. do c.a. das sapatas & 0,0000 \\
29 & $k_{1}$ & Rigidez do solo na sapata 1 & $-0,0192$ \\
30 & $k_{2}$ & Rigidez do solo na sapata 2 & $-0,4323$ \\
31 & $k_{3}$ & Rigidez do solo na sapata 3 & $-0,1825$ \\
32 & $k_{4}$ & Rigidez do solo na sapata 4 & $-0,0288$ \\
33 & $k_{5}$ & Rigidez do solo na sapata 5 & $-0,0288$ \\
34 & $k_{6}$ & Rigidez do solo na sapata 6 & 0,0096 \\
35 & $k_{7}$ & Rigidez do solo na sapata 7 & 0,2786 \\
36 & $k_{8}$ & Rigidez do solo na sapata 8 & 0,5572 \\
37 & $k_{9}$ & Rigidez do solo na sapata 9 & 0,2306 \\
38 & $\theta_{s}$ & Fator de erro para recalque & $-0,1813$ \\
\hline
\end{tabular}

Por fim, tem-se o valor resultante para o índice de confiabilidade $\beta=1,68$ o que representa aproximadamente uma probabilidade de falha $P_{f}=4,65 \times 10^{-2}$. Esta simulação demorou cerca de 1 hora e 30 minutos.

Com os resultados dessa simulação observou-se que, para o fenômeno estudado do recalque diferencial, algumas variáveis não possuem uma relevância expressiva. Sendo assim, a próxima análise eliminou algumas, de modo a se realizar uma análise com 22 variáveis aleatórias.

\subsection{Edifício com 9 elementos de fundação direta avaliado pelo FOSM e 22 variáveis aleatórias}

Como dito anteriormente, a análise a seguir trata-se de uma simulação do método FOSM aplicado no mesmo edifício prévio com 22 variáveis aleatórias, com os fatores variantes da carga acidental e da rigidez do solo diminuídos, e os demais iguais aos do exemplo precedente. Seguem os fatores de variação, indicados na Tabela 23. 
Tabela 23 - Variáveis aleatórias aplicadas na simulação

\begin{tabular}{|c|c|c|c|c|c|c|}
\hline Var. & Símbolo & Atribuição & Unid. & Média & $\begin{array}{l}\text { Taxa de } \\
\text { Variação }\end{array}$ & $\begin{array}{l}\text { Desv. } \\
\text { Pad. }\end{array}$ \\
\hline 1 & $V_{0}$ & Velocidade básica & $m / s$ & 45 & 0,15 & 6,75 \\
\hline 2 & $C_{P}$ & Coef. pressão & adim. & 1,4 & 0,15 & 0,21 \\
\hline 3 & $S_{1}$ & Fator $S_{1}$ & adim. & 1 & 0,15 & 0,15 \\
\hline 4 & $S_{2,1}$ & Fator $S_{2}$ do $1^{\circ}$ andar & adim. & 0,72 & 0,15 & 0,11 \\
\hline 5 & $S_{2,2}$ & Fator $S_{2}$ do $2^{\circ}$ andar & adim. & 0,78 & 0,15 & 0,12 \\
\hline 6 & $S_{2,3}$ & Fator $S_{2}$ do $3^{\circ}$ andar & adim. & 0,82 & 0,15 & 0,12 \\
\hline 7 & $S_{2,4}$ & Fator $S_{2}$ do $4^{\circ}$ andar & adim. & 0,85 & 0,15 & 0,13 \\
\hline 8 & $S_{2,5}$ & Fator $S_{2}$ do $5^{\circ}$ andar & adim. & 0,88 & 0,15 & 0,13 \\
\hline 9 & $S_{2,6}$ & Fator $S_{2}$ do $6^{\circ}$ andar & adim. & 0,9 & 0,15 & 0,14 \\
\hline 10 & $S_{2,7}$ & Fator $S_{2}$ do $7^{\circ}$ andar & adim. & 0,91 & 0,15 & 0,14 \\
\hline 11 & $S_{2,8}$ & Fator $S_{2}$ do $8^{\circ}$ andar & adim. & 0,93 & 0,15 & 0,14 \\
\hline 12 & $q_{s o b}$ & Carga acidental & $k N / m^{2}$ & 3 & 0,3 & 2,1 \\
\hline 13 & $k_{1}$ & Rigidez do solo na sapata 1 & $k N / m^{3}$ & 3000 & 0,3 & 900 \\
\hline 14 & $k_{2}$ & Rigidez do solo na sapata 2 & $k N / m^{3}$ & 3000 & 0,3 & 900 \\
\hline 15 & $k_{3}$ & Rigidez do solo na sapata 3 & $k N / m^{3}$ & 3000 & 0,3 & 900 \\
\hline 16 & $k_{4}$ & Rigidez do solo na sapata 4 & $k N / m^{3}$ & 3000 & 0,3 & 900 \\
\hline 17 & $k_{5}$ & Rigidez do solo na sapata 5 & $k N / m^{3}$ & 3000 & 0,3 & 900 \\
\hline 18 & $k_{6}$ & Rigidez do solo na sapata 6 & $k N / m^{3}$ & 3000 & 0,3 & 900 \\
\hline 19 & $k_{7}$ & Rigidez do solo na sapata 7 & $k N / m^{3}$ & 3000 & 0,3 & 900 \\
\hline 20 & $k_{8}$ & Rigidez do solo na sapata 8 & $k N / m^{3}$ & 3000 & 0,3 & 900 \\
\hline 21 & $k_{9}$ & Rigidez do solo na sapata 9 & $k N / m^{3}$ & 3000 & 0,3 & 900 \\
\hline 22 & $\theta_{s}$ & Fator de erro para recalque & adim. & 1 & 0,25 & 0,25 \\
\hline
\end{tabular}

Para as variáveis apresentadas, apresentam-se Tabela 24 os seus fatores de importância:

Tabela 24 - Fatores de importância obtidos

\begin{tabular}{cccc}
\hline Var. & Símbolo & Atribuição & Fator de Importância Resultante \\
\hline 1 & $V_{0}$ & Velocidade básica & $-0,3459$ \\
2 & $C_{P}$ & Coef. pressão & $-0,2018$
\end{tabular}




\begin{tabular}{|c|c|c|c|}
\hline Var. & Símbolo & Atribuição & Fator de Importância Resultante \\
\hline 3 & $S_{1}$ & Fator $S_{1}$ & $-0,3459$ \\
\hline 4 & $S_{2,1}$ & Fator $S_{2}$ do $1^{\circ}$ andar & $-0,0865$ \\
\hline 5 & $S_{2,2}$ & Fator $S_{2}$ do $2^{\circ}$ andar & $-0,0769$ \\
\hline 6 & $S_{2,3}$ & Fator $S_{2}$ do $3^{\circ}$ andar & $-0,0576$ \\
\hline 7 & $S_{2,4}$ & Fator $S_{2}$ do $4^{\circ}$ andar & $-0,0576$ \\
\hline 8 & $S_{2,5}$ & Fator $S_{2}$ do $5^{\circ}$ andar & $-0,0384$ \\
\hline 9 & $S_{2,6}$ & Fator $S_{2}$ do $6^{\circ}$ andar & $-0,0384$ \\
\hline 10 & $S_{2,7}$ & Fator $S_{2}$ do $7^{\circ}$ andar & $-0,0192$ \\
\hline 11 & $S_{2,8}$ & Fator $S_{2}$ do $8^{\circ}$ andar & 0 \\
\hline 12 & $q_{s o b}$ & Carga acidental & $-0,0096$ \\
\hline 13 & $k_{1}$ & Rigidez do solo na sapata 1 & $-0,0192$ \\
\hline 14 & $k_{2}$ & Rigidez do solo na sapata 2 & $-0,4323$ \\
\hline 15 & $k_{3}$ & Rigidez do solo na sapata 3 & $-0,1825$ \\
\hline 16 & $k_{4}$ & Rigidez do solo na sapata 4 & $-0,0288$ \\
\hline 17 & $k_{5}$ & Rigidez do solo na sapata 5 & $-0,0288$ \\
\hline 18 & $k_{6}$ & Rigidez do solo na sapata 6 & 0,0096 \\
\hline 19 & $k_{7}$ & Rigidez do solo na sapata 7 & 0,2786 \\
\hline 20 & $k_{8}$ & Rigidez do solo na sapata 8 & 0,5572 \\
\hline 21 & $k_{9}$ & Rigidez do solo na sapata 9 & 0,2306 \\
\hline 22 & $\theta_{s}$ & Fator de erro para recalque & $-0,1813$ \\
\hline
\end{tabular}

É possível também extrair os valores das variáveis no ponto de projeto, indicados na Tabela 25.

Tabela 25 - Valores das variáveis no ponto de projeto

\begin{tabular}{ccccc}
\hline Var. & Símbolo & Atribuição & Unid. & Valor no Ponto de Projeto \\
\hline 1 & $V_{0}$ & Velocidade básica & $\mathrm{m} / \mathrm{s}$ & 52,7 \\
2 & $C_{P}$ & Coef. pressão & adim. & 1,5 \\
3 & $S_{1}$ & Fator $S_{1}$ & adim. & 1,2 \\
4 & $S_{2,1}$ & Fator $S_{2}$ do 1ํandar & adim. & 0,8 \\
5 & $S_{2,2}$ & Fator $S_{2}$ do $2^{\circ}$ andar & adim. & 0,8
\end{tabular}




\begin{tabular}{|c|c|c|c|c|}
\hline Var. & Símbolo & Atribuição & Unid. & Valor no Ponto de Projeto \\
\hline 6 & $S_{2,3}$ & Fator $S_{2}$ do $3^{\circ}$ andar & adim. & 0,8 \\
\hline 7 & $S_{2,4}$ & Fator $S_{2}$ do $4^{\circ}$ andar & adim. & 0,8 \\
\hline 8 & $S_{2,5}$ & Fator $S_{2}$ do $5^{\circ}$ andar & adim. & 0,9 \\
\hline 9 & $S_{2,6}$ & Fator $S_{2}$ do $6^{\circ}$ andar & adim. & 0,9 \\
\hline 10 & $S_{2,7}$ & Fator $S_{2}$ do $7^{\circ}$ andar & adim. & 0,9 \\
\hline 11 & $S_{2,8}$ & Fator $S_{2}$ do $8^{\circ}$ andar & adim. & 0,9 \\
\hline 12 & $q_{s o b}$ & Carga acidental & $k N / m^{2}$ & 3 \\
\hline 13 & $k_{1}$ & Rigidez do solo na sapata 1 & $k N / m^{3}$ & 3029 \\
\hline 14 & $k_{2}$ & Rigidez do solo na sapata 2 & $k N / m^{3}$ & 3659 \\
\hline 15 & $k_{3}$ & Rigidez do solo na sapata 3 & $k N / m^{3}$ & 3286 \\
\hline 16 & $k_{4}$ & Rigidez do solo na sapata 4 & $k N / m^{3}$ & 3029 \\
\hline 17 & $k_{5}$ & Rigidez do solo na sapata 5 & $k N / m^{3}$ & 3029 \\
\hline 18 & $k_{6}$ & Rigidez do solo na sapata 6 & $k N / m^{3}$ & 3000 \\
\hline 19 & $k_{7}$ & Rigidez do solo na sapata 7 & $k N / m^{3}$ & 2571 \\
\hline 20 & $k_{8}$ & Rigidez do solo na sapata 8 & $k N / m^{3}$ & 2571 \\
\hline 21 & $k_{9}$ & Rigidez do solo na sapata 9 & $k N / m^{3}$ & 2656 \\
\hline 22 & $\theta_{s}$ & Fator de erro para recalque & adim. & 1,2 \\
\hline
\end{tabular}

Ao final, fora obtido o coeficiente de confiabilidade $\beta=2,36$ o que representa aproximadamente uma probabilidade de falha $P_{f}=9,10 \times 10^{-3}$. Esta simulação demorou cerca de 50 minutos.

\subsection{Edifício com 9 blocos de fundação com 4 estacas avaliado pelo FOSM e 22 variáveis aleatórias}

Com a rotina implementada no programa, procura-se estudar edifícios com fundações profundas, o que amplamente corrente em projetos tradicionais. Nesse caso, foi utilizado o modelo do item anterior, porém foram adotadas 4 estacas de diâmetro de $40 \mathrm{~cm}$ e $10 \mathrm{~m}$ de comprimento em cada sapata, de modo que as sapatas se comportem como um bloco de fundação e consequentemente foram adotados coeficientes de mola para as estacas indicadas na Tabela 26. 
Tabela 26 - Molas aplicadas nas estacas

\begin{tabular}{ccc}
\hline Profundidade $(\mathrm{m})$ & $\begin{array}{c}\text { Valores de K (kN/m) } \\
\text { Estacas } 1 \text { à } 24\end{array}$ & $\begin{array}{c}\text { Valores de K (kN/m) } \\
\text { Estacas } 25 \text { à } 32\end{array}$ \\
\hline 1 & 500 & 200 \\
2 & 500 & 200 \\
3 & 1000 & 200 \\
4 & 1000 & 500 \\
5 & 1500 & 500 \\
6 & 1500 & 500 \\
7 & 1500 & 500 \\
8 & 1500 & 1000 \\
9 & 2000 & 1000 \\
10 & 2000 & 1000 \\
\hline
\end{tabular}

Neste caso, adotou-se que as molas variavam por camadas, ou seja, como se a variação ocorresse em faixas de solo nas estacas em determinadas características, de modo que as variações de molas serão diferentes nas estacas 1 a 24 do que na de 25 a 36 de acordo com as posições indicadas na Figura 28. Portanto, as variáveis aleatórias são indicadas na Tabela 27.

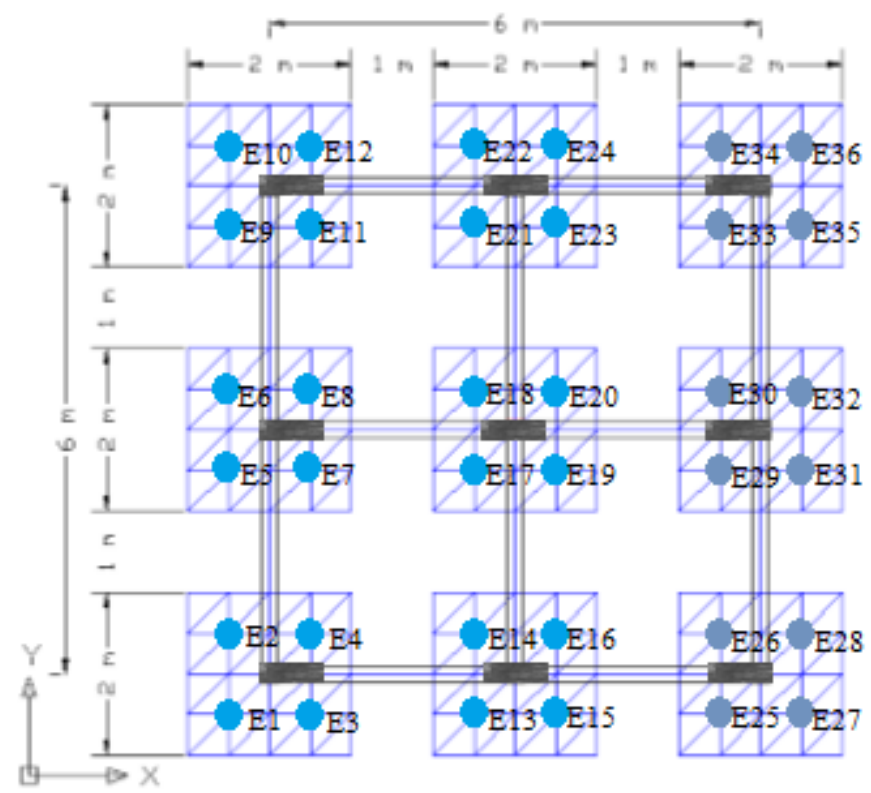

Figura 28 - Posições das estacas nos blocos, estacas azuis claro com a caracterização de molas distintas das azuis escuro. (Fonte: Autor) 
Tabela 27 - Variáveis aleatórias aplicadas na simulação

\begin{tabular}{|c|c|c|c|c|c|c|}
\hline Var. & Símbolo & Atribuição & Unid. & Média & $\begin{array}{l}\text { Taxa de } \\
\text { Variação }\end{array}$ & $\begin{array}{c}\text { Desv. } \\
\text { Pad. }\end{array}$ \\
\hline 1 & $V_{0}$ & Velocidade básica & $m / s$ & 45 & 0,15 & 6,75 \\
\hline 2 & $C_{P}$ & Coef. pressão & adim. & 1,4 & 0,15 & 0,21 \\
\hline 3 & $S_{1}$ & Fator $S_{1}$ & adim. & 1 & 0,15 & 0,15 \\
\hline 4 & $S_{2,1}$ & Fator $S_{2}$ do $1^{\circ}$ andar & adim. & 0,72 & 0,15 & 0,11 \\
\hline 5 & $S_{2,2}$ & Fator $S_{2}$ do $2^{\circ}$ andar & adim. & 0,78 & 0,15 & 0,12 \\
\hline 6 & $S_{2,3}$ & Fator $S_{2}$ do $3^{\circ}$ andar & adim. & 0,82 & 0,15 & 0,12 \\
\hline 7 & $S_{2,4}$ & Fator $S_{2}$ do $4^{\circ}$ andar & adim. & 0,85 & 0,15 & 0,13 \\
\hline 8 & $S_{2,5}$ & Fator $S_{2}$ do $5^{\circ}$ andar & adim. & 0,88 & 0,15 & 0,13 \\
\hline 9 & $S_{2,6}$ & Fator $S_{2}$ do $6^{\circ}$ andar & adim. & 0,9 & 0,15 & 0,14 \\
\hline 10 & $S_{2,7}$ & Fator $S_{2}$ do $7^{\circ}$ andar & adim. & 0,91 & 0,15 & 0,14 \\
\hline 11 & $S_{2,8}$ & Fator $S_{2}$ do $8^{\circ}$ andar & adim. & 0,93 & 0,15 & 0,14 \\
\hline 12 & $q_{s o b}$ & Carga acidental & $k N / m^{2}$ & 3 & 0,3 & 2,1 \\
\hline 13 & $k_{1}$ & Rig. solo 1 a 2 m est. 1 a 24 & $k N / m^{3}$ & 500 & 0,3 & 150 \\
\hline 14 & $k_{2}$ & Rig. solo 3 a $4 \mathrm{~m}$ est. 1 a 24 & $k N / m^{3}$ & 1000 & 0,3 & 300 \\
\hline 15 & $k_{3}$ & Rig. solo 5 a $8 m$ est. 1 a 24 & $k N / m^{3}$ & 1500 & 0,3 & 450 \\
\hline 16 & $k_{4}$ & Rig. solo 9 a $10 \mathrm{~m}$ est. 1 a 24 & $k N / m^{3}$ & 2000 & 0,3 & 600 \\
\hline 17 & $k_{5}$ & Rig. solo 1 a $3 m$ est. 25 a 32 & $k N / m^{3}$ & 200 & 0,3 & 60 \\
\hline 18 & $k_{6}$ & Rig. solo 4 a $7 m$ est. 25 a 32 & $k N / m^{3}$ & 500 & 0,3 & 150 \\
\hline 19 & $k_{7}$ & Rig. solo 8 a $10 \mathrm{~m}$ est. 25 a 32 & $k N / m^{3}$ & 1000 & 0,3 & 300 \\
\hline 20 & $\theta_{s}$ & Fator de erro para recalque & adim. & 1 & 0,25 & 0,25 \\
\hline
\end{tabular}

Com esses valores os coeficientes de importância obtidos foram:

Tabela 28 - Fatores de importância obtidos

\begin{tabular}{cccc}
\hline Var. & Símbolo & Atribuição & $\begin{array}{c}\text { Fator de Importância } \\
\text { Resultante }\end{array}$ \\
\hline 1 & $V_{0}$ & Velocidade básica & $-0,6216$ \\
2 & $C_{P}$ & Coef. pressão & $-0,3579$ \\
3 & $S_{1}$ & Fator $S_{1}$ & $-0,6216$
\end{tabular}




\begin{tabular}{|c|c|c|c|}
\hline Var. & Símbolo & Atribuição & $\begin{array}{c}\text { Fator de Importância } \\
\text { Resultante }\end{array}$ \\
\hline 4 & $S_{2,1}$ & Fator $S_{2}$ do $1^{\circ}$ andar & $-0,1360$ \\
\hline 5 & $S_{2,2}$ & Fator $S_{2}$ do $2^{\circ}$ andar & $-0,1298$ \\
\hline 6 & $S_{2,3}$ & Fator $S_{2}$ do $3^{\circ}$ andar & $-0,1026$ \\
\hline 7 & $S_{2,4}$ & Fator $S_{2}$ do $4^{\circ}$ andar & $-0,0942$ \\
\hline 8 & $S_{2,5}$ & Fator $S_{2}$ do $5^{\circ}$ andar & $-0,0670$ \\
\hline 9 & $S_{2,6}$ & Fator $S_{2}$ do $6^{\circ}$ andar & $-0,0607$ \\
\hline 10 & $S_{2,7}$ & Fator $S_{2}$ do $7^{\circ}$ andar & $-0,0335$ \\
\hline 11 & $S_{2,8}$ & Fator $S_{2}$ do $8^{\circ}$ andar & 0 \\
\hline 12 & $q_{s o b}$ & Carga acidental & $-0,0356$ \\
\hline 13 & $k_{1}$ & Rig. solo 1 a 2 m est. 1 a 24 & $-0,0209$ \\
\hline 14 & $k_{2}$ & Rig. solo 3 a 4 m est. 1 a 24 & $-0,0481$ \\
\hline 15 & $k_{3}$ & Rig. solo 5 a $8 m$ est. 1 a 24 & $-0,1423$ \\
\hline 16 & $k_{4}$ & Rig. solo 9 a $10 \mathrm{~m}$ est. 1 a 24 & $-0,0481$ \\
\hline 17 & $k_{5}$ & Rig. solo 1 a $3 m$ est. 25 a 32 & 0,0921 \\
\hline 18 & $k_{6}$ & Rig. solo 4 a $7 m$ est. 25 a 32 & 0 \\
\hline 19 & $k_{7}$ & $\begin{array}{l}\text { Rig. solo } 8 \text { a } 10 \mathrm{~m} \text { est. } 25 \text { a } \\
\qquad 32\end{array}$ & 0 \\
\hline 20 & $\theta_{s}$ & Fator de erro para recalque & 0 \\
\hline
\end{tabular}

Na Tabela 29 apresentam-se os valores de projeto.

Tabela 29 - Valore das variáveis no ponto de projeto

\begin{tabular}{ccccc}
\hline Var. & Símbolo & Atribuição & Unid. & $\begin{array}{c}\text { Valor no Ponto } \\
\text { de Projeto }\end{array}$ \\
\hline 1 & $V_{0}$ & Velocidade básica & $\mathrm{m} / \mathrm{s}$ & 52,1 \\
2 & $C_{P}$ & Coef. pressão & adim. & 1,5 \\
3 & $S_{1}$ & Fator $S_{1}$ & adim. & 1,2 \\
4 & $S_{2,1}$ & Fator $S_{2}$ do $1^{\circ}$ andar & adim. & 0,7 \\
5 & $S_{2,2}$ & Fator $S_{2}$ do $2^{\circ}$ andar & adim. & 0,8 \\
6 & $S_{2,3}$ & Fator $S_{2}$ do $3^{\circ}$ andar & adim. & 0,8 \\
7 & $S_{2,4}$ & Fator $S_{2}$ do $4^{\circ}$ andar & adim. & 0,9
\end{tabular}




\begin{tabular}{ccccc}
\hline Var. & Símbolo & Atribuição & Unid. & $\begin{array}{c}\text { Valor no Ponto } \\
\text { de Projeto }\end{array}$ \\
\hline 8 & $S_{2,5}$ & Fator $S_{2}$ do 5 andar & adim. & 0,9 \\
9 & $S_{2,6}$ & Fator $S_{2}$ do 60 andar & adim. & 0,9 \\
10 & $S_{2,7}$ & Fator $S_{2}$ do 70 andar & adim. & 0,9 \\
11 & $S_{2,8}$ & Fator $S_{2}$ do 8 andar & adim. & 0,9 \\
12 & $q_{s o b}$ & Carga acidental & $k N / m^{2}$ & 3,1 \\
13 & $k_{1}$ & Rig. solo 1 a 2m est. 1 a 24 & $k N / m^{3}$ & 505,3 \\
14 & $k_{2}$ & Rig. solo 3 a 4m est. 1 a 24 & $k N / m^{3}$ & 1024,5 \\
15 & $k_{3}$ & Rig. solo 5 a 8m est. 1 a 24 & $k N / m^{3}$ & 1608,5 \\
16 & $k_{4}$ & Rig. solo 9 a 10m est. 1 a 24 & $k N / m^{3}$ & 2024,5 \\
17 & $k_{5}$ & Rig. solo 1 a 3m est. 25 a 32 & $k N / m^{3}$ & 190,6 \\
18 & $k_{6}$ & Rig. solo 4 a 7m est. 25 a 32 & $k N / m^{3}$ & 500 \\
19 & $k_{7}$ & Rig. solo 8 a 10m est. 25 a & $k N / m^{3}$ & 100 \\
22 & $\theta_{s}$ & Fator de erro para recalque & $\mathrm{adim}$. & 1,0 \\
\hline
\end{tabular}

Ao final, fora obtido o coeficiente de confiabilidade $\beta=1,69$ o que representa aproximadamente uma probabilidade de falha $P_{f}=4,55 \times 10^{-2}$.

Com o resultado do modelo pela verificação tradicional, obteve-se um valor de recalque diferencial de $\delta \approx 2,20 \mathrm{~cm}$, portanto a estrutura estaria dentro dos limites estipulados pela norma e referências. Esta simulação demorou cerca de 2 horas de 30 minutos.

Ainda baseando-se no exemplo acima, é possível calcular um Fator de Segurança global $\left(F_{S}\right)$ para o edifício, em termos da verificação do recalque diferencial, relacionando-se coeficientes de variação e o $\beta$ anteriormente calculado. segundo Aoki (2014), esta relação é estabelecida conforme a seguinte equação:

$$
F_{S}=\frac{\left[1+\beta\left(V_{S}^{2}+V_{R}^{2}-\beta^{2} V_{S}^{2} V_{R}^{2}\right)^{0,5}\right]}{1-\beta^{2} V_{R}{ }^{2}}
$$

De modo que $V_{S}$ e $V_{R}$ correspondem aos coreficientes de variação da curva de solicitação e da curva de resistência, respectivamente. 
Nesse caso, as curvas podem ser obtidas através do MCS, para gerar e guardar os resultados, produzindo portanto, uma amostra para determinação dos parâmetros estatísticos refrentes às parcelas de resistência e de solicitação da equação de Estado Limite. Como a parcela de resistência da equação é um valor determinístico $\left(\delta_{\text {máx }}\right)$, o coeficiente de variação desta parcela é nulo. Foi gerada uma amostra de 100 valores, de modo que levou um tempo aproximado de 7 horas.

Com a amostra gerada, obtiveram-se os valores de média $\mu_{S}=1,78 \mathrm{~cm}$ e desvio padrão $\sigma_{S}=0,80 \mathrm{~cm}$, o que resulta no coeficiente de variação $V_{S}=0,45$ e por conseguinte, um Fator de Segurança de $F_{S}=1,76$, valor de acordo com recomendações da NBR6122 (2010).

\subsection{Verificação em Estado Limite Último dos Pilares do Edifício TIPO-B}

\subsubsection{Verificação global com modelo engastado}

$\mathrm{Na}$ seguinte verificação, analisa-se o dimensionamento da armadura dos pilares com seção 20x70 de acordo com os coeficientes parciais da NBR6118, de modo que a armadura calculada para os pilares resulta em 10 barras de $10 \mathrm{~mm}$.

Para a análise em confiabilidade, aplicou-se o método MCS, aliado ao programa de edifícios e subsequentemente aliado ao algoritmo de verificação de seções de concreto armado em flexo-compressão e não linearidade física (Pimenta, 2016). Como o algoritmo para a verificação da seção de concreto armado baseia-se na convergência numérica, é possível atribuir a condição de falha da estrutura na não convergência do algoritmo, portanto inviabilizando a aplicação do FOSM e justifica-se o MCS empregado.

Num primeiro momento, o edifício é estudado com a base engastada, conforme apresenta a Figura 29. As variáveis aleatórias utilizadas no modelo encontram-se na Tabela 30. 

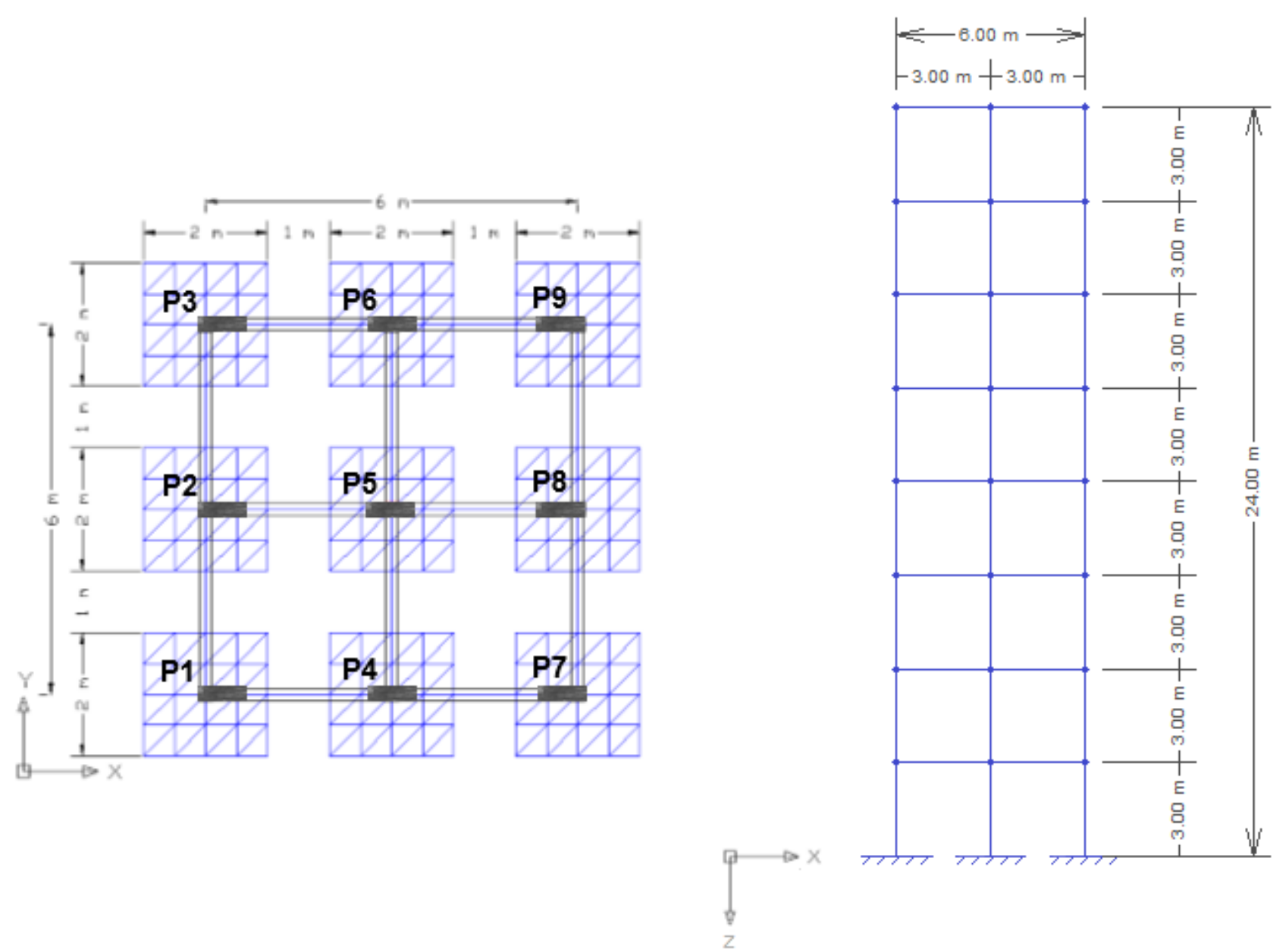

Figura 29 - Planta do edifício TIPO-B à esquerda e seção transversal no plano ZX à direita.

(Fonte: Autor)

Tabela 30 - Variáveis aleatórias aplicadas na simulação

\begin{tabular}{|c|c|c|c|c|c|c|c|}
\hline Var. & Símbolo & Atribuição & $\begin{array}{c}\text { Tipo de } \\
\text { Distribuição }\end{array}$ & Unid. & Média & $\begin{array}{l}\text { Taxa de } \\
\text { Variação }\end{array}$ & $\begin{array}{l}\text { Desv. } \\
\text { Pad. }\end{array}$ \\
\hline 1 & $V_{0}$ & Velocidade básica & Lognormal & $\mathrm{m} / \mathrm{s}$ & 45 & 0,15 & 6,75 \\
\hline 2 & $C_{P}$ & Coef. pressão & Normal & adim. & 1,4 & 0,15 & 0,21 \\
\hline 3 & $S_{1}$ & Fator $S_{1}$ & Normal & adim. & 1 & 0,15 & 0,15 \\
\hline 4 & $S_{2,1}$ & Fator $S_{2}$ do $1^{\circ}$ andar & Normal & adim. & 0,72 & 0,15 & 0,11 \\
\hline 5 & $S_{2,2}$ & Fator $S_{2}$ do $2^{\circ}$ andar & Normal & adim. & 0,78 & 0,15 & 0,12 \\
\hline 6 & $S_{2,3}$ & Fator $S_{2}$ do $3^{\circ}$ andar & Normal & adim. & 0,82 & 0,15 & 0,12 \\
\hline 7 & $S_{2,4}$ & Fator $S_{2}$ do $4^{\circ}$ andar & Normal & adim. & 0,85 & 0,15 & 0,13 \\
\hline 8 & $S_{2,5}$ & Fator $S_{2}$ do $5^{\circ}$ andar & Normal & adim. & 0,88 & 0,15 & 0,13 \\
\hline 9 & $S_{2,6}$ & Fator $S_{2}$ do $6^{\circ}$ andar & Normal & adim. & 0,9 & 0,15 & 0,14 \\
\hline 10 & $S_{2,7}$ & Fator $S_{2}$ do $7^{\circ}$ andar & Normal & adim. & 0,91 & 0,15 & 0,14 \\
\hline
\end{tabular}




\begin{tabular}{|c|c|c|c|c|c|c|c|}
\hline Var. & Símbolo & Atribuiçãa & $\begin{array}{c}\text { Tipo de } \\
\text { Distribuição }\end{array}$ & Unid. & Média & $\begin{array}{l}\text { Taxa de } \\
\text { Variação }\end{array}$ & $\begin{array}{l}\text { Desv. } \\
\text { Pad. }\end{array}$ \\
\hline 11 & $S_{2,8}$ & $\begin{array}{c}\text { Fator } S_{2} \text { do } 8^{\circ} \text { andar } \\
\text { Cargas }\end{array}$ & Normal & adim. & 0,93 & 0,15 & 0,14 \\
\hline 12 & $g_{p p, l}$ & $\begin{array}{c}\text { permanentes nas } \\
\text { vigas laterais } \\
\text { Cargas }\end{array}$ & Normal & $k N / m$ & 13,35 & 0,1 & 1,34 \\
\hline 13 & $g_{p p, m}$ & $\begin{array}{c}\text { permanentes nas } \\
\text { vigas centrais }\end{array}$ & Normal & $k N / m$ & 16,15 & 0,1 & 1,62 \\
\hline 14 & $g_{p p, p i l}$ & $\begin{array}{l}\text { Peso próprio do } \\
\text { pilar }\end{array}$ & Normal & $k N$ & 10,50 & 0,1 & 1,05 \\
\hline 15 & $q_{s o b}$ & Carga acidental & Lognormal & $k N / m^{2}$ & $3 \times 0,93$ & 0,2 & 0,56 \\
\hline 16 & $b_{\text {pilar }}$ & $\begin{array}{c}\text { Dimensão b dos } \\
\text { pilares }\end{array}$ & Normal & $m$ & 0,7 & 0,045 & 0,032 \\
\hline 17 & $h_{\text {pilar }}$ & $\begin{array}{l}\text { Dimensão h dos } \\
\text { pilares }\end{array}$ & Normal & $m$ & 0,2 & 0,06 & 0,012 \\
\hline 18 & $b_{\text {viga }}$ & $\begin{array}{c}\text { Dimensão b das } \\
\text { vigas }\end{array}$ & Normal & $m$ & 0,2 & 0,06 & 0,012 \\
\hline 19 & $h_{\text {viga }}$ & $\begin{array}{c}\text { Dimensão h das } \\
\text { vigas }\end{array}$ & Normal & $m$ & 0,55 & 0,045 & 0,025 \\
\hline 20 & $f_{c k, p}$ & $\begin{array}{l}\text { Res. carac. do c.a. } \\
\text { do prédio }\end{array}$ & Lognormal & $M P a$ & $25 \times 1,17$ & 0,05 & 1,46 \\
\hline 21 & $E_{S}$ & $\begin{array}{c}\text { Módulo de } \\
\text { elasticidade do aço }\end{array}$ & Lognormal & $G P a$ & $210 \times 1,08$ & 0,05 & 11,34 \\
\hline & & Tensão & & & & & \\
\hline 22 & $f_{y, k}$ & $\begin{array}{c}\text { característica de } \\
\text { escoamento } \\
\text { Coeficiente de }\end{array}$ & Lognormal & $M P a$ & $500 \times 1,08$ & 0,05 & 27 \\
\hline 23 & $\theta_{r}$ & $\begin{array}{l}\text { incerteza do modelo } \\
\text { de resistência } \\
\text { Coeficiente de }\end{array}$ & Lognormal & adim. & 1 & 0,05 & 0,05 \\
\hline 24 & $\theta_{s}$ & $\begin{array}{c}\text { incerteza do modelo } \\
\text { de solicitação }\end{array}$ & Lognormal & adim. & 1 & 0,05 & 0,05 \\
\hline
\end{tabular}


Com as variáveis aleatórias adotadas, foi aplicado o Método de Monte Carlo para os 9 pilares, nos casos com 10 barras de $10 \mathrm{~mm}, 16$ barras de $10 \mathrm{~mm}, 20$ barras de $10 \mathrm{~mm}, 10$ barras de $12,5 \mathrm{~mm}, 16$ barras de $12,5 \mathrm{~mm}$ e 20 barras de $12,5 \mathrm{~mm}$. A variação das armaduras deve diminuir as probabilidades de falha, de modo a se verificar o comportamento dos resultados gerados. Os resultados podem ser verificados e conclusões aferidas de acordo com os gráficos da Figura 30 e Figura 31.

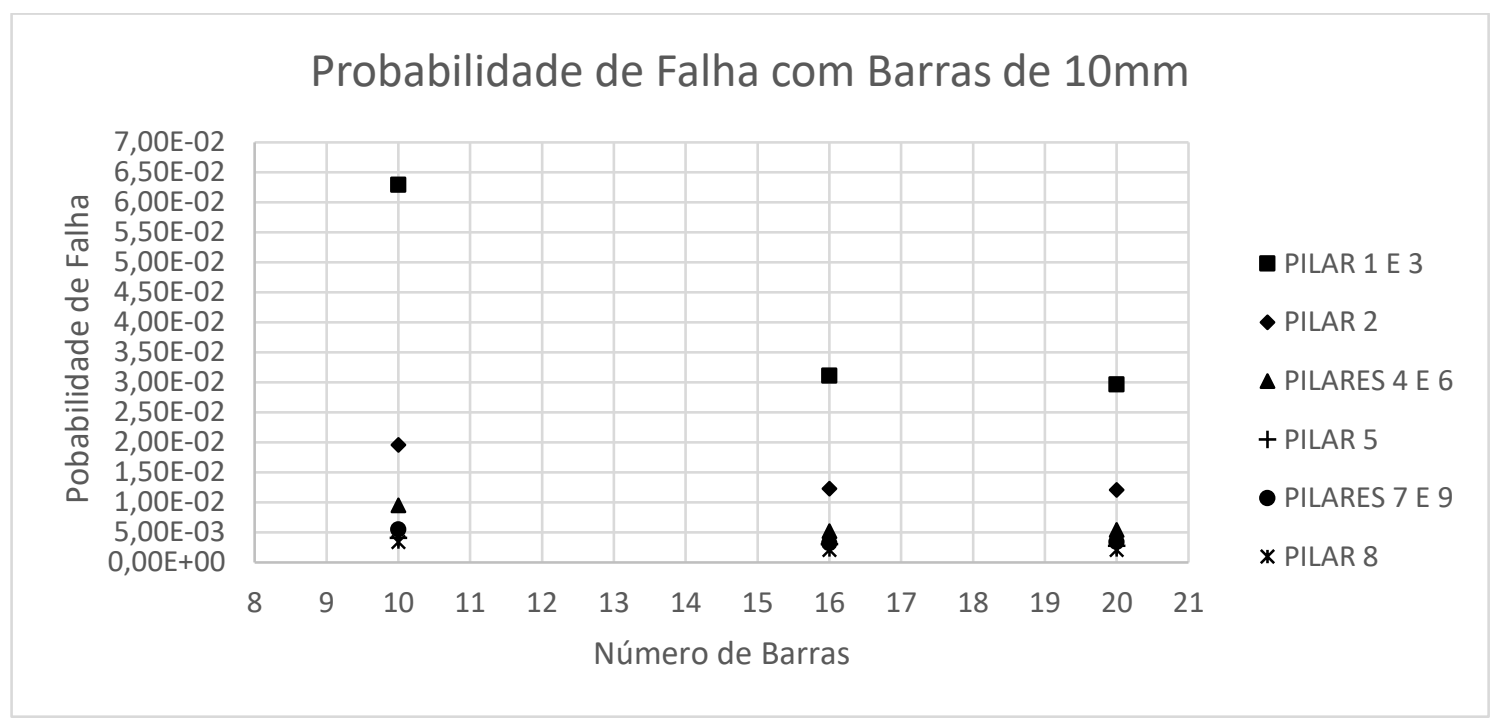

Figura 30 - Probabilidades de falha para seção com barras de 10mm. (Fonte: Autor)

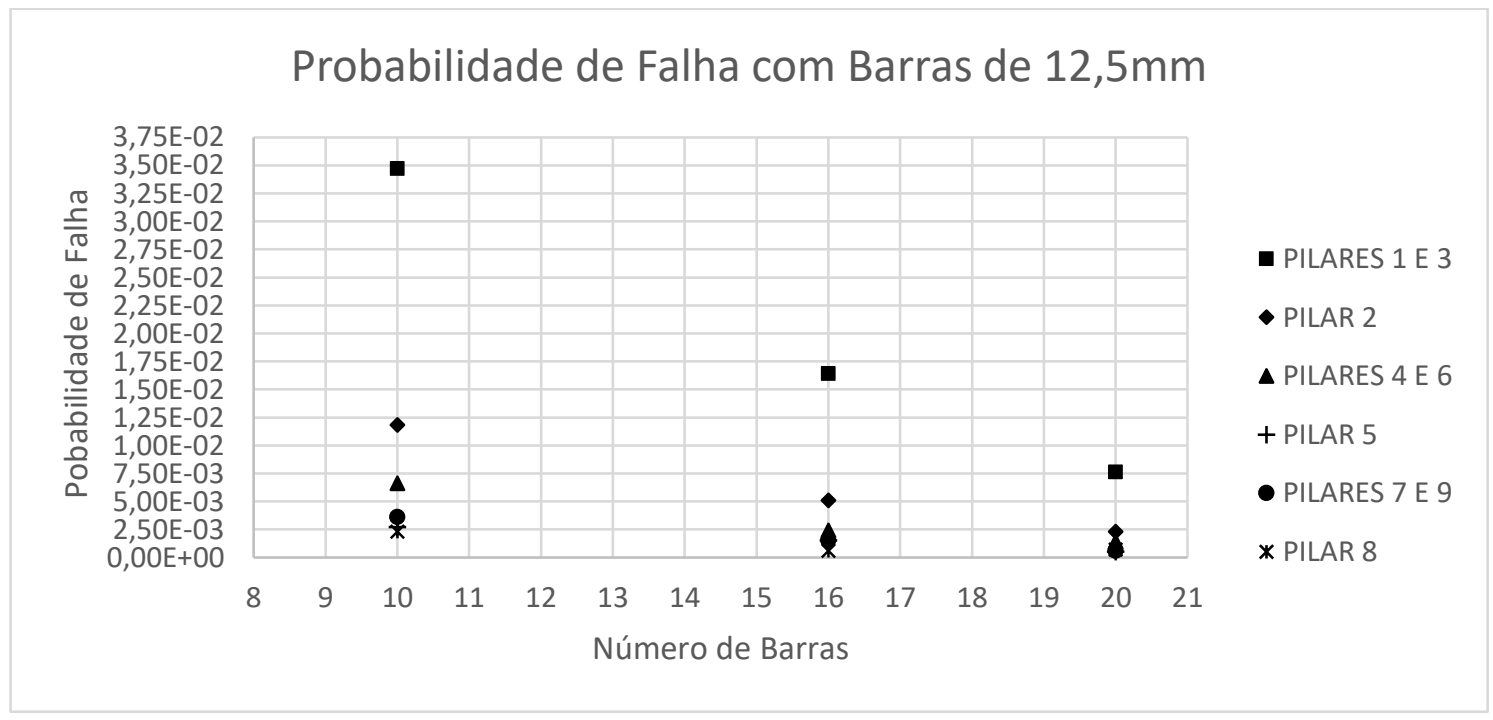

Figura 31 - Probabilidades de falha para seção com barras de 12,5mm. (Fonte: Autor)

As análises efetuadas foram feitas com 10.000 simulações, com um tempo médio de 7 horas cada. Os resultados plotados referem-se aos valores obtidos sem as margens. 


\subsubsection{Verificação individual com modelo engastado e comparação com solo- estrutura}

Neste item são estudados os comportamentos dos esforços solicitantes atuantes nos pilares. Rahul et al. (2016) desenvolvem uma análise semelhante para os esforços solicitantes em edifício de concreto armado, no qual são feitas 100 simulações com o MCS para obtenção dos histogramas dos esforços solicitantes. Neste trabalho, será apresentado o histograma para o edifício previamente apresentado, com 1.000 simulações desenvolvidas com o método MCS.

Para serem obtidos os histogramas é necessário que o algoritmo utilizado para o método com o programa de edifícios seja alterado, de modo a armazenar os resultados dos esforços resultantes, e não os aplicar diretamente numa equação de estado limite. Esses resultados foram manipulados em Microsoft Excel, e assim obtidos os histogramas. Finalmente, é executado o algoritmo para 1.000 simulações, com o edifício engastado, utilizando-se das variáveis aleatórias da Tabela 30, porém até a variável 20 apenas, cujas quais são referentes ao modelo do edifício.

Para estimar as classes (ou intervalos) dos histogramas, foi adotado a regra de Scott (Scott's rule), que em termos gerais é mais adequada para variáveis com distribuição Normal, contudo traz também uma simplicidade para calcular, na qual os trechos são definidos pela seguinte equação dependente do número de elementos da amostra e do desvio padrão da mesma (Scott, 1992):

$$
h=3,49 \sigma \cdot \mathrm{n}^{-1 / 3}
$$

Com $\sigma$ sendo o desvio padrão da amostra e n o número de elementos da amostra. Abaixo seguem os histogramas dos esforços solicitantes nos pilares para os eixos locais $\mathrm{X}$ (eixo do pilar), $\mathrm{Y}$ (paralelo à menor dimensão) e $\mathrm{X}$ (paralelo à maior dimensão). 
Pilar 1:

\begin{tabular}{|c|c|c|}
\hline Histograma NX & Histograma MY & Histogr \\
\hline 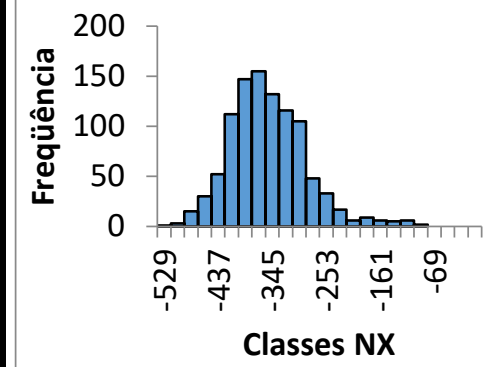 & 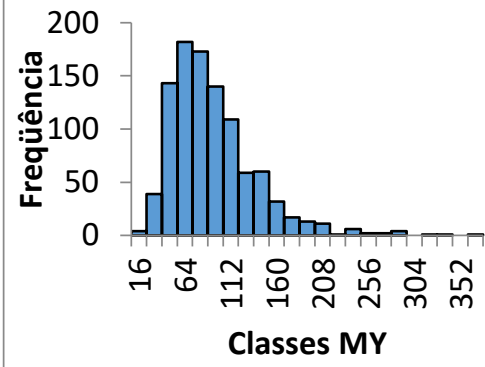 & 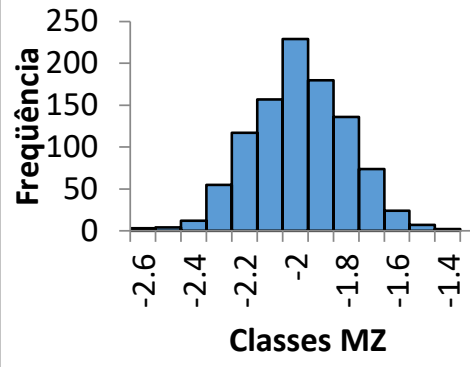 \\
\hline $\begin{aligned} \mu_{N x} & =-363,69 k N \\
\sigma_{N x} & =-65,58 k N\end{aligned}$ & $\begin{aligned} \mu_{M y} & =85,21 \mathrm{kNm} \\
\sigma_{M y} & =44,76 \mathrm{kNm}\end{aligned}$ & $\begin{aligned} \mu_{M z} & =-2,03 \mathrm{kNm} \\
\sigma_{M z} & =-0,19 \mathrm{kNm}\end{aligned}$ \\
\hline
\end{tabular}

Figura 32 - Histogramas dos esforços solicitantes no pilar 1 com respectivas média e desvio padrão, edifício engastado. (Fonte: Autor)

Pilar 2:

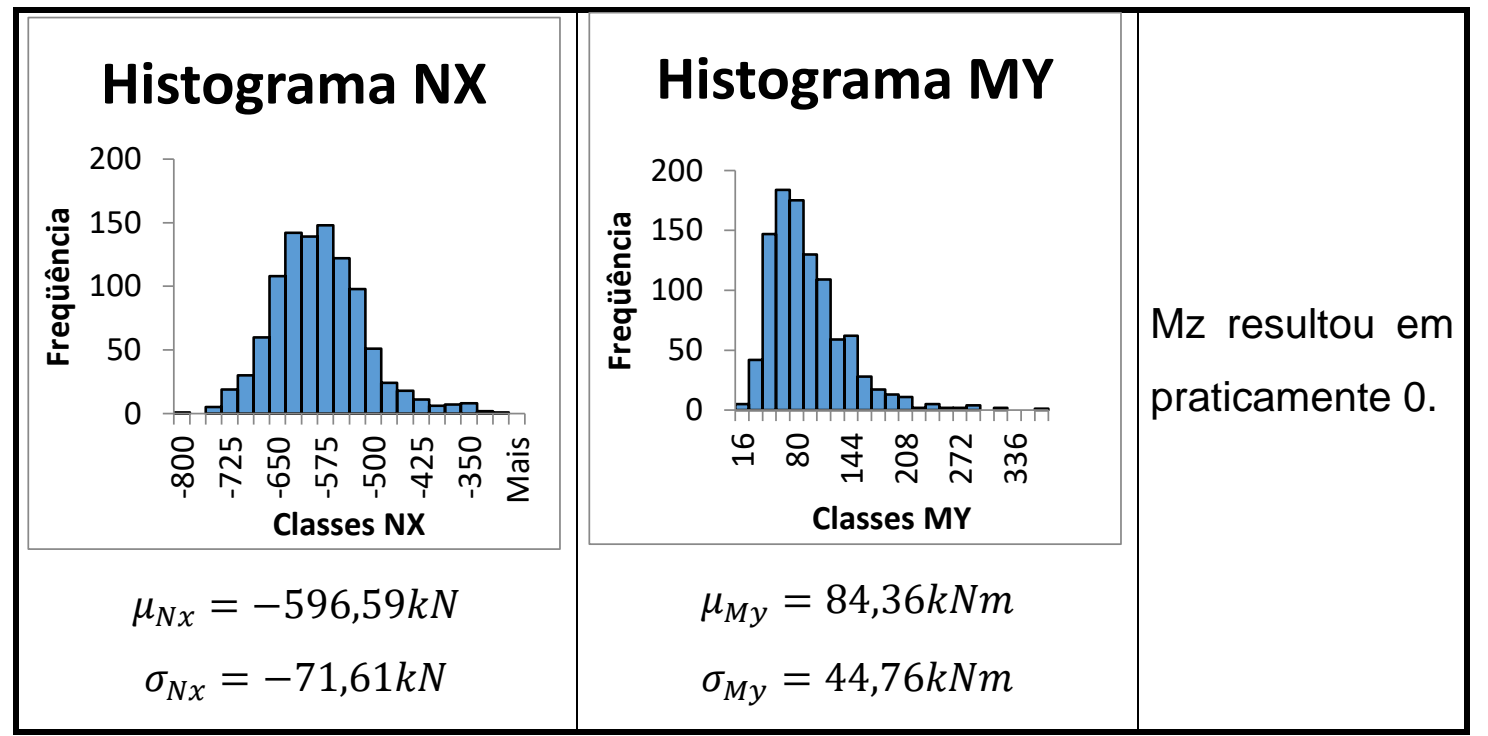

Figura 33 - Histogramas dos esforços solicitantes no pilar 2 com respectivas média e desvio padrão, edifício engastado. (Fonte: Autor) 
Pilar 4:

\begin{tabular}{|c|c|c|}
\hline 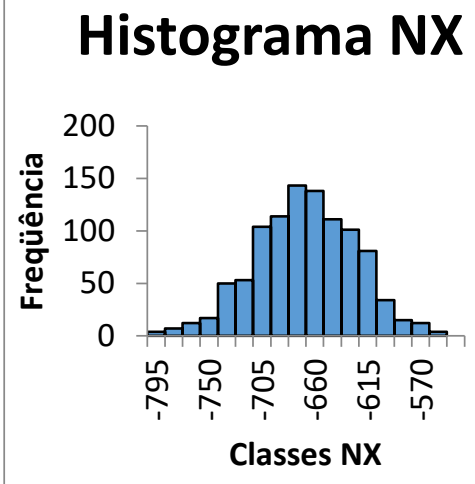 & 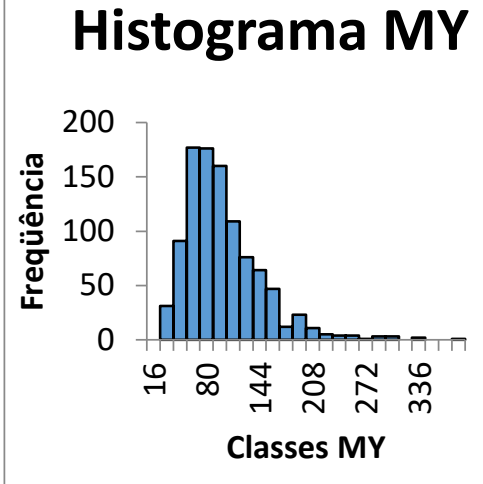 & 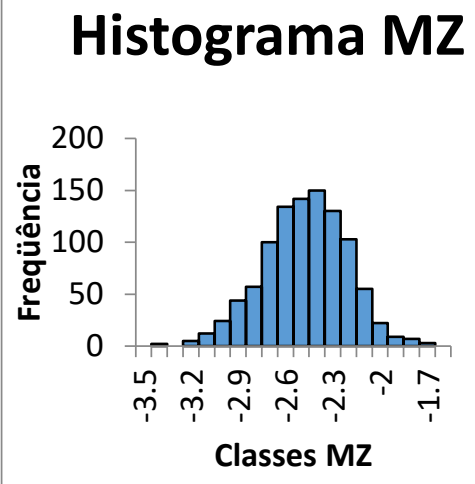 \\
\hline $\begin{aligned} \mu_{N x} & =-675,95 \mathrm{kN} \\
\sigma_{N x} & =-42,52 \mathrm{kN}\end{aligned}$ & $\begin{aligned} \mu_{M y} & =91,98 \mathrm{kNm} \\
\sigma_{M y} & =46,55 \mathrm{kNm}\end{aligned}$ & $\begin{aligned} \mu_{M Z} & =-2,53 \mathrm{kNm} \\
\sigma_{M Z} & =-0,26 \mathrm{kNm}\end{aligned}$ \\
\hline
\end{tabular}

Figura 34 - Histogramas dos esforços solicitantes no pilar 4 com respectivas média e desvio padrão, edifício engastado. (Fonte: Autor)

Pilar 5:

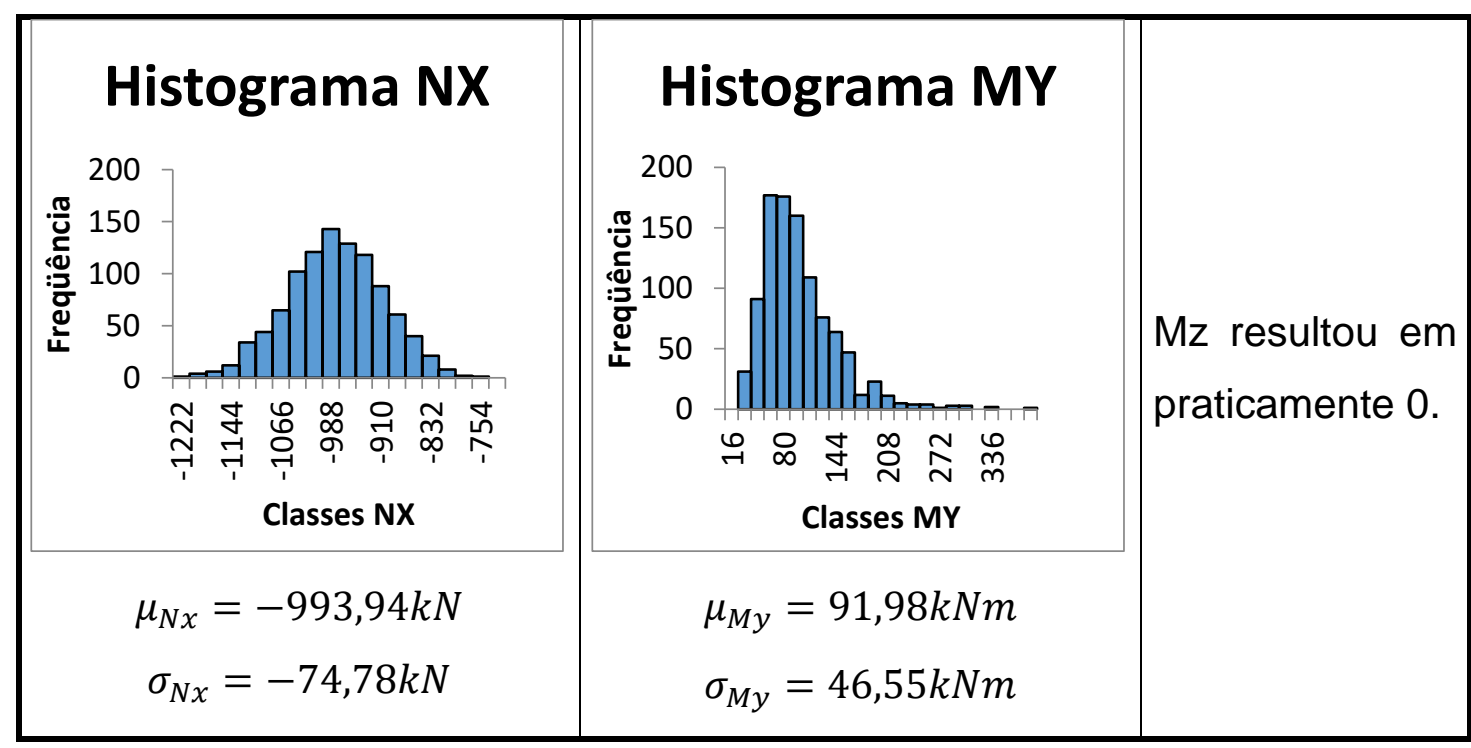

Figura 35 - Histogramas dos esforços solicitantes no pilar 5 com respectivas média e desvio padrão, edifício engastado. (Fonte: Autor) 
Pilar 7:

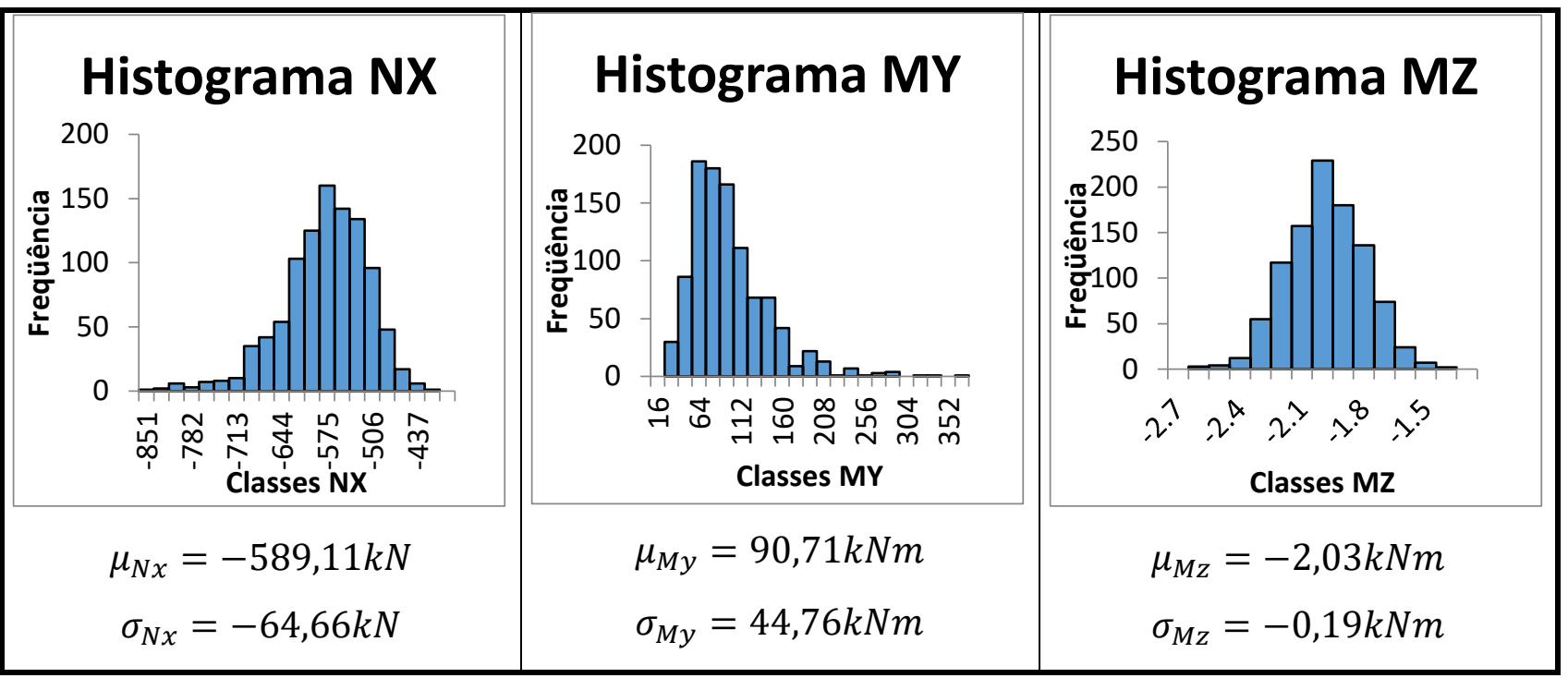

Figura 36 - Histogramas dos esforços solicitantes no pilar 7 com respectivas média e desvio padrão, edifício engastado. (Fonte: Autor)

Pilar 8:

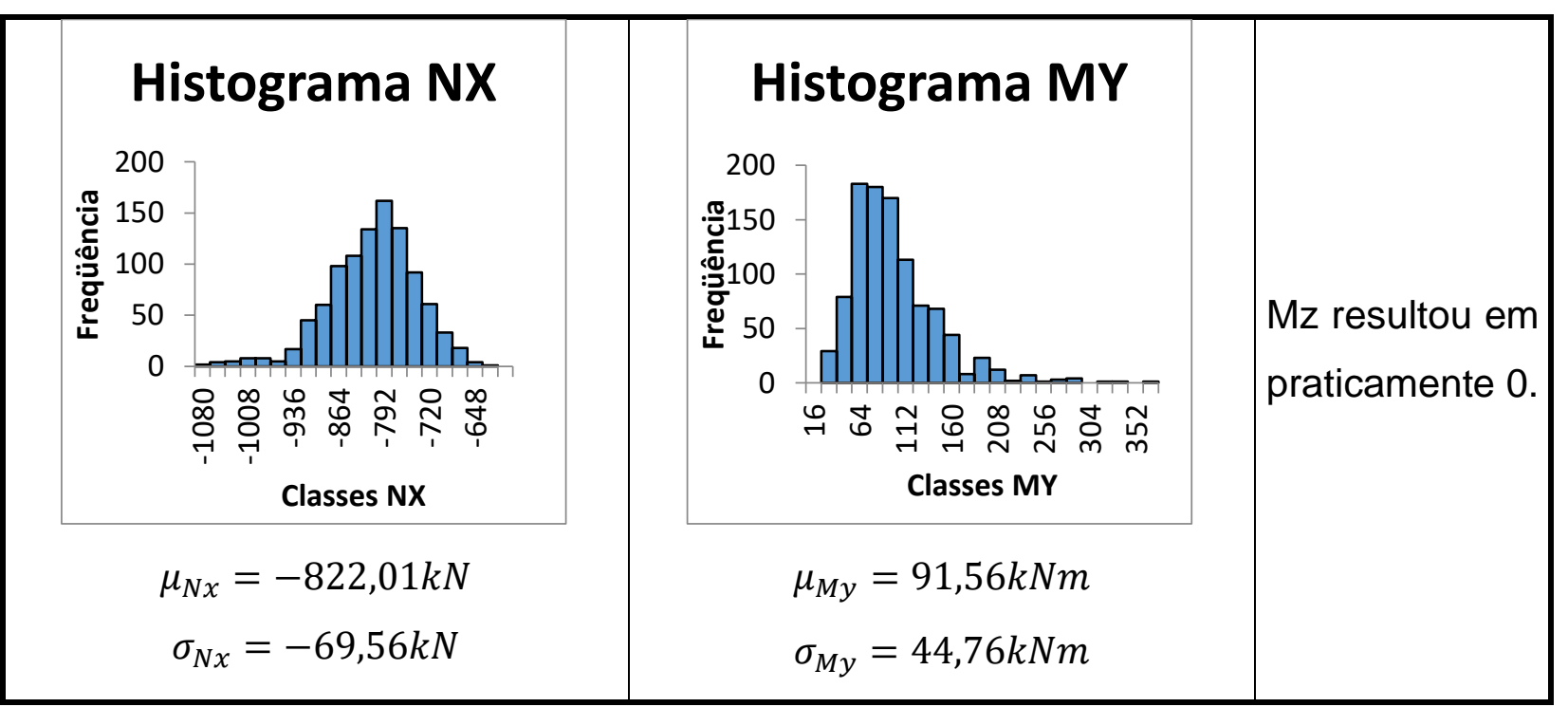

Figura 37 - Histogramas dos esforços solicitantes no pilar 8 com respectivas média e desvio padrão, edifício engastado. (Fonte: Autor) 
Como o problema em questão é simétrico, entende-se que os resultados para os pilares das extremidades são equivalentes em valores absolutos.

Em seguida, a mesma avaliação foi desenvolvida para o edifício considerando a interação solo-estrutura, com variáveis aleatórias da Tabela 30, até a variável 20, acrescidas as molas atribuídas na Tabela 23.

Por conseguinte, obtiveram-se os histogramas abaixo.

Pilar 1:

\begin{tabular}{|c|c|c|}
\hline 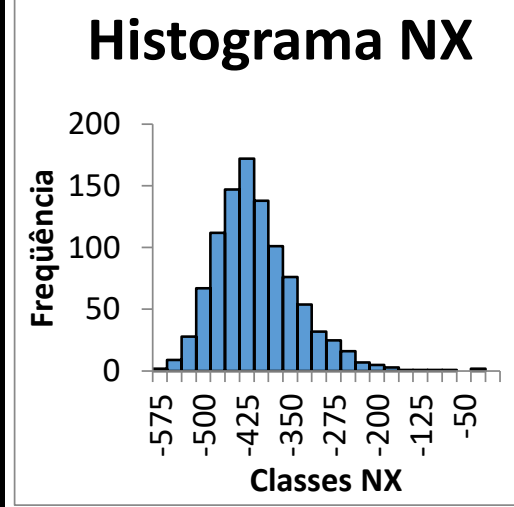 & 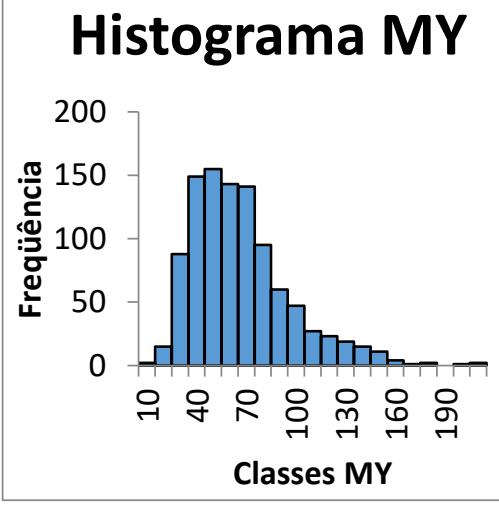 & 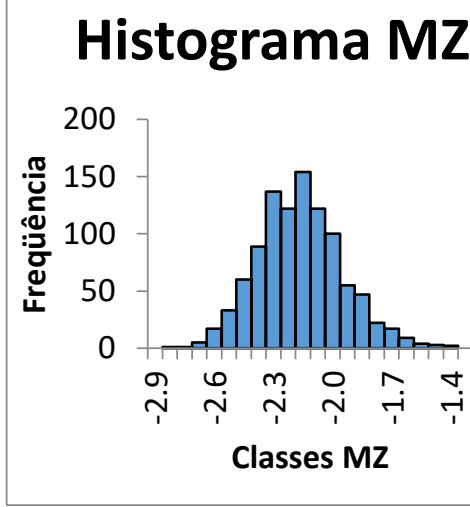 \\
\hline $\begin{aligned} \mu_{N x} & =-420,51 k N \\
\sigma_{N x} & =-71,77 k N\end{aligned}$ & $\begin{aligned} \mu_{M y} & =61,59 \mathrm{kNm} \\
\sigma_{M y} & =29,68 \mathrm{kNm}\end{aligned}$ & $\begin{aligned} \mu_{M z} & =-2,20 \mathrm{kNm} \\
\sigma_{M z} & =-0,23 \mathrm{kNm}\end{aligned}$ \\
\hline
\end{tabular}

Figura 38 - Histogramas dos esforços solicitantes no pilar 1 com respectivas média e desvio padrão, com interação solo-estrutura. (Fonte: Autor)

Pilar 2:

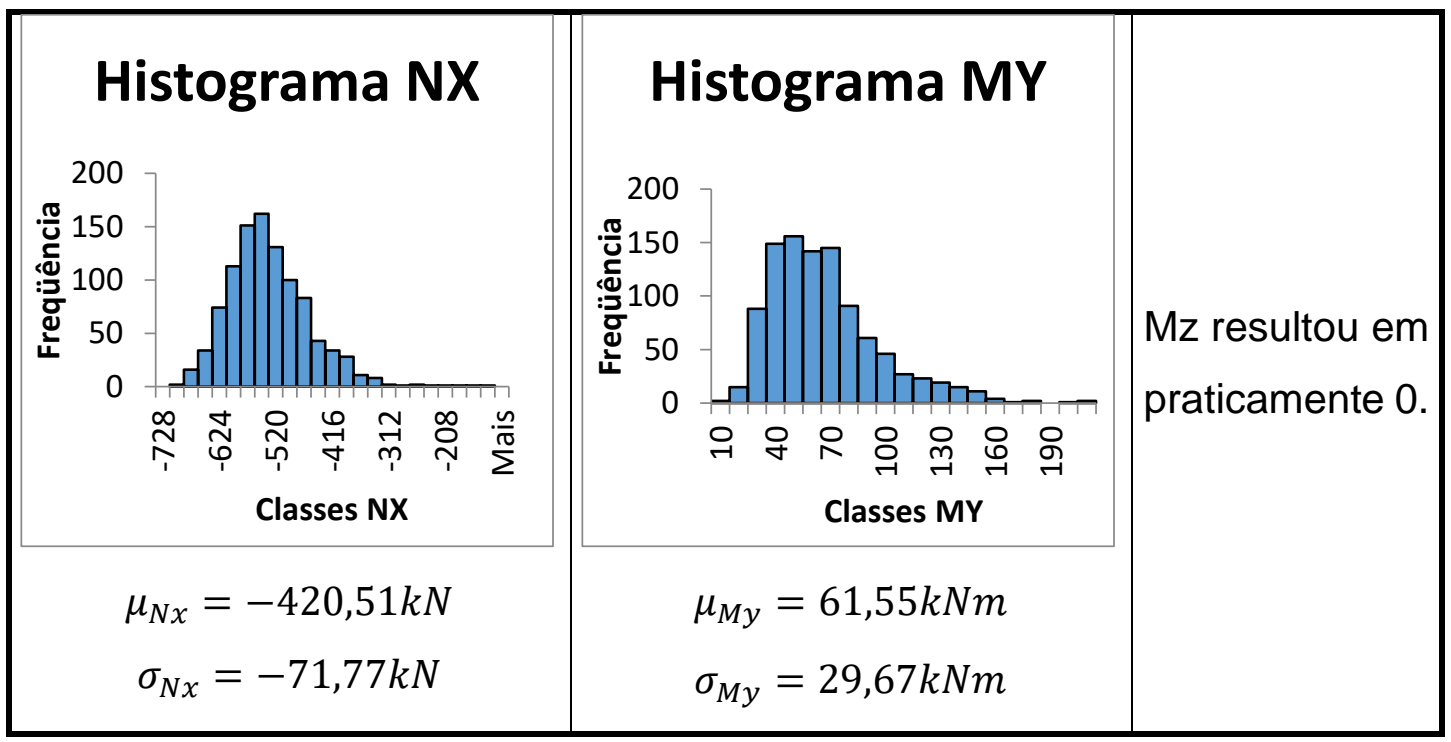

Figura 39 - Histogramas dos esforços solicitantes no pilar 2 com respectivas média e desvio padrão, com interação solo-estrutura. (Fonte: Autor) 
Pilar 4:

\begin{tabular}{|c|c|c|}
\hline Histograma NX & Histograma MY & Histograma MZ \\
\hline 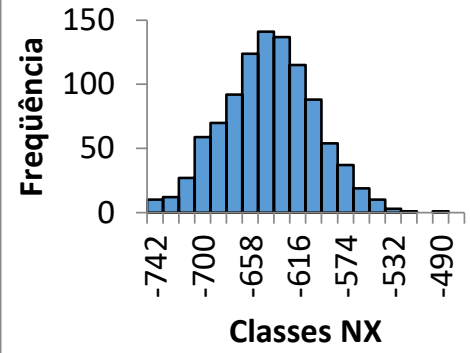 & 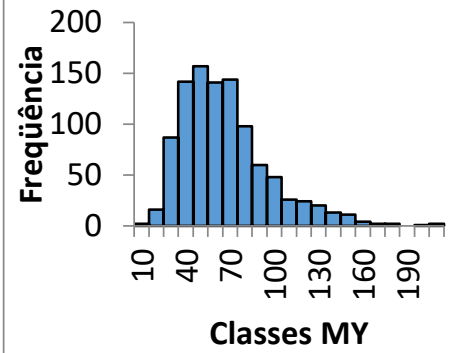 & 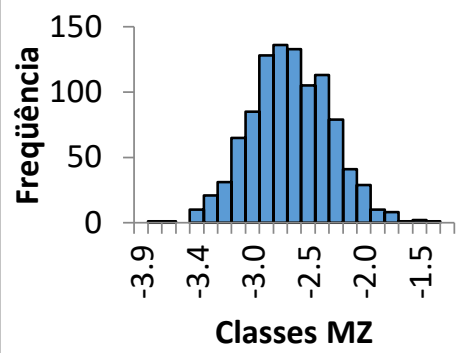 \\
\hline $\begin{aligned} \mu_{N x} & =-647,76 k N \\
\sigma_{N x} & =-40,45 k N\end{aligned}$ & $\begin{aligned} \mu_{M y} & =61,86 \mathrm{kNm} \\
\sigma_{M y} & =29,80 \mathrm{kNm}\end{aligned}$ & $\begin{aligned} \mu_{M z} & =-2,68 k N m \\
\sigma_{M z} & =-0,35 k N m\end{aligned}$ \\
\hline
\end{tabular}

Figura 40 - Histogramas dos esforços solicitantes no pilar 4 com respectivas média e desvio padrão, com interação solo-estrutura. (Fonte: Autor)

Pilar 5:

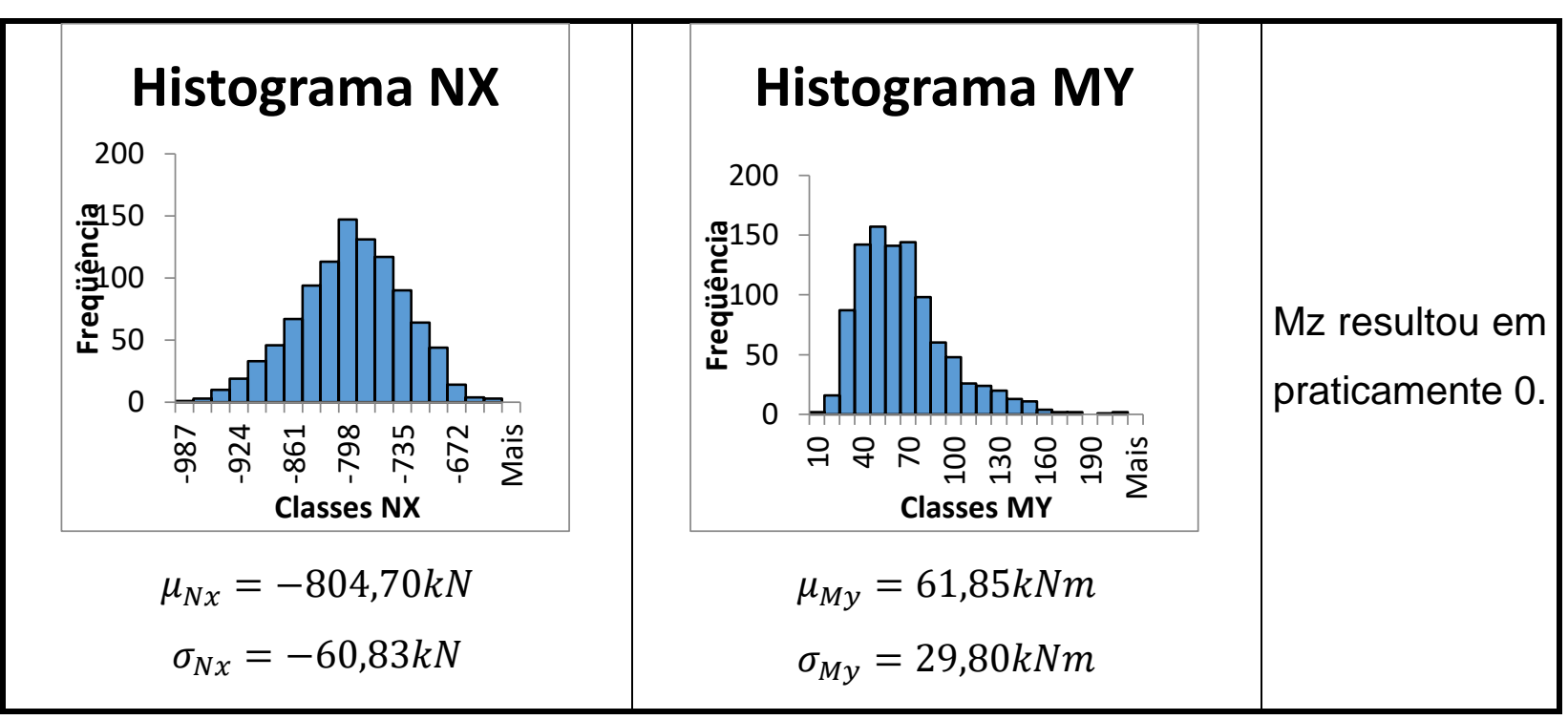

Figura 41 - Histogramas dos esforços solicitantes no pilar 5 com respectivas média e desvio padrão, com interação solo-estrutura. (Fonte: Autor) 
Pilar 7:

\begin{tabular}{|c|c|c|}
\hline 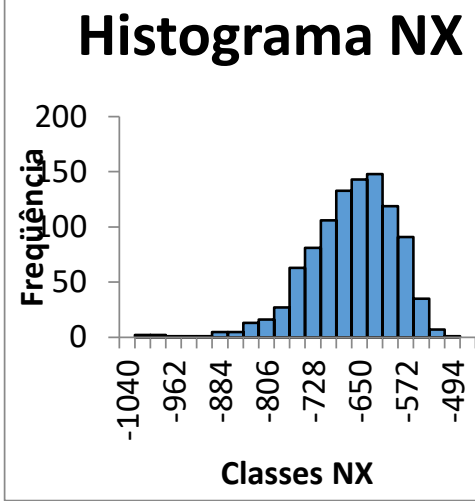 & 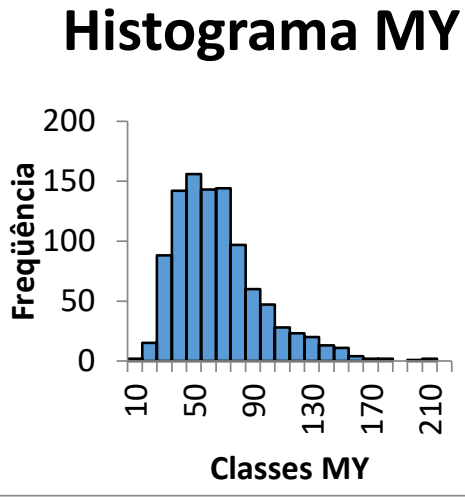 & 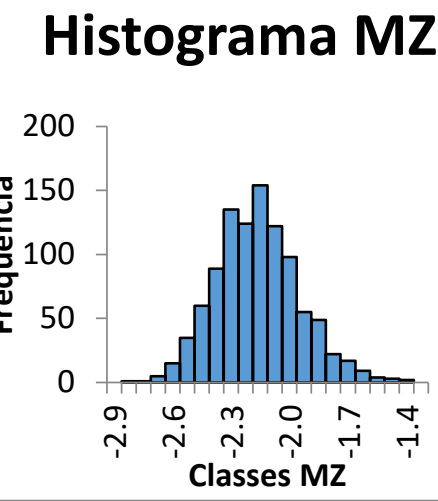 \\
\hline $\begin{aligned} \mu_{N x} & =-675,97 k N \\
\sigma_{N x} & =-73,11 k N\end{aligned}$ & $\begin{aligned} \mu_{M y} & =61,85 \mathrm{kNm} \\
\sigma_{M y} & =29,73 \mathrm{kNm}\end{aligned}$ & $\begin{aligned} \mu_{M z} & =-2,20 \mathrm{kNm} \\
\sigma_{M z} & =-0,23 \mathrm{kNm}\end{aligned}$ \\
\hline
\end{tabular}

Figura 42 - Histogramas dos esforços solicitantes no pilar 7 com respectivas média e desvio padrão, com interação solo-estrutura. (Fonte: Autor)

Pilar 8:

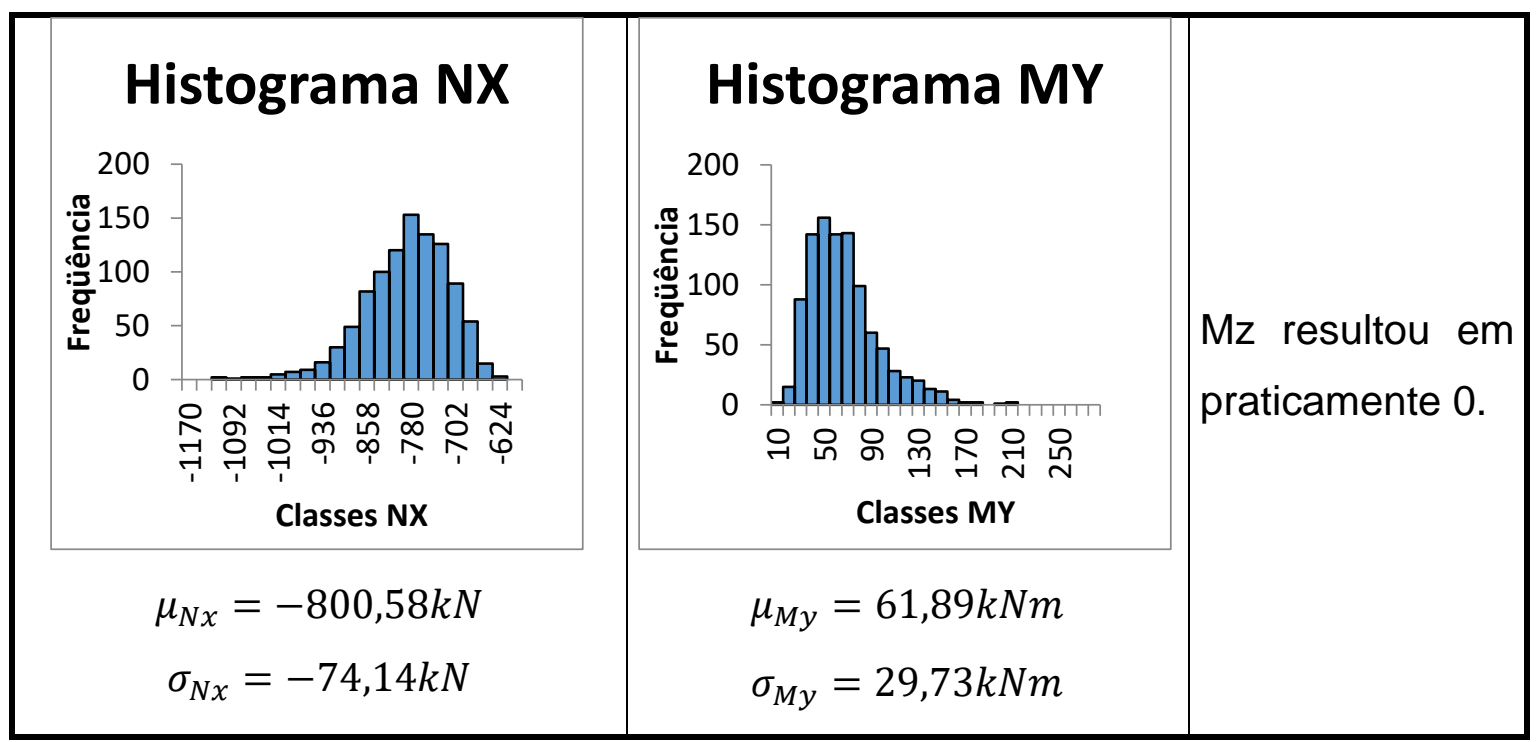

Figura 43 - Histogramas dos esforços solicitantes no pilar 8 com respectivas média e desvio padrão, com interação solo-estrutura. (Fonte: Autor) 
Com os resultados obtidos, foi feita a aproximação dos esforços Nx e Mz como variáveis com distribuição de densidade estatística Normal e My como uma distribuição Lognormal, exclusivamente baseadas nas observações dos diagramas obtidos, de modo a simplificar a análise. As simulações para a geração das amostragens levaram cerca de 5 horas para o edifício engastado e 46 horas para o edifício com solo-estrutura.

Doravante, tendo em vista o Pilar 1 como o potencial elemento com esforços mais desfavoráveis, será feita uma comparação nos esforços atuantes no modelo com base engastada e no modelo com interação solo-estrutura. De pronto, a média obtida no momento fletor My no modelo com solo-estrutura corresponde a $72 \%$ do modelo engastado, portanto houve uma redução de aproximadamente $30 \%$ do momento fletor. Nota-se ainda que não houveram diferenças expressivas entre o esforço compressivo Nx e o momento fletor Mz como esperado.

Para a verificação da probabilidade de falha do Pilar 1, executou-se o algoritmo com o método MCS acoplado com o programa de verificação de elementos de concreto armado em flexo-compressão. Inicialmente para o modelo engastado, com as variáveis aleatórias apresentadas da Tabela 31 e para o modelo com solo-estrutura apresentadas na

Tabela 32.

Tabela 31 - Variáveis aleatórias aplicadas na simulação com edifício engastado

\begin{tabular}{|c|c|c|c|c|c|c|c|}
\hline Var. & Símbolo & Atribuição & $\begin{array}{c}\text { Tipo de } \\
\text { Distribuição }\end{array}$ & Unid. & Média & $\begin{array}{l}\text { Taxa de } \\
\text { Variação }\end{array}$ & $\begin{array}{l}\text { Desv. } \\
\text { Pad. }\end{array}$ \\
\hline 1 & $N_{x}$ & Esforço axial & Normal & $k N$ & $-363,69$ & 0,18 & $-65,58$ \\
\hline 2 & $M_{y}$ & Momento fletor eixo Y & Lognormal & $k N \mathrm{~m}$ & 85,21 & 0,53 & 44,76 \\
\hline 3 & $M_{Z}$ & Momento fletor eixo Z & Normal & $k N m$ & $-2,03$ & 0,09 & $-0,19$ \\
\hline 4 & $b_{\text {pilar }}$ & $\begin{array}{l}\text { Dimensão b dos } \\
\text { pilares }\end{array}$ & Normal & $m$ & 0,7 & 0,045 & 0,032 \\
\hline 5 & $h_{\text {pilar }}$ & $\begin{array}{c}\text { Dimensão h dos } \\
\text { pilares }\end{array}$ & Normal & $m$ & 0,2 & 0,06 & 0,012 \\
\hline 6 & $f_{c k, p}$ & $\begin{array}{l}\text { Res. carac. do c.a. do } \\
\text { prédio }\end{array}$ & Lognormal & $M P a$ & $25 \times 1,17$ & 0,05 & 1,46 \\
\hline 7 & $E_{S}$ & $\begin{array}{c}\text { Módulo de } \\
\text { elasticidade do aço }\end{array}$ & Lognormal & $G P a$ & $210 \times 1,08$ & 0,05 & 11,34 \\
\hline
\end{tabular}




\begin{tabular}{cccccccc}
\hline Var. Símbolo & Atribuição & $\begin{array}{c}\text { Tipo de } \\
\text { Distribuição }\end{array}$ & Unid. & Média & $\begin{array}{c}\text { Taxa de } \\
\text { Variação }\end{array}$ & $\begin{array}{c}\text { Desv. } \\
\text { Pad. }\end{array}$ \\
\hline 8 & $f_{y, k}$ & $\begin{array}{c}\text { Tensão característica } \\
\text { de escoamento } \\
\text { Coeficiente de }\end{array}$ & Lognormal & $M P a$ & $500 \times 1,08$ & 0,05 & 27 \\
9 & $\theta_{r} \quad \begin{array}{c}\text { incerteza do modelo } \\
\text { de resistência } \\
\text { Coeficiente de }\end{array}$ & Lognormal & adim. & 1 & 0,05 & 0,05 \\
10 & $\theta_{s} \quad \begin{array}{c}\text { incerteza do modelo } \\
\text { de solicitação }\end{array}$ & Lognormal & adim. & 1 & 0,05 & 0,05 \\
\hline
\end{tabular}

Tabela 32 - Variáveis aleatórias aplicadas na simulação com edifício com solo-estrutura

\begin{tabular}{|c|c|c|c|c|c|c|c|}
\hline Var. & Símbolo & Atribuição & Dist. & Unid. & Média & $\begin{array}{l}\text { Taxa de } \\
\text { Variação }\end{array}$ & $\begin{array}{l}\text { Desv. } \\
\text { Pad. }\end{array}$ \\
\hline 1 & $N_{x}$ & Esforço axial & Normal & $k N$ & $-420,51$ & 0,18 & $-71,77$ \\
\hline 2 & $M_{y}$ & Momento fletor eixo $\mathrm{Y}$ & Lognormal & $k N m$ & 61,59 & 0,48 & 29,68 \\
\hline 3 & $M_{z}$ & Momento fletor eixo $Z$ & Normal & $k N m$ & $-2,20$ & 0,10 & $-0,23$ \\
\hline 4 & $\mathrm{~b}_{\text {pilar }}$ & $\begin{array}{l}\text { Dimensão b dos } \\
\text { pilares }\end{array}$ & Normal & $m$ & 0,7 & 0,045 & 0,032 \\
\hline 5 & $h_{\text {pilar }}$ & $\begin{array}{l}\text { Dimensão h dos } \\
\text { pilares }\end{array}$ & Normal & $m$ & 0,2 & 0,06 & 0,012 \\
\hline 6 & $f_{c k, p}$ & $\begin{array}{l}\text { Res. carac. do c.a. do } \\
\text { prédio }\end{array}$ & Lognormal & $M P a$ & $25 \times 1,17$ & 0,05 & 1,46 \\
\hline 7 & $E_{S}$ & $\begin{array}{c}\text { Módulo de } \\
\text { elasticidade do aço }\end{array}$ & Lognormal & $G P a$ & $210 \times 1,08$ & 0,05 & 11,34 \\
\hline 8 & $f_{y, k}$ & $\begin{array}{l}\text { Tensão carac. de } \\
\text { escoamento }\end{array}$ & Lognormal & $M P a$ & $500 \times 1,08$ & 0,05 & 27 \\
\hline 9 & $\theta_{r}$ & $\begin{array}{c}\text { Coeficiente de } \\
\text { incerteza do modelo } \\
\text { de resistência }\end{array}$ & Lognormal & adim. & 1 & 0,05 & 0,05 \\
\hline 10 & $\theta_{s}$ & $\begin{array}{c}\text { Coeficiente de } \\
\text { incerteza do modelo } \\
\text { de solicitação }\end{array}$ & Lognormal & adim. & 1 & 0,05 & 0,05 \\
\hline
\end{tabular}


Os Pilares foram contemplados com a armação de 10 barras de $10 \mathrm{~mm}$ conforme ora apresentado no item anterior, para a verificação de ELU do pilar.

Por conseguinte, fazendo-se as simulações com as variáveis aleatórias apresentadas, o algoritmo mencionado foi executado para 100000 simulações, deste modo obtiveram-se os valores de probabilidade de falha de $6,35 \times 10^{-2} \pm 1,41 \times 10^{-3}$ para o edifício engastado e $1,05 \times 10^{-2} \pm 6,25 \times 10^{-3}$ para o edifício com soloestrutura. Ambas as verificações estimando confiança de $95 \%$. Vale destacar que para os casos simulados, o tempo aproximado de execução foi de 1 hora de 30 minutos cada.

Em ambos os casos analisados, nota-se que o desvio padrão resultante dos momentos fletores $M_{Y}$ geram coeficientes de variação entorno de 0,50, ou seja, uma grande variação nos momentos fletores, fato que influencia diretamente no cálculo das probabilidades de falha, o que contribui significativamente aos altos valores obtidos para as probabilidades de falha.

Baseando-se nos coeficientes de variação utilizados por Santos et. al. (2014), atrelando as cargas permanentes aos resultados de $N_{X}$ e as cargas acidentais aos resultados de $M_{Y}$, considera-se à seguir os coeficientes de variação para $M_{Y}$ o valor 0,15 e para $N_{X} \circ$ valor 0,10 . Deste modo, executando-se novamente 100000 simulações para cada caso, foram obtidas as probabilidades de falha de 9,80 $\times 10^{-4} \pm$ $1,97 \times 10^{-4}$ para o edifício engastado e $1,00 \times 10^{-5} \pm 1,96 \times 10^{-5}$ para o edifício com solo-estrutura. 


\section{RESULTADOS E DISCUSSÕES}

Com as simulações executadas, foi possível extrair resultados relevantes sobre os diferentes métodos aplicados e as variações na aplicação de várias variáveis aleatórias nos modelos de cálculo.

No exemplo de um edifício quadrangular com 4 elementos de fundação direta, utilizando a presente formulação, obtiveram-se resultados satisfatórios dentro do esperado, com as variáveis aleatórias apenas nos valores de rigidez do solo em cada sapata, porém um elevado tempo de execução do programa.

Já o segundo modelo, edifício TIPO-A, é um pouco mais complexo, além de introduzirmos os fatores de variação para os coeficientes do vento. Desta vez foram feitas duas simulações com esse modelo, alterando os coeficientes do solo, de modo que a probabilidade de falha foi maior para o modelo com solo de menor rigidez, conforme esperado. O tempo de execução do programa foi ainda maior, obviamente, do que o exemplo precedente.

$\mathrm{Na}$ avaliação do edifício TIPO-B que, apresenta maior complexidade, foi utilizado o procedimento de simulação de Monte Carlo. Para este modelo, além da variação de diversos parâmetros, variou-se também os coeficientes do vento e do solo, a fim de buscar uma simulação com o qual representasse um modelo mais próximo de todas as possíveis variáveis aleatórias para um modelo proposto. Além da formulação de confiabilidade, foram introduzidas formulações para calcular os carregamentos em função de todos os parâmetros para compatibilizar as variações dos parâmetros com os carregamentos resultantes na estrutura. Nesse sentido, a análise trivial realizada para este edifício mostrou-se relevante permitindo concluir que o resultado está em concordância, dentro dos padrões comuns de projeto, porém não tanto para as recomendações da JCSS (2001), do qual contempla uma tabela com valores recomendados sobre custo relativo para tomada de medidas de segurança, de acordo com a probabilidade de falha, para Estado Limite de Serviço, indicado na Tabela 33. 
Tabela 33 - Valores limites de acordo com o JCSS (2001) para ELS.

\begin{tabular}{cc}
$\begin{array}{c}\text { Custo Relativo para Medida } \\
\text { de Segurança }\end{array}$ & $\begin{array}{c}\text { Valores de } P_{f} \\
(\text { ELS) Irreversível }\end{array}$ \\
\hline Alto & $\approx 1,00 \times 10^{-1}$ \\
Médio & $\approx 5,00 \times 10^{-2}$ \\
Baixo & $\approx 1,00 \times 10^{-2}$ \\
\hline
\end{tabular}

Contudo, apesar da estrutura estar com valor de recalque diferencial menor do que o limite sugerido pela literatura, a estrutura estaria um tanto que insegura com relação à uma possibilidade de recalque diferencial em um futuro próximo. Vale destacar também, que o número de simulações foi baixo relativo ao indicado por Bjerager (1990), de modo que um número maior de simulações pode variar a probabilidade de falha. $O$ tempo de execução da simulação foi maior de o dobro do exemplo do TIPO-A.

No primeiro exemplo usando a rotina que aplica o método FOSM, além do valor da probabilidade de falha, o método pode ser utilizado para averiguar a relevância das variáveis aleatórias. Como esperado, evidenciaram-se diversas variáveis aleatórias que influenciavam pouco na probabilidade de falha, neste caso o resultado do método FOSM foi menor que o do método de Monte Carlo, mas deve-se que levar em consideração também o número relativamente baixo de simulações para o método, conforme explanado anteriormente. Nesse caso, segundo a tabela da JCSS (2001), o custo para medidas de segurança seria médio. Destaca-se também que o tempo de execução desse caso, levou cerca de $5 \%$ do mesmo com o método MCS.

Com a retirada de variáveis com relevância nula, fora simulado o edifício TIPOB avaliado pelo FOSM, no qual levou-se em consideração também a diminuição da variação de alguns parâmetros. Como esperado, o resultado foi menor que o anterior, devido à menor variação das variáveis aleatórias, o que as tornaria mais confiáveis de maneira na qual diminuísse a probabilidade de falha. Dessa vez, segundo a os valores de Estado Limite de Serviço da JCSS (2001), estaria sujeita a um baixo custo para aplicação de medidas de segurança. Neste caso o tempo de execução foi ainda menor, devido ao menor número de variáveis aleatórias, na qual influencia no número de procedimentos necessários para aplicação das DF.

Enfim, elaborou-se um modelo com a rotina para estacas, para um estudo dos resultados em edifício com fundação profunda. Executou-se novamente o edifício 
TIPO-B avaliado pelo FOSM, agora com blocos com 4 estacas cada. Tendo o modelo executado pelo método tradicional, os resultados mostraram que o valor limite não teria sido atingido, portanto a estrutura estaria segura para o fenômeno, porém a análise com confiabilidade mostrou que com o resultado da probabilidade de falha obtida de acordo com o JCSS (2001), a estrutura estaria na faixa de um possível valor médio de recuperação futura, o que poderia levar à uma reavaliação dos parâmetros para uma possível diminuição dessa probabilidade de falha. Houve um acréscimo de tempo para execução desta simulação devido à nova estrutura de fundação profunda. Nesse modelo ainda, foi calculado um Fator de Segurança global para a verificação de recalque diferencial, à partir dos fatores estatísticos obtidos, traçando assim uma relação entre segurança e probabilidade de falha. Vale observar que neste caso, houve uma probabilidade de falha relativamente alta mesmo que o fator de segurança tenha sido atendido, observação cujo qual deveria ser fornecida a um possível cliente do projeto.

Nos últimos casos numéricos, desenvolveram-se estudos para o Estado Limite Último para os pilares de concreto armado do edifício TIPO-B, considerando alguns diferentes valores probabilísticos, como em Santos et al. (2014), de modo a fazer a verificação probabilística dos elementos, de maneira semelhante a Rahul et al. (2016) e Pustka et al. (2008), com a ideia de se utilizar um programa de verificação de seções de concreto armado em flexo-compressão com não linearidade física, cujo qual baseia-se na convergência numérica iterativa para um pilar que resiste aos esforços aplicados. Deste modo, o método MCS é aplicado, ora com o programa acoplado com o de edifícios e ora executados em diferentes fases. Num primeiro estudo, foi feita a verificação acoplada com a execução do programa de edifícios, ou seja, para cada simulação, o programa de pilares era executado em seguida ao de edifícios, metodologia empregada para diferentes casos de armações nos pilares. Neste caso foi possível verificar a grande diferença que a compressão exerce a resistência dos pilares, de modo que para momentos fletores de grandeza semelhante, a probabilidade de falha variou bastante, chegando a uma diferença de $91 \%$ no caso de 10 barras de $10 \mathrm{~mm}$ para os pilares 1 e 3 com 7 e 9 . Comparando-se com o JCSS (2001), com valores da Tabela 34. 
Tabela 34 - Valores limites de acordo com o JCSS (2001) para ELU.

\begin{tabular}{|c|c|c|c|}
\hline Custo Relativo para & \multicolumn{3}{|c|}{ ELU - Consequências de falha } \\
\hline Medida de Segurança & Pequenas & Moderadas & Grandes \\
\hline Alto & $\begin{array}{c}\beta=3,1 \\
\left(P_{f} \approx 10^{-3}\right)\end{array}$ & $\begin{array}{c}\beta=3,3 \\
\left(P_{f} \approx 5 \times 10^{-4}\right)\end{array}$ & $\begin{array}{c}\beta=3,7 \\
\left(P_{f} \approx 10^{-4}\right)\end{array}$ \\
\hline Médio & $\begin{array}{c}\beta=3,7 \\
\left(P_{f} \approx 10^{-4}\right)\end{array}$ & $\begin{array}{c}\beta=4,2 \\
\left(P_{f} \approx 10^{-5}\right)\end{array}$ & $\begin{array}{c}\beta=4,4 \\
\left(P_{f}\right. \\
\left.\approx 5 \times 10^{-6}\right)\end{array}$ \\
\hline Baixo & $\begin{array}{c}\beta=4,2 \\
\left(P_{f} \approx 10^{-5}\right)\end{array}$ & $\begin{array}{c}\beta=4,4 \\
\left(P_{f} \approx 5 \times 10^{-6}\right)\end{array}$ & $\begin{array}{c}\beta=4,7 \\
\left(P_{f} \approx 10^{-6}\right)\end{array}$ \\
\hline
\end{tabular}

Assim, é possível observar que a estrutura dimensionada com 10 barras de $10 \mathrm{~mm}$ não atende a nenhum critério segundo JCSS (2001), no entanto para disposição de 16 barras de $10 \mathrm{~mm}$ alguns pilares passam a ter custo alto pequenas consequências de falha, o que não seria o ideal para pilares em edifícios, cujos quais deveriam atender, pelo menos, algum critério para consequências moderadas de falha.

Ainda aplicando a metodologia anterior, foram geradas amostras com o método MCS, com 1.000 simulações, para o edifício engastado e com solo-estrutura. Com essas amostras foi possível desenvolver histogramas para uma análise do comportamento estatístico dos esforços solicitantes nos pilares, concluindo-se de maneira simplificada distribuições Normal para Nx e Mz e Lognormal para My. Com as variáveis definidas, executou-se o algoritmo com o programa de pilares, de modo a se obterem as probabilidades de falha do pilar 1 para o edifício engastado e com solo-estrutura, com 10 barras de $10 \mathrm{~mm}$. De imediato evidenciou-se a congruência do resultado da probabilidade de falha obtida neste método com edifício engastado quando do método anterior, portanto as aproximações das distribuições estatísticas dos esforços solicitantes provaram-se eficazes. Finalmente, a probabilidade de falha dos resultados entre os dois modelos para o pilar em questão provou-se de uma distinção considerável, de maneira que a probabilidade de falha do edifício engastado foi 4,5 vezes maior do que a probabilidade de falha considerando solo-estrutura, fato que pode ser aliado diretamente com a armadura do elemento, uma vez que a probabilidade de falha do pilar $1 \mathrm{com}$ modelo engastado, adotadas 16 barras de 
$12,5 \mathrm{~mm}$, foi cerca de $1,64 \times 10^{-2} \pm 2,45 \times 10^{-3}$, ou seja, muito próxima ao valor obtido para o pilar considerando interação solo-estrutura com 10 barras de $10 \mathrm{~mm}$, dentro da porcentagem de erro.

Com esses casos desenvolvidos, foi possível evidenciar a importância de um estudo estatístico bem elaborado sobre o projeto em questão, no qual cada parâmetro pode ter sua relevância e seu controle tecnológico influenciando de diversas maneiras no resultado do fenômeno, de modo que uma análise trivial ou em estados limites em tipos mais simples podem estar subestimando ou superestimando um resultado não tanto intuitivo.

Evidenciou-se também que, dependendo do estado limite a ser avaliado, apenas alguns fatores do modelo têm importância significativa de modo a serem levados em consideração como variáveis aleatórias do problema. Tal importância pode ser calculada mediante o método FOSM, resultando na redução do número de variáveis aleatórias e consequentemente menor número de iterações, aumentando a eficiência do método. Nos casos estudados para edifícios simétricos, obtiveram-se as variáveis aleatórias que são indispensáveis na avaliação por confiabilidade são aquelas relacionadas ao vento, ou seja, velocidade, coeficientes de pressão, rugosidade e altura, valores de rigidez do solo plicados em forma de molas e coeficiente de erro de modelagem.

Como observado nos casos estudados, o tempo de execução dos métodos pode variar bastante, aliado à avaliação da importância das variáveis aleatórias do problema como explanado acima, de modo que a escolha do método utilizado deva ser feita assertivamente caso o tempo seja fator limitante para o desenvolvimento do projeto ou estudo.

Destaca-se a importância de um profissional capacitado para o controle das variáveis estatísticas do projeto, tendo em vista a grande importância do controle dos parâmetros estatísticos das variáveis aleatórias do problema. Assim como evidenciado nas simulações FOSM com o edifício TIPO-B, a diminuição dos parâmetros estatísticos resultou na diminuição da probabilidade de falha.

Através do estudo acoplado dos programas, e da geração de amostragem dos esforços, foi comprovada a eficiência do resultado das distribuições estatísticas estabelecidas, de maneira que, uma vez com os parâmetros estatísticos dos esforços solicitantes, podem ser feitas diversas análises de maneira posterior, sem a necessidade de se obterem mais resultados do programa de edifícios. 
Uma outra questão importante encontra-se na avaliação de estruturas em ELU, de modo que ao depender dos critérios estipulados, a análise considerando a interação solo-estrutura pode reduzir significativamente a probabilidade de falha do elemento, resultado que nos leva para possibilidades de estruturas mais econômicas e seguras, não necessariamente de modo concomitante. Foi evidenciado também o grau de importância dos coeficientes de variação das variáveis, de modo que o controle desse eficientes de maneira adequada influencia de maneira significativa no cálculo das probabilidades de falha, de modo que a redução nos coeficientes de variação resultaram em valores de probabilidade de falha dos quais transitam entre as recomendações do JCSS.

Com os modelos elaborados e resultados gerados evidencia-se um conjunto de ferramentas com uma importante aplicação prática para elaboração de projetos. De modo que tais análises podem ser necessárias quando da complexidade da estrutura em questão e confiabilidade dos parâmetros, com finalidade de se atingir um nível de segurança adequado quanto ao recalque diferencial e estados limites últimos na edificação. É importante trazer à tona também a questão de que mesmo as estruturas verificadas e calculadas de acordo com fatores de segurança e metodologias tradicionais recomendadas pelas normas, toda estrutura contempla uma probabilidade de ruina (risco), da qual neste trabalho foi avaliada apenas com métodos numéricos e variáveis com parâmetros estatísticos estabelecidos, ou seja, apenas foi observado e levado em consideração variáveis de controle imediato. Uma análise de risco real deve ser feita considerando toda a concepção e execução do projeto bem como o controle com o tempo, chamando-se a atenção ao fato de que fatores de segurança aplicados não implicam em uma estrutura sem riscos, e que há relação numérica entre fatores de segurança e índices de confiabilidade, o que afirma a ideia de que mesmo que os coeficientes de segurança estejam adequados às verificações, a probabilidade de falha, ou risco, não será nula. Portanto, é importante trazer o equacionamento para o cálculo de risco previamente mencionado, de acordo com Aoki (2014):

$$
\text { Risco }=P_{f} \times C \times V
$$

De modo que $C$ corresponde ao custo de reparação do dano causado pela ruína e $V$ corresponde à vulnerabilidade. Por conseguinte, torna-se mais evidente que, por 
menor que possa ser a probabilidade de falha para um determinado projeto, o risco não será nulo.

Destaca-se ainda que os algoritmos apresentados não dependem do programa de edificações, e sim de uma rotina de estado limite, ou seja, não há restrições para o tipo de estado limite e estrutura a serem analisados, tendo em vista o custo computacional do modelo à ser gerado. Conclui-se então com a produção de uma ferramenta de grande potencial para o estudo de confiabilidade estrutural de inúmeros fenômenos e modelos.

Para atividades futuras, têm-se a implementação de nova rotina de inversão de matrizes otimizada para aumentar a eficiência computacional, assim como uma rotina para solução de sistemas lineares no programa de edifícios. Aplicação da teoria de redes neurais utilização otimizada do Método de Monte Carlo de maneira mais eficiente e implementar o método First Order Reliability Method (FORM), método que abrange a variação conjunta das variáveis aleatórias, e o método Second Order Reliability Method (SORM). Todas as atribuições mencionadas vêm com os objetivos de aplicação de confiabilidade em estruturas reais e de maiores complexidades, para análises distintas em ELU e ELS dos elementos estruturais, de maneira que possa ser viabilizado o sistema gerado neste trabalho para a avaliação em confiabilidade estrutural de edifícios muito altos com aplicação do efeito de rajada, aliada à metodologia de vento sintético. 


\section{REFERÊNCIAS}

ALMEIDA, V. S. Análise da interação solo não-homogêneo/estrutura via acoplamento MEC/MEF. 2003. 192p. Tese (Doutorado), Escola de Engenharia de São Carlos - USP, São Carlos, 2003.

AOKI, N. Praticando a análise de risco em obras de fundações. Minicurso de Fundações, Congresso Brasileiro de Mecânica dos Solos e Engenharia Geotécnica COBRAMSEG, Goiânia, 2014.

AOKI, N.; LOPES, F. R. Estimating stress and settlements due to deep foundation. $V$ TH PAN AMERICAN CONFERENCE ON SOIL MECHANICS AND FOUNDATION ENGINEERING, Buenos Aires, Tomo I, p.377-386, 1975.

AOKI, N.; VELLOSO, D. A. An approximate method to estimate the bearing capacity of piles. $V$ TH PAN AMERICAN CONFERENCE ON SOIL MECHANICS AND FOUNDATION ENGINEERING, Buenos Aires, Tomo I, p.367-376, 1975.

AQUINO, R. D.; SALTARELLI M.; ALMEDA; V. S. Comparação entre Modelo Contínuo e discreto na análise do Conjunto Solo-Fundação-Edifício. XXXIII Jornadas Sudamericans de Ingenieria Estrutural. Santiago, Chile, 2008

AQUINO, R. D. Análise não linear geométrica de edifícios 3D considerando a deformabilidade do solo. 2008. 103p. Dissertação (Mestrado), Universidade Federal de Ouro Preto - Escola de Minas, Ouro Preto, 2008.

ASSOCIAÇÃO BRASILEIRA DE NORMAS TÉCNICAS. NBR6118: Projetos de estruturas de concreto - Procedimento, Rio de Janeiro, 2014

ASSOCIAÇÃO BRASILEIRA DE NORMAS TÉCNICAS. NBR6122: Projeto e execução de fundações, Rio de Janeiro, 2010. 
ASSOCIAÇÃO BRASILEIRA DE NORMAS TÉCNICAS. NBR6123: Forças devidas ao vento em edificações, Rio de Janeiro, 1988.

ASSOCIAÇÃO BRASILEIRA DE NORMAS TÉCNICAS. NBR8681: Ações e segurança as estruturas, Rio de Janeiro, 2003.

BATOZ, J.L.; DHATT, G. Incremental Displacement Algorithms for Nonlinear Problems. Int. J Numer. Methods Eng., Vol. 14, p. 1262-1267, 1979.

BERGAN, P.G.; FELIPPA, C.A. A triangular membrane element with rotational degrees of freedom. Comp. Meths. in Appl. Mech. Eng., v.50, p.25-69, 1985.

BECK, A. T. Curso de confiabilidade estrutural. São Carlos: EESC/USP, 2015. 243p. Apostila para disciplina de pós-graduação do Departamento de Engenharia de Estruturas, SET5915 - Confiabilidade Estrutural, 2015

BECK, A. T., ROSA, E. Structural reliability analysis using deterministic finite element programs. Latin American Journal of Solids and Structures - LAJSS, 2006.

BECK, A. T. Um método para análise de confiabilidade para elementos finitos. 1999. 194p. Dissertação (Mestrado), Universidade Federal de Santa Catarina - UFSC, Santa Catarina, 1999.

BECK, A. T. StRAnD: Structural Risk Analysis and Design. Manual do Usuário Release 1.03, Escola de Engenharia de São Carlos - EESC/USP, São Carlos, 2008

BAZÁN, J. A. V. Fadiga de Pórticos Planos via Mecânica do Dano Concentrado Considerando Incertezas. 2017. 123 p. Tese (Doutorado) - Escola de Engenharia de São Carlos, Universidade de São Paulo, São Carlos, 2017.

BUNGENSTAB, F. C.; Bicalho K. V.; RIBEIRO. O Uso de Análise Probabilística para Avaliar Recalques de Sapatas Apoiadas em Solos Arenosos, Universidade Federal do Espírito Santo - UFES, Vitória/ES, 2012. 
BJERAGER, P. On Computation Methods for Structural Reliability Analysis, Structural Safety,9 (1990) 79-96, Elsevier, 1990.

BOWLES, J. Foundation Analysis and Design. Mc Graw-Hill, 1997.

CALAVERA, J. Cálculo de estructuras de cimentación. 4 Ed. Intemac., 2000.

COELHO, C. M. M. Análise probabilística de propagação de trincas para planejamento de inspeções à fadiga de estruturas offshore. 2018. $105 \mathrm{p}$. Dissertação (Mestrado em Engenharia Civil) - Instituto Alberto Luiz Coimbra de PósGraduação de Pesquisa de Engenharia (COPPE), Universidade Federal do Rio de Janeiro, Rio de Janeiro, 2018.

COELHO, J. D. Confiabilidade de vigas de concreto armado no estado limite de serviço. 2011. 272 p. Tese (Doutorado em Engenharia Civil) -Programa de PósGraduação em Engenharia Civil (PPGEC), Universidade Federal de Santa Catarina, Florianópolis, 2011.

COMPANHIA DO METROPOLITANO DE SÃO PAULO - METRÔ. Normas técnicas complementares - NC03, Departamento de Projeto Civil, São Paulo, 1980.

COVAS, N.; ALMEIDA V. S.: Sistema de Interação Solo-Estrutura: Sises/TQS, Congresso Ibero-Latin-Americano de Métodos Computacionais na engenharia (CILAMCE), 2010.

CINTRA, J.C.A.; AOKI, N.; ALBIERO, J.H. Tensão admissível em fundações diretas. Ed. Rima., 2003.

DU, X. Probabilistic Engineering Design Chapter Seven: First Order and Second Reliability Methods. University of Missouri - Rolla, 2005.

ERASO, A. I. R.; VELASCO, M. S. L.; ALMEIDA, A. A. D. Análise de Confiabilidade de Longarinas de Pontes Ferroviárias de Concreto Armado. Rio de Janeiro, 2011. 128 p. Dissertação (Mestrado) - Departamento de Engenharia Civil, Pontifícia Universidade Católica do Rio de Janeiro, 2011. 
FERREIRA, E. G. Análise de confiabilidade estrutural via método SORM DG. 2016. 215 p. Tese (Doutorado em Engenharia Civil) - Escola de Minas, Universidade Federal de Ouro Preto, Ouro Preto, 2016.

GUTIERREZ-MIRAVETE, E. Introduction do Monte Carlo simulation, notas de aula, Rensselaer Polytechnic Institute, disponível em: <http://www.ewp.rpi.edu/hartford/ ernesto/S2007/SMRE/Notes/F031407/IntrotoMCSi mulationtoRPIMarch142007.pdf >. Acesso em 20 de Abril 2017.

HACHICH, W.; FALCONI, F. F.; SAES, J. L.; FROTA, R. G. Q.; CARVALHO, C. S.; NIYAMA, S. Fundações teoria e prática $2^{\mathrm{a}}$ edição, Editora Pini, São Paulo, 1998.

IWAMOTO, R. K. Alguns aspectos dos efeitos da interação solo - estrutura em edifícios de múltiplos andares com fundação profunda. 2000. 157p. Dissertação (Mestrado) - Escola de Engenharia de São Carlos, Universidade de São Paulo, 2000.

JOINT COMMITTEE ON STRUCTURAL SAFETY - JCSS. Probabilistic model code, disponível em: $<$ http://www.jcss.byg.dtu.dk/Publications/Probabilistic Model Code $>$. Acesso em 20 de Abril 2017.

KHATIBINA, M.; FADAEE, M. J.; SALAJEGHEH, J.; SALAJEGHEH, E. Seismic reliability assessment of $R C$ structures including soil-structure interaction using wavelet weighted least squares support vector machine. Reliability Engineering \& System Safety V.110, Fev. 2013, p. 22-33

LOPEZ, M. Análise de confiabilidade de estruturas aplicada ao projeto de reforço à força cortante de vigas em concreto armado com compósitos de fibras de carbono. 2007. 209 p. Tese de Doutorado - Pontifícia Universidade Católica do Rio de Janeiro, Departamento de Engenharia Civil, Rio de Janeiro, 2007.

MADSEN, H.O. S.; KRENK \& N.C. LIND. Methods of Structural Safety. PrenticeHall, 1986. 
MAPA, D. L. S. Confiabilidade estrutural de pórticos metálicos planos. 2016. 149 p. Dissertação (Mestrado em Engenharia Civil) - Escola de Minas, Universidade Federal de Ouro Preto, Ouro Preto, 2016.

MELCHERS, R, E. Structural Reliability Analysis and Prediction. Ed. Wiley, 2d. Edition, 1998.

MINDLIN, R. D. Force at a point in the interior of a semi-infinite solid. Physics, v.7, p. 195-202, 1936.

MORAES, M. C. Estruturas de Fundações. Mc Graw - Hill do Brasil, 3a.ed., 1981.

MORRISON, N. Interacción suelo-estructuras: semi-espaço de Winkler. Universidad Politécnica de Cataluna, Barcelona-Espanha, 1993.

NACACCE, E.A.K. Confiabilidade aplicada ao problema de interação estaca-solo. 2016. 215 p. Dissertação (Mestrado), Escola Politécnica da USP, 2016.

NIETIEDT, J. A. Análise da confiabilidade de estaqueamento através da teoria bayesiana. 2018. 178 p. Dissertação (Mestrado em Engenharia Civil) - Instituro Alberto Luiz Coimbra de Pós-Graduação de Pesquisa de Engenharia (COPPE), Universidade Federal do Rio de Janeiro, Rio de Janeiro, 2018.

PIMENTA, P. M. Mecânica Não Linear de Estruturas. Escola Politécnica da Universidade de São Paulo - EPUSP, 2016. Disciplina de pós-graduação do Departamento de Engenharia de Estruturas e Geotécnica, PEF5713, 2016

PUSTKA D.; ČAJKA R., KUBEČKA K.; MAREK P. Reliability analysis of slender reinforced concrete column using probabilistic SBRA method. Proceedings of the third international conference: Reliability, safety and diagnostics of transport structures and means 2008, University of Pardubice, Czech Republic, 2008 
RAMIREZ R. G. Análise de confiabilidade em estruturas de contenção. 1998, 170

p. Dissertação (Mestrado), Departamento de Engenharia Civil da Universidade Estadual de Maringá, Maringá, 1998

RAHUL, M.; MANJUNATH, K.; SANDEEP KUMAR D. S.; MANJUNATH, J. A Study on Probability of Failure of a Column in RC Framed Building by Changing Orientations, International Journal of Engineering Science and Computing (IJESC), Volume 6, 2016.

SANTOS, D. M.; STUCCHI, F. R.; BECK, A. T. Confiabilidade de vigas projetadas de acordo com as normas brasileiras. Revista IBRACON de estruturas de materiais, São Paulo, 2014.

SCOTT D.W. Multivariate density estimation: theory, practice, and visualization. Wiley, New York, 1992.

SIGMAN, K. Introduction to Reducing Variance in Monte Carlo Simulation. Class Notes, University of Columbia, 2007. Disponível em: $<$ <ttp://www.columbia.edu/ ks20/4703-Sigman/4703-07-Notes-ATV.pdf>. Acesso em 26 de Abril 2018.

SHEWHART W. A. Economic Control of Quality of Manufactured Product, D. Van Nostrand Company, Inc. New York, 1931.

SILVA, G. R. Análise da confiabilidade da ligação laje-pilar interno sob punção de acordo com a NBR-6118:2014. 2017. 174 p. Dissertação (Mestrado em Engenharia) - Programa de Pós-Graduação em Engenharia Civil, UFRGS, Porto Alegre, 2017.

SILVA, J. L Metodologia de Projeto de Fundações por Estacas incluindo Probabilidade de Ruína. 2004, 121 p. Dissertação (Mestrado) - Escola de Engenharia de São Carlos, Universidade de São Paulo. São Carlos, 2004. 
SOUZA JUNIOR, A. C. Aplicação de confiabilidade na calibração dos coeficientes parciais de segurança de normas brasileiras de projeto estrutural. 2008. $149 p$. Dissertação (Mestrado) - Escola de Engenharia de São Carlos, Universidade de São Paulo, São Carlos - SP, 2008.

TERZAGHI, K. Evaluation of Coefficients of Subgrade Reaction, Geotechnique, vol. 5, no 4 - Dec. 1995

TESSARI, R. K. Projeto Baseado em Desempenho de torres metálicas sujeitas à ação do vento. 2016. 161 p. Dissertação (Mestrado em Engenharia de Estruturas) Escola de Engenharia de São Carlos, Universidade de São Paulo, São Carlos, 2016.

VELLOSO, D.A.; LOPES, F.R. Fundações, v.01, Nova Ed.: Oficina de Textos, São Paulo, 2004.

VERZENHASSI, C. C. Otimização de risco estrutural baseada em confiabilidade. 2008.154 p. Dissertação (Mestrado) - Escola de Engenharia de São Carlos, Universidade de São Paulo, São Carlos - SP, 2008.

ZHANG Y, DER KIUREGHIAN A. Finite Element Reliability Methods for Inelastic Structures; Report No. UCB/SEMM-97/05. Berkeley: University of California;1997. 